\title{
UC-NRLF
}

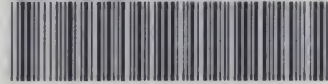

+5 2 $271 \quad 765$ 


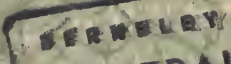

GENERAL LIBRARY UNIVERSITY OF CALIFORNIA
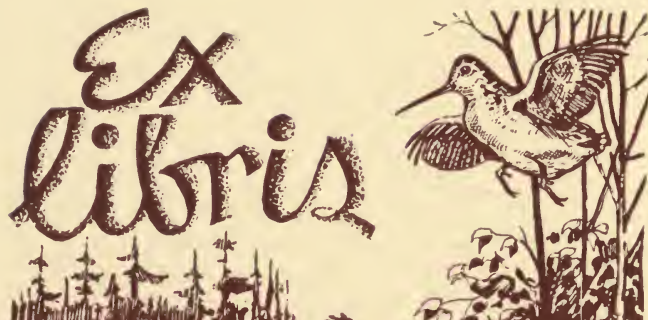

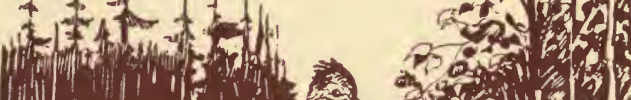

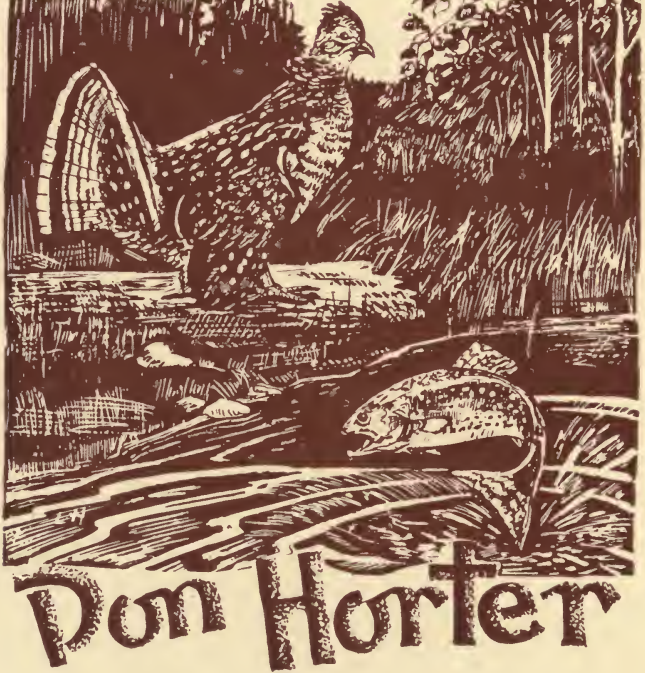


W

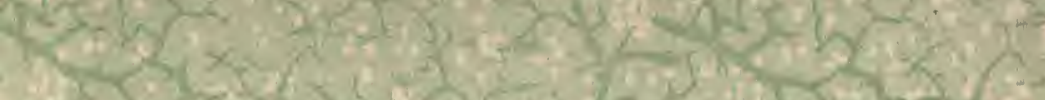
Dr.

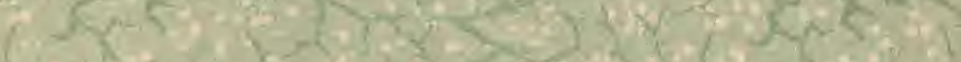

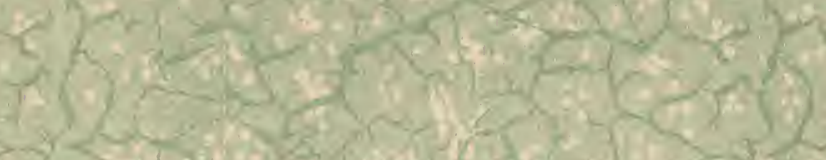

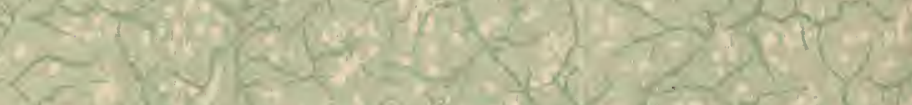

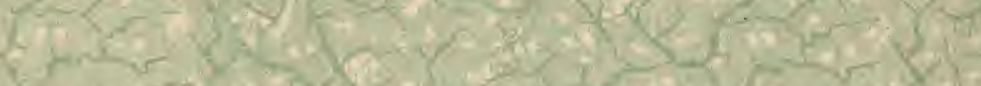
两 in $=2020$ LCW Theora 1 antaing. 30

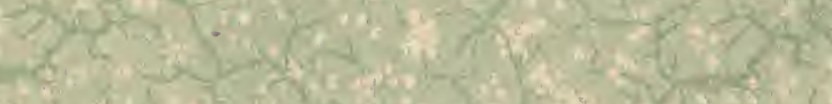
S.s. (2)

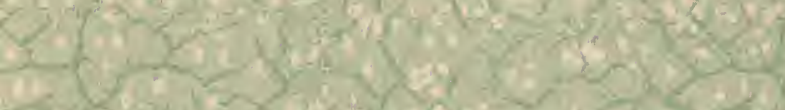
(6)

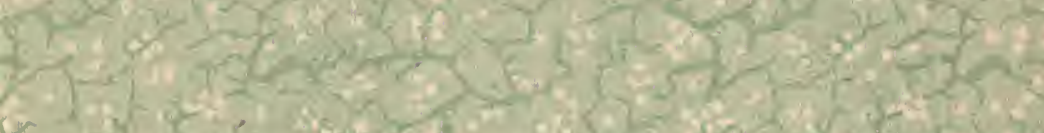

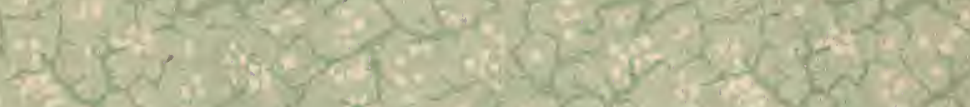

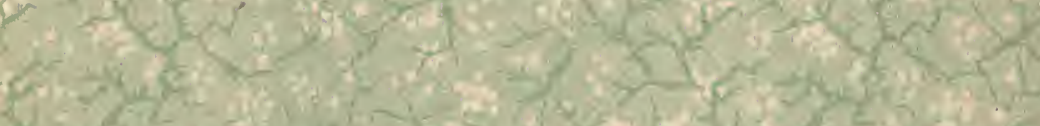

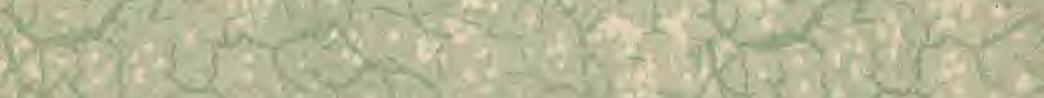
Ron 



Digitized by the Internet Archive in 2007 with funding from Microsoft Corporation 

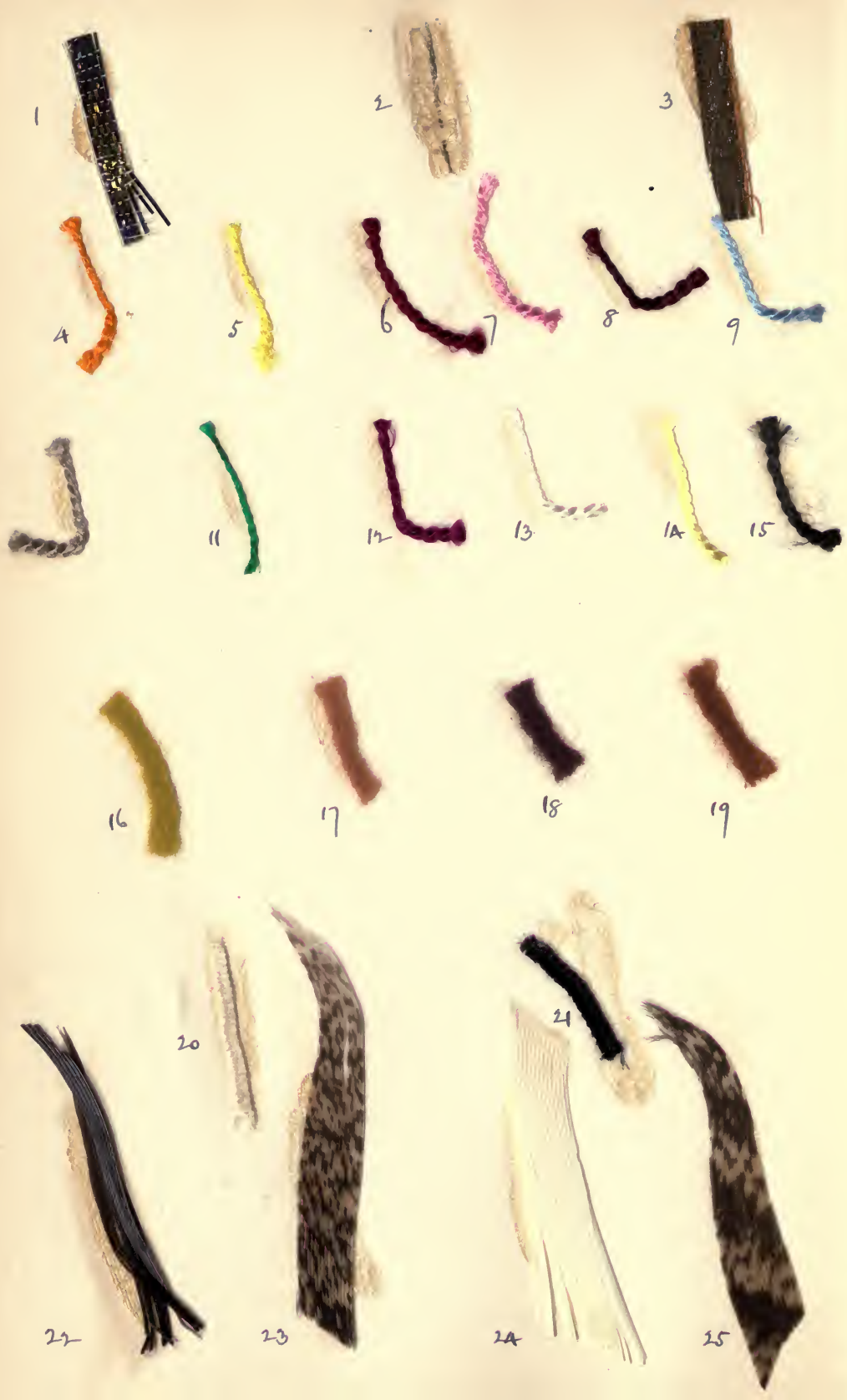


\section{FLY-FISHING AND FLY-MAKING}

FOR

TROU T, E T C.

BY

J. HARRINGTON KEENE,

AUTHOR OF "THE PRACTICAL FISHERMAN," "THE ANGLER's COMPLETE GUIDE

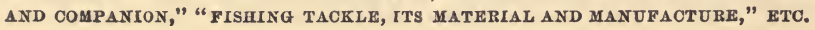

WITH PLATES OF THE ACTUAL MATERIAL FOR MAKING FLIES OF EVERY VARIETY,

I L L U S T RA T ED.

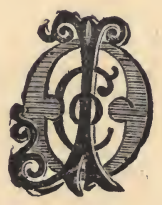

NEW YORK :

0. JUDD CO., DAVID W. JUDD, Pres'T,

751 B R O A D W A Y.

$188 \%$. 
Entered, according to Act of Congress, in the year 1886, by the O. JUDD CO.,

In the Ofice of the Librarian of Congress, at Washington. 


\section{O N T E N T S.}

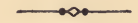

อ

\section{Chapter I.}

The Senses of Fishes in Relation to the Fly-fisherman .......... 7

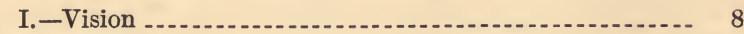

II.-Hearing -...

III.-Taste . . . . . . .

IV.-Smell _. .

Chapter II.

Practical Fly-fishing .

The Rod, Reel and Line .................... 39

Chapter III.

Trout Fly-making ... . .

Chapter IV.

Lessons in Fly-making.

Chapter V.

Standard Trout Flies and their Dressings _...................... 95

Lake Flies.............. 106

Flies with Gut or Quill Bodies and Scale Wings............ 110 

Fly-Fishing and Fly-Making. 



\section{FLY-FISHING AND FLY-MAKING.}

\section{H A P T E R I.}

THE SENSES OF FISHES IN RELATION TO THE FLYFISHERMAN.

In order to arrive at a right method in the capture of any of the fera naturce it is unmistakably necessary to first become acquainted with the creature's personal habits. No man in his senses would go out to trap-say, beaverknowing nothing of the tastes, faculties and general intelligence of the animal, nor would the ordinarily sensible man expect to get much sport with his gun unless he possessed at least an elementary knowledge of the game he sought. Yet this is precisely what a majority of anglers do, with regard to fish. Fishes depend exclusively on their senses for safety against the wiles of the fisherman, and yet he uses, for the most part, entirely what is provided for him in the shape of tackle, and does as he is told in the arrangement of baits, and his own comportment. Verily, such an one has usually too great a reward, but he 
is no angler. In these days of competition, it is necessary for the true angler to excel, and patient observation, added to the experience of others, is demanded. The more the angler becomes a naturalist, the more he finds out the beauties and weaknesses of his quarry, and the greater the enjoyment of the craft. The more he observes the various powers employed by these beautiful animals, the more skilful does he become. It is with this firm conviction that I offer the result of many years of observation of the habits of fish, with especial reference to their senses. They are particularly necessary to the fly-fisherman who aspires to be worthy of the name, for his is the most artistic, as well as the most difficult, of all the varied methods of fishing. My remarks are, however, intended, above all, to be suggestive rather than conclusive.

\section{I.-VISION.}

The faculty of vision is probably the most important of all to the fish-at all events, to the fish that come within the ken of the sportsman. Blind fish exist in subterranean waters-for example, those found in the Mammoth Cave, Kentucky - and in the case of fishes feeding in deep water, the existence of barbules or feelers is, without question, for the purpose of assisting the vision. I can say nothing about the methods providing for the sustenance of these blind subterranean fish. Probably they exist on stationary food of some kind; so far as the present purpose is concerned they may be dismissed from further consideration. Trout, and other sport-fish, unquestionably make great use of their eyes, and it is very surprising to what state of education nearly all our fresh 
water fishes may and do arrive, under the pursuance of the angler, or general fisherman.

The formation of the eye of the fish does not materially differ, one species from another, among the angler's fishes. The cornea is somewhat flat in sectional outline, and the shape, or, so to speak, the ground plan, is virtually similar in save the European grayling (S. thymallus). The pupil of the eye of this fish is oval instead of circular-the oval of the plover's egg rather than that of the hen, being sharper than a true oval at one end. The apex of this sharp end is pointed toward the upper part of the head, tailward, giving the fish a somewhat sinister appearance. What purpose this particular configuration serves I do not know, but one thing is certain : 'The visual ability of the grayling is equal, if not superior, to that of the trout, as is proved by its rising, often from a great depth, to the fly. I notice, also, that the normal waiting position of this fish is inclined toward the water's surface instead of being horizontal, as is usually the case with trout. This being so, the greater mass of the rays of direct sunlight would fall on the forward part of the eye, and I offer it as a conjecture, based on the law of development, that this, continued through generations, has evolved the peculiar shape. The grayling of this country, though apparently similar in every other respect, does not exhibit the peculiarity referred to.

It is a general law, observable through the whole range of animal life possessing vision, that the eye is peculiarly adapted to the medium through which (and to the manner in which) it receives the light. The more closely we look into this truth, the more apparent and wonderful 
is the adaptability. Indeed, these premises are truisms, and would not need repetition did not we so habitually forget that design is the key to all the natural phenomena around us. Admitting this, it follows that the structure of the eye of a fish and its position are admirably adapted for seeing in a denser medium than air with great precision and certainty. Observation ratifies this conclusion in its entirety. The vitreous and crystalline humors of the organ are not different from those of other animals. The muscles moving the body of the eye are large and permit great freedom, and the power of contraction and expansion of the irides is also distinct and pronounced. In air, this latter feature is, indeed, very noticeable in the case of some fishes, and the angler has only to accurately measure the breadth of the pupil of such fish in shaded water, and compare this with the measurement of the same after the fish has lain in full sunlight a few moments, to be at once forcibly impressed by the fact. The position of the orbit also needs a word of comment. In fish which readily and constantly rise and descend, to feed, it is placed so as to command a large area around; in fact, as large as in the nature of the creature is possible. In such as chiefly rise to their prey, as the pikes, it is placed quite near the top of the head. In the barbel (Cyprinus barbus) and gudgeon (Gobio fluviatilis) the converse obtains. In the trout, however, the orbit is more central, and the broad visual grasp of this fish, therefore, is one of the reasons why it, in due time, becomes so wary and so capable of protecting itself against its arch enemy-man. A pike cannot possibly see its ventral fin; a trout undoubtedly could, if it felt so dis- 
posed. On the other hand, a pike could see much further behind and backward than a trout. Indeed, the practice of up-stream fly-fishing, to which I record my own attachment, is based on the theory that the trout cannot see behind it but an exceedingly short distance.

Taking the trout as a fish not likely to seriously vary in regard to its faculties and their possibilities because of habitat, let us endeavor to ascertain the range of this power of vision, both in the light of what has been said, and what follows. First, one small but important fact has to be noted as bearing collaterally but interestingly on the subject. The fish is hard to frighten by means of any object it sees in water only, as separate and distinct from its cause or connection in air, if such exist. To make this plainer: If an object be presented so that another person, besides the presentor, can see its reception by the fish (himself unseen), that person will notice it seldom happens that the trout retires or darts away unless actually or positively touched-say with the point of a rod. Even then, so that the impact be gentle, he is not alarmed, and this fact is taken advantage of by the "groping" poacher of Europe, who gently places his hand under the trout-lying with its eyes buried in the weeds thinking itself secure, as does the ostrich when it buries its head in the sand-and lifts it suddenly to the bank. Be the object presented a stone or a fly, so that its connection with the arch enemy of fishdom be not discovered, the fish fears not. Its brilliant, infallible visual faculty has apprehended the innocuousness of the object, per se, and no fear is aroused.

Try the experiment with the operator in full sight. 
What a difference in the result! The trout vanishes like a lightning flash, and be very certain that he will not again present himself to be "fooled" with, however good your intentions. "Of course he won't, and what of it?" you say. "But why," I ask, "did he bolt?" "Let bears and lions growl and fight, it is their nature to," you reply, quoting the saintly Watts. That might satisfy the feminine mind, and be absolutely conclusive to a majority of the masculine persuasion, but I don't propose to let the reader, who has followed thus far, off so easily. We ought to look a little deeper into this apparently transparent matter, and I want the patient reader's close attention.

Now, water, if clear, is a particularly pleasant medium through which to view its contents, even with the human eye. Of course, I do not quite know how fish feel about it, but I do know that if I am watching the movements of an aquatic insect-be it water-flea or waterdevil (larva of the dragon-fly), I do not choose, as the best way, to gaze at it through the air into the water. No, I endeavor to immerse my eyes-I've slipped in head first more than once doing this-and thus I get a more distinct and clearer view than if I only held my head just above in the air. This is a "dodge" taught me by the Reverend J. G. Wood, than whom there is no better "minute philosopher" in the world. The fact is that the interposition of two media-air and water-between the eyes and the object have a tendency to distort or render the image indefinite. The human eye is perfectly fitted for seeing in either a dense or rare medium, but not through both so well as through one separately. I do not claim 
that fish can see indifferently well in either, of course, but rather from the fact that it sees so excellently in water, and from the comparative fixity of the irides, I would argue that the image it perceives through water and air is ill-defined, blurred, uncertain, and altogether, in most cases, grotesque and awesome to the piscine intelligence. Ergo, the fish is startled by any moving object.

A well-known optical law, which does not affect the main argument, must now be referred to. Ronald, in "The Fly-Fisher's Entomology," gives it and, as I do not think that its importance is sufficiently recognized, I reproduce it with grateful acknowledgements: When Mr. A. B., situated upon a certain eminence at a given distance from a fish, which is near the bottom of the water, looks over the edge of a bank, in its direction, he might, if unacquainted with the laws of refraction, imagine that neither the fish, nor any other fish below the line of his direct vision, could see him; whereas, the fish could see A. B. by means of the pencil of light, bent or refracted at the surfice of the water, and the image of A. B. would appear in the eye of the fish, shortened and transferred to a much higher point. The fish, in fact, could see the whole of the man round or over the corner of the bank by the aid of the water above it; but if the surface of the water should be about as low as the fish's eye, then he could not see any part of A. B.'s figure, because a straight or unrefracted pencil of light would be obstructed by the bank.

Increasing obliquity in pencils of light falling from an object upon a surface of water is accompanied by still 
more rapidly increasing refraction, but the distinctness with which the object is seen increases in inverse proportion.

The bending or refraction which a pencil of light, falling very obliquely on the surface of the water, undergoes before arriving at the eye of a fish, is sufficient to produce very great indistinctness and distortion of the image of the man formed in his eye.

Long before a pencil of light becomes horizontal, it will not enter the water at all ; consequently, although the fish may see the upper part of the man wading, he will do so very indistinctly and in a new position, because the pencil will be very much refracted; he will not see the middle part of the man at all, because the pencil does not enter the water, and he will see, probably, his legs in the clear water, because there is neither refraction nor obstruction to prevent him. So that the figure of the man will be, in the eye of the fish, cut in two portions, separated from each other by a long unsubstantial interval.

The lessons to be drawn from these theories are, briefly, three. 1st. A low bank on the level of the water is a great advantage to the fisherman. $2 \mathrm{~d}$. The wader has a great advantage over the bank fisher. $3 \mathrm{~d}$. It is of great advantage to fish up stream, wading when the fish are heading in that direction. "Observe," says Ronald, "that fish cannot see behind them ; all optics forbid it." To which I add an emphatic endorsement.

But the trout has, probably, in addition, another and more subtle reason why my presence, or that of a waving rod, is a signal for taking his leave-standing not on the 
order of his going, but going at once; and this is an instinct-intuitive, I believe-which, apart from the direct teachings of the senses, informs him that certain creatures are his enemies. I have seen a stream literally boiling with rising trout, one moment, and the next, as a weird, ghostly heron sailed slowly over it, you would swear it did not possess a fish, so quickly had they ceased rising, and so instantly had they hidden themselves. Yet, when a flock of rooks had passed just as close only a few minutes before, though they ceased rising for a few seconds during the actual flight, there was no general stampede. Explain that circumstance if you can, gentle reader, on any hypothesis than that the fish recognized the foe of their race, instinctively. Once I caught a kingfisher in a trap set just over the water of my tank of young, feeding trout, and did not release its body, seeing it was dead, ere I proceeded to cast to the fish the victuals I had brought. Now, on other occasions previously, these little, domesticated farios would rise en masse to the chopped meat and meal, on which I was wont to feed them, for I accustomed them to be fed a little at a time but often, and they rather regarded my presence in a friendly spirit. On this occasion, however, their alacrity was turned to a startled, restless demeanor, which is easily detected by the watchful fish-breeder and lover. Was the kingfisher the cause of the uneasiness? I won't assert so much, but I have a private belief, built up and strengthened by many trivial observations, of which these two are but samples. "Credat Judceus Apella!" you mutter. Nathless, however, I doubt not, oh, sceptic! there are more things between 
heaven and earth than are dreamt of in your philosophy, and this mysterious instinct may be one of them.

Again, why is it that no matter how quiet I stand, the fish that has stopped rising a few yards down stream will not rise again if I remain where he can see me, though I be as still as the Great Pyramid, or anything else that is mighty quiet? Of course I am referring to a much fished, clear river.

I can only reply that the evils of taking the imitation fly, without due circumspection, have somehow been inculcated as an experimental lesson-experientia docet, we are taught every hour of our lives-so often that at last it has become a part of the fishy nature, and is transmitted hereditarily. And does not that sum up what instinct is? Denuded of all the elaborations and jargon of metaphysics, is not instinct the result of súccessive experiences which have become actual, permanent impressions on the brain? Some may smile at this, but let me ask what makes the young wild duck, just in the act of breaking from its shell, hustle this off in great trepidation, as I stoop to pick it up, and break for the water as if a horde of miniature fiends were pursuing it? An inherent instinct derived from the parents is the reply, for it certainly was not acquired from bygone personal experiences.

And I doubt not that the necessity for the finest tackle and closest of imitations of the natural insect on the much fished streams of England is due to a like progressive evolving education (which I may as well refer to in this section on "Vision," though it concerns all the other observaut perceptions). 'The earliest work on 
angling in the English language is that of the fair Dame Berners (1496), and it is too practical internally for us to doubt that the drawings and descriptions she gives of tackle are, indeed, representations of what caught fish in her day. Yet an angler would be mad to attempt the use of such rough implements now, either in this or any other country.

And further, on virgin streams, which still exist, though rarely, the comparative tameness and unsophistication of the fish argue that the march of intellector as a "too, too utter" Boston writer terms it, the "march of cephalization"-in a comparative sense applies to fish as to all other animals. The ancient angler, whose rod was a sturdy oak-

"His line a cable that in storms ne'er broke, His hook was baited with a dragon's tail, He sat upon a rock and bobbed for whale,"

- this man would probably scorn the gossamer gut and tiny, accurately imaged fly used on clear, hard-fished streams. Yet hundreds of fly-fishers will bear me witness that the latter are indispensable. Probably this extreme refinement is not yet so absolutely necessary in this country, but the day is not far distant when it will be, and many good anglers of my acquaintance are even now embracing it as a means to more invariable good sport on clear streams.

One palpable result of this education of trout "on the other side" is the general adoption of the dry fly upstream fishing. The angler stalks his fish from behind as he lies head up stream and, drying the fly by means of a couple or three flips backward and forward in the air, 
he casts it just before the rising fish and lets it float, taking care that no move is imparted to the lure as it rides downward on the stream. If the imitation is a good one the fish takes it ; if bad, he pronounces on it adversely. Now let it be understood that it is emphatically well-nigh impossible to get good sport on an English chalk stream, especially among the "big uns," in any other way whatsoever-barring bait fishing. Let this latter be Anathema; Maranatha! always and forever where the fly can be used.

"Why can the fish be caught in no other way?" you ask. Because, I reply, this style places the lure before the fish in the nearest possible approach to its natural way of sailing down stream after falling on the water or rising from it. "But," you object, "there are no imitations of the struggling insect in this style!" I deny that the water insect does struggle. Those flies whose previous larval existence has been in the water are not afraid of their natural element, and sail down with erect wings (they chiefly belong to the neuroptera) and immovably out-spread legs, with majestic nonchalance. So does the imitation, and hence the rise of the fish. The land flies certainly do struggle like the fly in your milk jug, and the down-stream angler who jerks and jiggers his flies to make them lively, may be thankful that he has that one small piece of nature to be faithful to. It just saves his credit to be like snmething, but the llies he imitates are in a miserable minority.

The education of the eye in individual trout can occasionally be met with advanced to a degree actually astounding. This is chiefly found in connection with fish 
who have passed the grand climacteric and are getting old and learned and, in many cases, lean as well. Learning seems to render mankind lean also, and the "sock dolager" of the stream rarely maintains his aldermanic outline when his education is at the meridian. His seven or eight summers have filled him full of suspicion, and he knows precisely the difference between even the most artfully imitated fly and the real Simon Pure. Before now I have caught specimens of the fly that such a fish has actually been taking, and by the aid of the magnifying lens and the closest study, have selected the exact colors for the imitation-nay, more, the exact size and shape of the insect has been duplicated. And to what purpose? Deftly have I, with throbbing pulse, cast that fly over the grand old patriarch poised in midstream ready for any emergency, only to see him sail calmly toward it, examine it, and then turn tail on it, saying, just as plainly as if he spoke in the eloquent vernacular of the glorious English language, "See you d-d first." Ugh! the intellectual accomplishments of the more than one "beastie" of that kind make me weary when I think of them !

I particularly recall one old fellow that annoyed me for three mortal years, till I became almost monomaniac. He took up his quarters close to the buttress of a rustic bridge which spanned the stream, and in clear, bright weather you could easily watch his movements from daylight till dark if you had a mind to do so. Just so long as I would blow, from a pea-shooter, fat, large, green drakes, so long would he come up with his huge whip lips smacking out, plop! and take them. On the other hand, just 
as soon as I put a hook through a couple of the live insects and lowered them to him, even using-quite against the rule in this style of "dapping" - the finest of gut and a small hook, would he retire like a duchess from Queen Victoria, backward-into deeper water. 'The next minute I would see him going for other natural flies. Now, this fish unquestionably knew and saw the gut and hook, and connected them with me. I don't see how we can avoid that conclusion. And it occurred continually during the three years; try what I would, he would not be tempted. At the end of the third season, however, I determined to get him out, for I could see that age had rendered him lank and thin, and during the ensuing winter he would probably have become a spawn-eater. Still, I venerated the "varmint" too much to net him. I wanted to deceive him somehow; to get even with his transcendent wile, and at last screwed my courage to the "sticking point" of "foxing" him, as Charles Kingsley would say. This is what I did, and it succeeded: Morning after morning, for a week or so, I fed him on bread-of which trout are very fond in some waters, by the byeand he seemed to relish that diet with extreme gusto. One fatal morning I rigged up a single hook on fine gut, and after he had one or two boluses of bread as sweeteners, I floated one down with the hook in it. He rose and took it-chung! went the line as I struck the keen steel into his rough old jaw. There never was a madder fish on this side of the Styx, but I landed him. And so he died at the weight of three and three-quarter pounds avoirdupois, with eye undimmed, and natural force unabated. 
Not only is this education of the eye of old fishes noticeable in reference to daylight fishing, but it is equally so in reference to the use of such night flies as the various white moths, which are very deadly on dark evenings if used properly-and that, amongst the largest and best fish for the most part. The capacity of the trout's eye for making the most of the scarce light of night may be greater than we know, owing to our difficulty of estimating it in the dark. I never, however, noticed that there was anything specially favorable in the fact that the moth was white, as one might supposesport being equally good in my experience when the Fetid Brown or Cinnamon flies were used in place of the moth. Besides, it is probable that each and all look equally dark when outlined against the sky, and, therefore, the faculty which enables these patriarchs of the stream to secure their prey at night in the dark as well, or nearly so as in the light, may, I submit, be fairly presumed to arise from the education of the eye which, as we know in the case of some astronomers, is possible to a very exalted degree as the result of persistent and long continued training.

Although the whole of the foregoing screed is intended to throw light (howsoever dimly) on the rationale of the taking of the fly in its character as an imitation of the natural food-insect, I am aware that it does not touch the fact that trout will take fancy flies of any and all conceivable patterns, which are like nothing in the " heavens above, the earth beneath, or the waters under the earth." I have even known trout to rise at $\mathrm{Mr}$. H. Cholmondeley Pennell's three typical nondescripts, which 
is, on the fish's part, piling the Pelion of idiocy on the Ossa of absurdity. 'Then, again, the salmon takes that poem of color, a salmon fly, when the natural minnow fly or worm will not lure him. Why? Is it sheer wantonness akin to that which prompts the omnivorous appetite of the ostrich or camel, who swallow with relish anything from a door-key to a newspaper, or are the fish, as Sir Bedivere,

\section{" Like a girl}

Valuing the giddy pleasure of the eyes"

over the gem-like insect, counterfeit ? The man who says, honestly, "I don't know," is to be respected. Respect me, therefore, oh ! gentle reader, for I am ignorant in this matter. Perchance the fish see in the fancy fly some of the qualities which are the quintessence of delight and piquancy to its fishy palate. Suppose a boy came across a fruit, hanging on atree, within reach, having the odor of strawberry and pine-apple, the juicy, luscious appearance of pear and peach, together with the creamy pulp of the banana-in short, possessing all the sublimated fualities of the most delicious of imaginable fruits, to the eye and nose-could we wonder at him for plucking and attempting to eat it, even if the taste were ashes-like that of Dead Sea apples? Indeed, the "gardener Adam and his wife," did just that thing. Perhaps, I say, the trout and salmon find themselves in an analogous position. Imagine one of the Silver Doctor's or Parmachene Belle's, made by Orvis, floating over a blasé trout, the sunlight rippling through its many-hued fibers, and lighting it up until its appearance excels that of the apparel of an Eastern queen, and further remember that 
the trout cannot put forth a hand to grasp the glittering trifle; it has, like a baby, one universal receptacle only -its mouth - whereby to test the quality of all comfits, then, I say, ask yourself where is the wonder that the wary fish loses caution in the sensuous pleasure of the momentary acquisition, bites and ends its life, not ignominously, but fighting to the last. I am not joking. This is the only explanation I can offer after a quarter of a century's wondering.

\section{II.-HEARING.}

Hearing is the power of perceiving vibration, whether possessed by a land or water animal, and as abundant evidence exists that fish are sensible of vibration, there can be no excuse for saying that they cannot hear. Hear, they do, and, in their way, most readily, but not in the same way as a creature in the air.

I need hardly remind the reader, that the ear of a human being is a structure of excelling adaptability equally fitted to appreciate the melodies and harmonies of a Mendelsohn, or to the stunning monotone of the thunder clap, and to convey, according to the degrees of refinement, definite impressions of each to the mind. This organ in man is also divided into two sections, broadly distinguished as the outer and inner-external and internal ear. The former of these is wanting in fish, and as an apparatus for the collection and magnification of sound, as it is in air, is not required in water, the denser medium, its absence is precisely what we should expect to find. In place of this, a nerve running from the base of each scale to a large ganglion in the 
head, allows the fish to perceive vibration instantly from the whole of its surface, as well as immediately from the outer part of the head. The trout is specially furnished in this way, and the interior mechanism of the ear in all fishes is very beautifully adapted to their requirements. The curious oolith, or brain ivory, possessed by nearly all fishes, forms the bones guarding this aural development, and sometimes these are of exceeding delicacy and beauty. In the loaches there is a connection between the ear and the air cavity, situated in the anterior part of the head, which may be supplementary to their impaired sight in daylight, and the same peculiarity is noticeable in the Cobitis Barbatula, a small loach of English streams, and the Cottus gobio, a bull-head. Both these are almost exclnsively night feeders.

Sound travels in air at the rate-roughly-of eleven hundred feet per second ; in water, accurate experiments fix it at over five thousand feet in that space of time. When quite a youngster I satisfied myself of its extreme rapidity and the great conducting power of water, on several occasions, in the following way: The fishermen of the Thames use an iron-shod pole, termed a ryepeck, to fix the punt when fishing, and this experiment was made: A friend took a boat and rowed down on a long clear reach of water to the end of a measured mile. I remained at the starting point, divested of my clothes. As he got to the end of the mile I stepped into the water, which was about up to my armpits, with a small red flag in my hand, and as soon as he saw my head disappear under the surface it was agreed he should ram the iron down, and I was to exhibit the flag on hearing the sound. Well, 
I need not say that no exact result accrued; but one or two wholesome lessons, certainly, were taught me. One wasand this was just then most valuable, $I$ being the son of a professional fisherman-that it was a great mistake to ram a pole in the river to fasten the boat at all, for the sound was startingly clear, though made a mile away, and the grating of the gravel and iron was louder than in air even to my ears, which, it must be borne in mind, were fitted rather for sounds in air. The water seems to act as a sort of microphone-indeed, magnifying the sound, considering the distance, of course.

I do not believe that sound made in air is heard at all under water. The experiments of Ronald faror this opinion, and of course my own are, to my mind, conclusive, or I should not give in my belief so sweepingly. Dr. Henshall ("Book of Black Bass"), however, thinks differently. Let us see how the assertions of these two redoubtable sportsmen look side by side: 
Dr. Henshall, "Book of Black Bass," page 184.

"I have frequently observed that fist exhibit symptoms of great fright or alarm at the report of fire-arms, or other loud noises, and be scared and dart away at the sound of the human voice or the barking of a dog, when the fish could not see the originators of the noises."
Alfred Ronald, "Hly-Fisher's Entomology," pagc 7.

"In order that we might be enabled to ascertain the truth of the common assertion (riz.:) that fish ean hear voices in conversation on the banks of a stream, my friend, the Reverend Mr. Brown, of Gratwich, and inyself selected for close observation a trout poised about six inches deep in the wrater, whilst a third gentleman, who was situated behind the fishing house-i.e., dianetrically opposite to the side where the fish was, fired off a gun. The possibility of the flash being seen by the fish was thus wholly prevented and the report produced not the slightest effect upon hirn.

"The second barrel was then fired; still be remained immovable, evincing not the slightest symptom of having heard the report. This experiment was often repeated, and precisely similar results obtained. Neither could I, or other persons, ever awaken symptoms of alarm in fishes near the boat by shouting to them in our loudest tones, although our distance from them sometimes did not exceed six feet. * * It is sufficient to know that the above trout had no ears to hear either the voices or the gun, and I firmly believe that the zest which friendly chat often imparts to the exercise of our captivating art need never he marred by an apprehension that sport will be impaired thereby."

Who shall decide when doctors disagree?

Speaking of firing off a gun to test the hearing of trout reminds me of the only incident I can call to mind which apparently contradicts the conclusions reached by Ronald. 
It occurred on one of Queen Victoria's birthdays. Windsor Park, England, possesses a beautiful ornamental lake named Virginia Water, and located on this is a miniature frigate of twenty-one guns-five-pounders, I think. On each royal birthday it is customary to fire a salute with these, and on the occasion of which I speak the small fish, roach, etc., were in shoals of hundreds of thousands near the surface of the water surrounding the vessel. This is not uncommon on a still, fine day-the lake being so overwhelmingly full of the little fellows. The salute was fired, gun after gun, at minute intervals, and the vibratory reverberating boom seemed to startle the small fish, and all around the vessel the water broke into ripples, as if stirred by wind, as each report was fired. Now this seems as if the fish heard the sound and didn't approve of it; but if we look deeper, it is possible-nay, probable -that the mechanical shock of sound was strong enough to make itself felt in the layer of water which is most laden with atmospheric air-aamely, the top or surface.

Of course the vibration of the vessel itself from the recoil may have been the true cause, and is the solution of the mutter I most favor. Shortly, my experience is that you may whistle, laugh, sing and talk-I except "cussing"-but you must not stamp your feet in the boat or on the bank if you desire to capture trout.

Against my opinion that fish cannot hear sounds in air is David Foster's ("Scientific Angler") funny reference to a friend who always took a musical box to sit on, and this he set going while he fished. A reritable Sybarite in angling like this ought to catch a good string. A far greater example, howerer, of different opinion is that 
which credits carp coming to the call of a bell or whistle at feeding time. I doubt not that such instances are true-that the fish did respond. In the range of angling literature I could pick out a dozen recorded instances of such docility and obedience.

"Then," says the impartial reader, "you have contradicted yourself-the fish can hear sounds coming from the air." Let us make haste slowly, fair sir, and, prithee, let me put a few questions to the writers of these records of clever fish. First, Mr. Historian, were you positively there when the incident occurred? Did the fish-feeder not feed at a regular time, and did he not walk in an unguarded, ordinary manner to his fish ponds? Did they not see him coming or hear his step? The answers enclose the gist of the question. Why, at Denham Fishery, in England, I have seen a herd of thousands of fontinalis trout, up to three and four pounds, following the proprietor, General Gerald Goodlake, as he walked up the bank. These fish were fed regularly once a day with chopped, cooked horse flesh. But there was no calling in the matter. They heard the heavy tread of this Saul among men, and saw his mighty form and remembered the old, large check suit in which he always fed his pets. Nothing more. Foster, in the "Scientific Angler," states that "no noise which does not occasion a vibration of the element which they inhabit reaches them ;" and with this opinion I fully agree.

\section{III.-TASTE.}

Authorities of all kinds agree in denying that fish possess a very discriminating palate. I grant that there are 
degrees of discriminating power, and that the voracious fish are but slightly endowed with them to any nicety; but then, are there not degrees in connection with the human gastronomist? Would not the blubber-eating Greenlander prefer his gross meal to the pate de foie gras of the Parisian gourmand? "A question not to be asked," as Falstaff would say, and I have myself met a specimen of the genus homo, who would disdain the juicy steak and dine off bacon-fat in preference. If there is a lack of delicacy among men in this particular, why not among fishes? But is there a lack of particularity which would indicate an absolute absence of taste in the inhabitants of the water? Let us see.

The pikes will take anything when hungry, you will say, from a lead sinker to a red cork float. Yes, I adınit, that if you meet him on the aqueous highway, and you possess a spark of bright metal about you, he will assail you. It is, as Tennyson puts it, "Sense at war with soul." The fish jumps out on a spoon in the hope that when he crushes it, it will be fish-like, and so meat for him. I say he will do this on impulse, but try a fish-bait that is not fresh, and though he may seize it he will never swallow it, no matier how ravenous he may be. Again, in England, there is an olive, mucous coated, flat-fish, termed the tench, which for some reason (some say gratitude!) the fish will not touch. Though Esox Lucius will grow fat on every other member of the family of the Cyprinidæ, or carps, yet you may fish all day in a lake or river thronged with pike, using tench, and you will not catch a pike. Again, with a golden fish (Cyprinus auratus) I can catch four times more pike than with any other bait. 
Next in point of favor comes the dace or dare, and next, the gudgeon. Says honest Jack Falstaff, "Why, if a dace be a bait for an old pike, may I not grab him ?" So, from.these irrefragable facts, even the pike "fell, tyrant of the watery plain," though he be, does, possess a sense quite worthy of the appellation-taste.

And now, in regard to trout, which chiefly concerns us here-though a passing consideration of other fish is eminently useful in order to lead to a wide comprehension of the subject-who shall assert its lack of discrimination in matters gastronomic? Can it not tell the difference between the flavor of a spent May fly and a female Green Drake full of luscious, creamy eggs? Or, between the various kind of flies, which at different times may be upon the water. When the beautiful Blue Dun is rising, I have seen that it alone is taken, to the absolute exclusion of other flies; yet, the trout are hungry, or why do they feed, and if they do not discriminate, why not feed on everything before them ?

The meaning of the word taste requires exposition in this connection. First-It indicates a perception of pleasant or unpleasant tastes in foods or liquids conveyed to the mouth. Second-The sense of taste is in intimate connection with the stomach, and that which violently disagrees with this organ is usually unpleasant and rejected instinctively.

Here are two instances of the antipathies of European fresh water fishes, which cannot be accounted for in the absence of a sense of taste in the fish:

(1.) Roach (Leuciscus rutilus) are often taken in great numbers by a bait made of flour paste. In the full tide 
of catching fish, if the experiment of squeezing a few drops of tobacco juice into the paste from the end of a wet cigar is tried, not one fish more will take that paste. Expert roach fishermen never smoke when fishing, for this reason.

(2.) Barbel (a gregarious ground feeder), are often canght one after the other, as rapidly as it is possible to reel in with the fresh lob worm, (garden worm). If you throw in a handful of worms that are dead, you will put them off their feed for that day. A single fact such as these is worth a cartload of mere theories. It proves incontestably that fish possess discriminating palates.

The tasting powers of trout were made the object of special experiments by Ronald. He projected, by means of a blow-pipe, house flies to his trout, and plastered various strong condiments, such as mustard and pepper, over them. He says the fish took them indifferently. Now, it would be interesting to know how much of the spices remained on the flies as they sailed down the water after going through the air from the blow pipe? And it is fair to presume that they would not be covered so completely as to hide their identity as flies. Howbeit, it is also said that a large bee was thrown to a trout, which he took; but he rejected a wasp-didn't relish the "business end" of him, perhaps!

Of course, I do not assert that fish have the sense of taste in the same perfection as warm-blooded animals, but I contend they exhibit like and dislike in a lesser degree certainly, but by no means in a dissimilar way. Especially would I insist that the carp family, with their soft, palatal tongues, possess it in a high degree. The 
large, massive molar teeth crush and masticate, in the throat of them all, whatever food is passed, and it would seem extraordinary to me if by sight alone this "fox of the water" builds up his oft-times colossal form and fat.

\section{IV.-SMELL.}

I think, after what I have seen of the manifestations of this sense in fishes that it does not exist in such a high state of development as does even taste. The sense of smell in air depends on the perception of minute particles thrown off by the odorate body. Hence, the necessity for a refined sense of smell does not exist in water, for it cannot be supposed that particles of any object could diffuse themselves in the denser medium with the rapidity and completeness with which they do it in air.

Nevertheless, fishes possess nostrils, though these hare no communication with tile gills or mouth cavity. I remember that Mr. Frank Buckland passed a fine bristle far into the head of a thirty-six pound pike (caught by my late father in Windsor Great Park) he was casting, in my presence some years ago, from each of the small orifices which extend in a row on either side of the muzzle.

Pollutions of the water are avoided by fish; and when some poisonous chemical refuse was once thrown into a stream under my care, I saw many fish throw themselves out upon the banks to avoid encountering the horrible corroding flood. This, however, might have been due to an impending sense of suffocation, and the pain consequent on the cauterizing effect the poison had on the branchice. Fish are not adverse to even a large amount 
of sewage if the latter be fresh, but putrid fæcal matter is a horrible and unqualified destroyer of all watercourses whatsoever, and should be utterly and relentlessly reprobated by all interested in the preservation of fish for food and sport.

So far as trout are concerned, the sense of smell does not appear superiorly developed, in comparison with other fishes. I am not willing to believe that this sense exists in a state of higher refinement in fish as compared with ourselves, and, therefore, as we cannot detect any particular odor in the food of this species (except in such flies as the Fetid Brown, or Cinnamon fly, limnephilus stigmaticus, and a few others), it is fair to presume that the trout do not. It is true that the ancient works on angling frequently speak of oils and unguents for the attraction of fish, but I never could find they were of any use, and I have tried scores of recipes. Some time since, a firm in Encland began selling "stinking Gladwin" as an infallible enticer of fish. I used some, and was disappointed, as I deserved to be. If trout or any other fish perceive the whereabouts of food from a distance, it is owing to their microscopic keenness of sight in perceiving the tiny detached fragments flowing from it. These they will follow up and find-as is well-known to the still fisherman who has ground baited-by taste and sight rather than smell. The latter sense, in fish, I am inclined to place amongst the impossibilities, though I hare, somewhat "Hibernically," to use an euphemism, devoted quite a space to its consideration. 


\section{V.-FEELING.}

This sense is well developed in all the angler's fishes, but varies in its development. 'This variation appears to me to depend on or is adjusted to the degrees of development manifested by the other senses, especially that of vision. For instance: 'The pike (Esox Lucius) is an exceedingly sharp-sighted fish. If you fix your eyes on his as he lies, perdu, sunning himself in the water, you may so chain his attention as to allow of another person placing a wire noose around his body and hauling him out. But if your eyes waver, or the gaze be removed, like lightning he is gone. I have done this hundreds of times when snaring pike from a trout stream, and mention it chiefly to prove his quick sight. Now you may catch him with a "flight" or "gang" of four or five hooks, belonging to some previous angler, stuck in his jaw. I have taken him with a lead-bound hook already fixed in his maw, and have lost a hook on a pike and in thirty minutes captured the fish with the tackle hanging to him. This does not look much like evidence that fish suffer pain. Indeed, the extremely dogmatic Mr. Cholmondeley Pennell, says, in the "Fisherman's Magazine :" "In sober seriousness, it has been proved over and over again-on evidence strong enough to hang a man-or what has been considered still more difficult, to build a church-the organization of a fish, which is a cold-blooded animal, does not admit of its feeling pain." Then there is the grayling, which I believe to be one of the sharpest sighted of fishes; he will come again and again to a fly, even after being pricked by the hook, and 
who has not caught a trout with somebody else's fly in its jaw?

Such fish, it is true, feel but little pain in the process of capture, but I feel certain the matter is far different with others possessing softer mouths and greater development of nerve-perceptive power. Nevertheless, I lay it down as a dictum borne out by examination-why, I do not know, of course-that the greater the refinement and power of sight, the less is that of feeling or perception of pain on being caught. The connection between the two is not apparent. These are the facts, however. Of course, I am now only referring to the jaws and head generally, When I come to consider perception in the other parts of a fish's body, the circumstances vary somewhat, and the sense of sight does not exhibit the same bearing.

I opine that in those fish which feed in deep places, and collect their aliment chiefly from the soil, the act of capture by hook is painful. Most of these possess barbules, and of all fresh water fish, the cat-fish and its relations furnish the most striking examples. Next to these the carp family provide ample illustrations. One English fish-the barbel-to which I have before referred, gives point to my meaning perfectly. The fish grows to some - six or seven pounds, though its average size does not exceed two and a half, and they congregate in large shoals. Its feelers, or barbules, are four in number, and in a fish of several pounds are quite half an inch in length. On dissecting these, they are found to abound in nerve filaments, somewhat like the trunk of an elephant, and there is a very free movement. Doubtless 
the dissection of the feelers of the cat-fish would reveal a similar and probably greater derelopment of nerve fiber, and this fact is sufficient presumption of exquisite perceptive power.

So, also, the carp is gifted in a similar manner, and the daintiness of the fish is proverbial, whilst the loach (Cobitis barbatula), which lies under stones during the day-time and feeds best on the darkest night, has, in proportion, the most plenteous organs of perception of all. It has six barbules, and if you are so fortunate as to see the little fish feeding in the shady corner of an aquarium, you will observe the investigating movements of the tentacles in a state of great activity. These organs-who can doubt it-are precisely analogous to those of the feline tribe, namely the whiskers, and even to the fingers of the genus homo.

I apprehend, also, that this perceptive faculty is in correspondence with the development of the soft parts of the jaw and their neighboring processes; hence, the bony pike cares little for the hook, whilst no mortal ever yet caught a carp with a lost hook in its jaw, or a barbel or a chub! (I euciscus cephalus).

The perception of sensation in reference to other parts of the body of fishes is an obscure subject, and I shall detail what I have observed, drawing this inference only-that in proportion as the scales are small, the sensitiveness of the cuticle increases. Reasoning thus, we would therefore expect to find the eel the most highly gifted of all, seeing that its scales are microscopical in their minuteness. Nor are we disappointed. The eel will remain quite unconscious of your presence in the 
bright sunlight, "like an owl in a holly-bush," as the saying is; but gently touch it with the tip of your rod, and see the celerity with which it undulates away. The trout does not resent the touch of the hand if it does not see you ; but if, as is asserted by Professor Cope, in Dr. Henshall's "Book of the Black Bass," it hears through its scales, its perceptions must, in this regard, be exquisitely delicate.

That fish feel exquisite pain on the wounding of their bodies, I cannot doubt. The barbarous method of bass and other fishing, which compels the passing of a hook under the skin of a minnow, shows by the shudders and quivers of agony in the luckless bait how fearfully it suffers. Don't talk to me about "reflex action" of the muscles in this case! Again, the pestilent salmon disease, which, like a loathsome leprosy, first covers up the eyes and nostrils of the fish with a fungoid growth (Saprolegnia ferax) and then spreads orer the entire body, often causes the hapless fish to dash itself against the rocks, or leap out on shore, under the sense of the intolerable irritation. Again, the presence of internal as well as external parasites, are particularly a source of pain to trout. I have several times dissected trout which had previously appeared unhealthy and darkcolored, to find them infested with either the larval tapeworm (ligula digamma of Creplin), or a liver fluke similiar to that of sheep. Indeed, the subject of fish diseases is a very interesting one, and quite worth more investigation, apart from its bearing on the question of pain. 


\section{H A P T E R I I.}

\section{PRACTICAL FLY-FISHING.}

Practical anglers, as a rule, are not reading men. Your " reading" man-he who with unfeigned delight reads carefully every angling work that comes in his way; weighs the pros and cons of the controversy "up versus down stream fishing," "dry" versus "wet" fly, "eyed" versus " ordinary" hook, "typical" versus "imitation" flies, etc., etc., is commonly not a very practical angler, and I firmly believe that the really successful fishermen who have derived solid benefit from the many beautiful works published on fishing are in the minority. I am forced to this conclusion after a lengthened experience of anglers and their ways. The fact is, that literary style and finish is usually incompatible with concrete and pithy direction and explanation. One can hardly put polish and style into a book of prescriptions, and yet this is really the sort of thing that the practical man needs when he wants to learn about "How to catch fish." He cares little for the Walton style of writing, which breathes of poesy and worms in the same paragraph, but would listen readily to this grand old angler if he were told in the brevity of a formula how to collect, preserve and use the annelids, omitting references to the nightingale's trill or the saints in Heaven. Yet, all thanks to good old Walton for his gracious advocacy of the art and to the other refined and scholarly men who have written in the Waltonian vein. In the quiet of our sanctum sanctorum, when the winter winds shriek and whistle outside, 
and the sugar-wood log burns brightly in the grate, there is nothing so enjoyable as the pages of a Prime's " $\mathrm{I}$ go a Fishing," or the many genial and truly idyllic sketches of a Francis, a Mather, or a Cheney.

The following endeavors to meet the case of the angler who wants to know, and to see at a glance the information he seeks, or where he can get it. What is here set down is the result of a long experience, and has been "boiled down" with a merciless severity, till the essence is alone presented.

THE ROD, REET, AND LINE.

The modern fly-rod, as represented by the Americanmade solid and split cane weapons, approaches absolute perfection as nearly as it is possible for any mundane implement to do so. The catalogues of any of the tackle makers will furnish particulars, and it is not necessary, in a little work of this kind, to do more than indicate the general characteristics of what the author, himself, prefers.

My favorite rod, therefore, is a split cane hexagonal, ten feet long, with the Orvis patent reel seat, which allows of the reel being instantly adjusted. One peculiarity of all Orvis' rods (which is the make I prefer) is that they are made with ferrules without dowels. These never loosen in the casting (because they fit true), and this cannot be said of any other rod with dowels. In English rods with dowels and the ordinary brass ferrules, which nerer fit accurately, it is necessary to tie the joints together with soft thread, as they would infallibly fly apart if not so tied. This results, first, from the imperfect fit of the 
male and female ferrule and the wedge-shaped dowel, which has the express property, owing to its form, of loosening on being shaken. Any mechanic-even knowing nothing of rods-will tell you that a tapered dowel always has a tendency to shake itself loose by vibration. Even those dowels that are not tapered are objectionable, because they impair the elasticity of the rod. As short a joint as possible should be insisted on if one would possess a useful and perfectly satisfactory rod. In these days one is so absolutely safe in the hands of a respectable tackle maker that I should only be occupying space uselessly if I dilated further on rods for fly-fishing. Let these rules guide you in your purchase: Go to a well-known, good maker, pay a fair price-cheap is generally nasty in fishing tackle-and rather get too light a rod than one too heavy, and eschew dowelled ferrules.

The name of the reels in constant use is legion. In buying, observe one thing-obtain no multiplier. A multiplier illustrates the mechanical law, every time you use it, which is stated thus: What you gain in speed you lose in force. A click or check reel of good make, with wide diameter of barrel is sufficient for anyone's requirements in trout fishing.

And now, as to the reel line. Let it ever be proportioned to the dimensions and strength of your rod. A too thin line is a greater nuisance than one too stout, and necessarily, of course, he who builds your rod will indicate the right kind of line. For my own part, I prefer one of the new "Acme" lines, patented by the Brothers Foster, of Ashbourne, Derbyshire, England, the peculiarity of which is the incorporation of a fine copper wire 
with the silk. In the most approved specimens of this make the wire is in the center of the line. The idea is to give a stiffness and weight to the line without increasing the size-a most important point when you are fishing with the wind against you. The great point in adjusting your fly-trout fishing tackle is to be careful that the whole tackle, from rod-butt to end of leader, tapers truly, right to the fly. I do not know of a better rule, or one more likely to facilitate the learner in the pleasant art than this, or one more likely to increase the pleasure of the "Senior Angler" by its observance. Having thus briefly touched on the subject of the rod, reel and line, I now come to refer to the leader, about which $I$ have some more extended observations to make, as it is quite within the power of the angler to tie his own.

I need scarcely remind the reader that the gut used by the fisherman is made from the fluid silk, before it is spun, of the silk-worm. The chief part of it comes from Murcia, a Moorish town in Spain, and the longest is seldom over twenty-three inches in length. A Mr. Ramsbottom showed some of that length at the Great Fisheries Exhibition, held in London in 1883, and it was said to be the longest of the season of 82-3. Whether the larger American worms will ever prođuce.longer gut, available and marketable, remains to be seen. Personally, I do not doubt that it will eventually be done, and I hope to have a finger in the doing. I have myself seen a single strand of gut measuring six feet in length, of good quality, of American production.

Good gut should be round and without opacity. No gut with a blen.ish ought to be admitted; but as there is 
so much of the best grades that are, if judged by a strict standard, unusable, I will relax this dictum so far as to say that the flat gut, and that which is, from some reason, brittle on being bent, need alone be absolutely condemned. The spotted gut, if fairly round, may be benefited by a soaking in warm water. Thereafter, it should be lightly stretched, and after this, and when it is quite dry, it may be rubbed quickly and gently with chamois leather. This polishes the surface, and makes its appearance much more presentable than would otherwise be the case. If, however, the gut breaks on bending, with a greenwood fracture-as the surgeons term it-that is, splinters up but does not separate, reject it ruthlessly; it is no good, and will lose you a fish when you least want it to do so.

There are ever so many methods of making leadırs, but generally the single gut ones are tied. Those that are whipped together with silk are rery neat when new, but if they are used on a rocky-bottomed river, speedily become the reverse. The whipping ravels up and becomes insecure. The same objection applies to those having knots and whipped ends, and also to those joined by the "buffer" knot, which simply consists of two "fishermen's" knots drawn tight but not close together, the intervening space being whipped with fine silk. The virtue of the arrangement lies in the fact that no sudden strain can come directly on the knots, but must pass through the silk, which, of course, is not absolutely unyielding. Hence, the leader never snaps suddenly at the junction. So far, the idea is good but, as I have sail, liable to the objection that the knot frays. 
Suppose you are determined to make your own ieaders. Buy the best gut; it is cheapest. Then set to work and soak the gut. While that is soaking in cold water, (warm water loosens the fibers unduly, and should be avoided if you are not in great haste) learn to make the

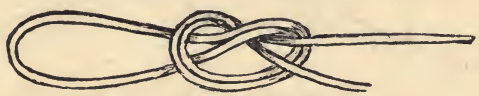

Fig. 1.-SIMPLE LOOP FOR LEADER.

following knots. Figure 1 shows the ordinary loop; if you desire to make it additionally secure--supposing that to be possible-take the loop end once more through. A stout hook is necessary, as a fixture, on your work-table, and over this the loop should then be hung and pulled tight. The result should be symmetrical, and the loose end can be cut off very close. Figure 2 is a much more difficult knot to tie, but it is convenient, especially for snells, and once learned, is a very pleasing loop and ex-

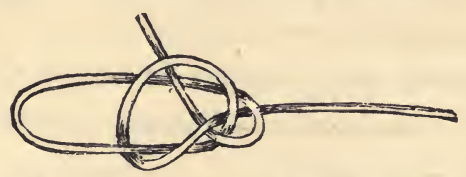

Fig. 2.-ANOTHER LOOP FOR LEADER.

tremely secure. So far as loops are concerned, I do not think it is necessary to add to these. The trout and salmon fishermen do not want any more under any circumstances, and it is folly to cram one's brains with unnecessary knowledge, which, by the bye, is an exceedingly prevalent fault, caused by the teachers of the art seeking rather to exploit themselves, than impart useful lessons. 
The best junction knots in leader-making are shown at Figures 3, 4 and 5. Take a piece of cord and practice on

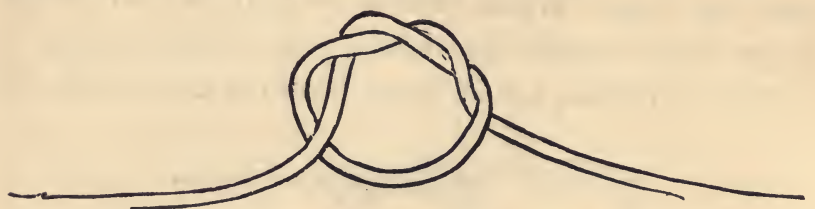

Fig. 3.-JUNO'TION KNOT FOR LEADER.

it till you are perfect, then tie the gut. Be sure to draw whatever knot you tie-tight, slowly. The best attachment of a loop for droppers is found by placing the knot of a loop in between the component knots of either Figure 4, or Figure 5, or in the center of Figure 3. A

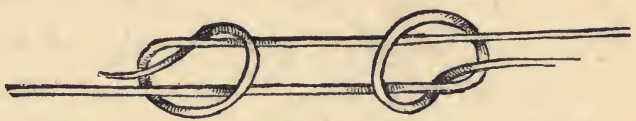

Fig. 4.-THE "FISHERMAN'S" KNOT FOR LFADER.

loop tied in, however, provides by far the most preferable method of attaching dropper flies.

If we proceed seriatim the fly would naturally next come up for consideration, but as I propose giving full

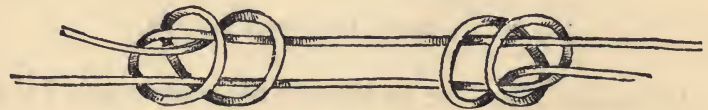

Fig. 5.-JUNCTION KNOTS FOR LEADER.

details of manufacture, etc., a separate chapter is necessary for its full exposition. Lacking this at present, therefore, I propose giving details of what I consider a most important branch of the fly fisherman's educationnamely, Casting. 
Now, there is no better plan than for the tyro to go down to the water and patiently practice. The attitude should be easy and that which suits the angler best; it is absurd to tell a man exactly how he should stand, as if he were learning ballet-dancing, and indeed, so far as mere verbal instruction is concerned, I am conscious that I might almost as well give instructions in the " manly art

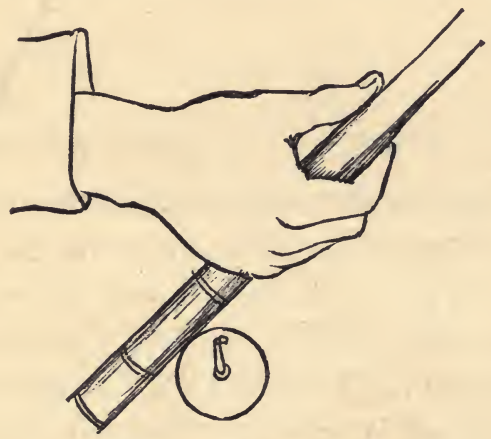

Fig. 6. -MODE OF HOLDING ROD.

of self-defence" as in the manly art of fly-casting. However, I take my chances of making myself clear and instructive by the aid of the illustrations.

The trout-rod, if single handed-and I don't favor a double handed one unless you are fishing in rery wide water-should be taken in hand as shown in Figure 6, and the elbow should be kept as close to the side as possible. My father used to put me through my exercises with a small book placed between my elbow and side, and I have found this a remarkably good corrective for the disposition to swing the arm unduly. This latter does not add to the length of the cast, and certainly detracts from 
its neatness and precision. The fundamental idea is, "Let your rod do all the work its strength allows"- that is what it is for.

The overhand cast is that which is most generally used, and it is probably the easiest. Let out your line in

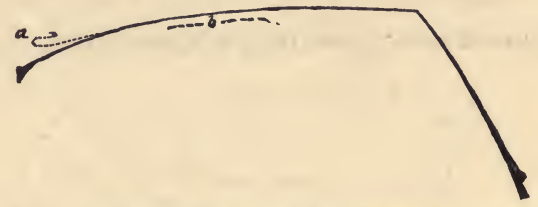

Fig. 7. - OVERHAND CAST, BACKWARD MOVEMENT.

the water, allowing the current to take it ; then recover it till the fly appears on the surface of the water. At this point, sharply throw the point of the rod back over the right shoulder, so that the line is impelled back, as shown in Figure \%. When the limit is reached, and not till then, the rod is urged forward and the cast, shown in Figure 8, is made. This movement ought to be made as the line is falling (see $b$, fig. 7), and is a matter rather for the intuitive perception of the hand than

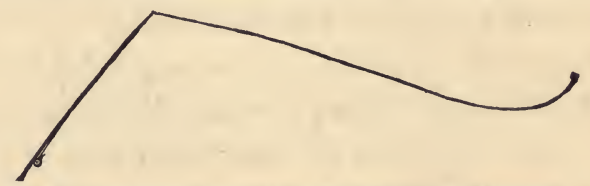

Fig. 8. - OVERHAND CAST, FORWARD MOVEMENT.

for nice calculations on paper. If this forward throw or cast is made before the limit of the line is reached, the latter curls and snaps (see $a$, fig. 7 ) like a whip, and the result is the loss of your fly. Now, there isn't much in this to learn, and I purposely refrain from giving further and 
more minute particulars as to how this cast is made. The learner, in trying to follow the minutiæ of such detailed explanations, gets too particular and nervous-fussy, and in trying so very hard to perform what he imagines a difficult task, he throws a great deal ton much conscious effort into it and fails ignominiously. Preferably, take a friend to the water-side with you who is warranted to be absolutely

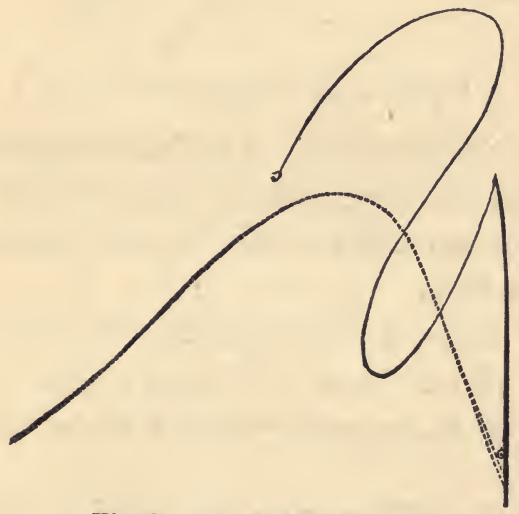

Fig. 9. -THE "WIND" CAST.

ignorant of fly-casting and, necessarily, unable to criticise, and assign him the task of telling you, by a word, when the forward motion is to be made. After a short time you will come to appreciate the precise moment and can send him home. Don't be disappointed at failure. The line should fall forward, as shown in Figure 8. When you can place twenty yards out straight in front of you, as represented, consider yourself graduated as an "overhand caster."

The "wind cast" is one that is very useful when the wind is dead against one. The dotted line in Figure 9 
indicates the movement of the rod in the beginning. The line must, with the full strength of the arm, be propelled up overhead and then brought down and forward, right in the teeth of the wind, till the rod's point almost touches

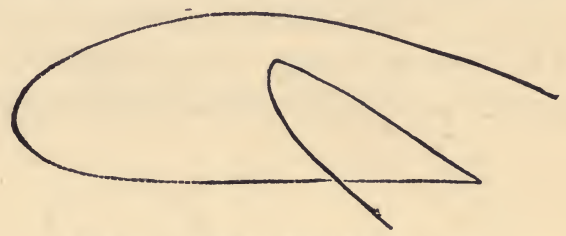

Fig. 10. -THE " UNDERHAND" CAST.

the water, without pause. The full strength of the rod is exerted by this cast, and the success of it is greatly assisted by the use of one of the "Acme" lines referred to a few pages back.

The "underhand cast" is made from right to left, as shown in Figure 10, or vice versa. This is probably the easiest of all the casts-the rod doing nearly all the work.

The "flip casts" are extremely useful when one is "negotiating" water under trees, and, indeed, the line is, in

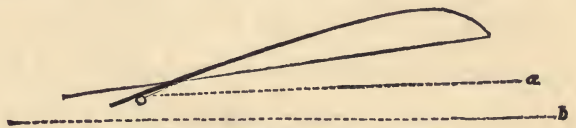

Fig. 11.-THE "FLIP" CAST.

some cases, impossible of extension in any other way. The cuts (figs. 11, 12 and 13) explain themselves. The hook is taken in the hand between thumb and forefinger (and be careful not to hook yourself !), and the rod then bowed so that on your releasing the bait it flies to the spot it is desired to reach. In Figure 11, a represents 
the path of the fly and $b$ the water-line in which the angler is standing.

"Clark's spey cast" is a difficult but beautiful cast to make, and a Mr. Clark, from whom it takes its name, is

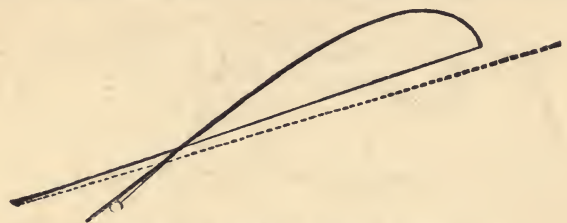

Fig. 12.-THE "FLIP" CAST.

credited with throwing fifty yards. Figure 14 shows the entire movement of the rod's point. In Figure 15 we have several movements; $a, b$ and $c$ indicate stages of the recovery from the water, during which the rod's tip describes the dotted line, Figure $14 ; d$ shows the result of

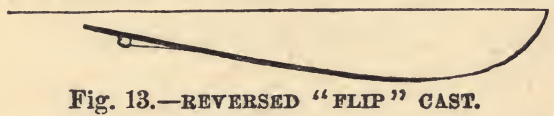

the downward thrash and the course in which the line should travel.

But of all casts, that explained by Figures 16,17 and 18-namely, the "switch"-by means of which Harry

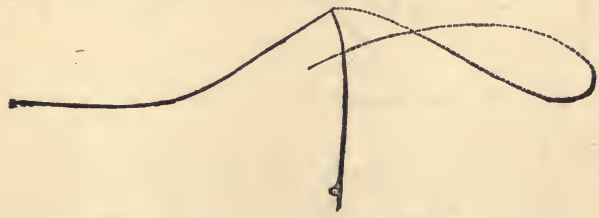

Fig. 14.-CLARI'S "SPEY" CAST.

Pritchard and his son achieve such extraordinary distance casting-stands pre-eminent. Figure 16, $a$, shows the first movement; the line is bellied, as shown from its 
former outline (see dotted line) by a rapidly increasing movement. Now twitch the front of the rod forward by a sharp, short action of the wrist (see $b$ ), causing the line to bow in an opposite direction; then, with a bold, ellip-

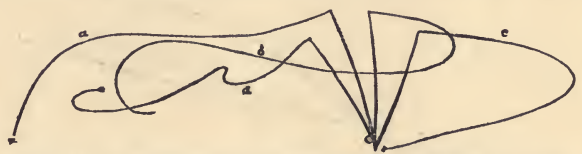

Fig. 15.-MOVEMENT IN CLARK's "SPEY" Cast.

tical sweep (see fig. 17), from the right overhead to left, make the downward thrash (c), and the line should fall in undulating outlines, as in Figure 18. Let the reader take plenty of time to practice and he will not regret the result-keeping in view the diagrams given, which are of photographic correctness.

Having mastered the method of casting a fly with tolerable neatness, next turn your attention to catching the

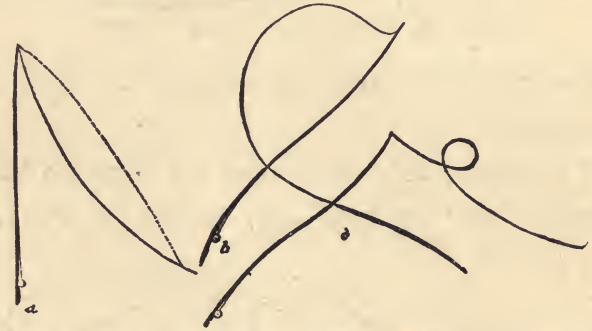

Fig. 16. -MOVEMENT IN THE "sWitch" CAST.

fish. The first question which presents itself is, "Shall I fisn up stream or down?" To this I reply, with all the emphasis of which I am capable, "Up stream, by all means, whenever possible." There is every reason for it, but here are a few, briefly put: (1.) Trout invariably lie with their heads up stream-ergo, take their food in 
that position. (2.) Trout cannot see the angler more than a few feet behind them, whilst they can and do see many yards in front. (3.) The vibration of the water, caused by the movement of the advancing angler, if

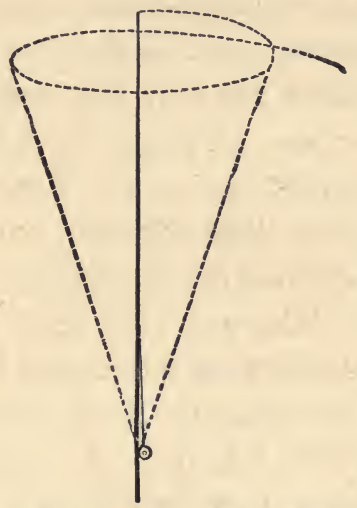

Fig. 17.-Movement in the "switch" Cast.

wading, does not penetrate up stream as it does down stream. (4.) The water is not "roiled" or muddled for the fish by wading up stream.

These include the chief reasons for up stream fishing, and in the face of them I cannot understand there being the ghost of a shadow of reason for arguing for the down

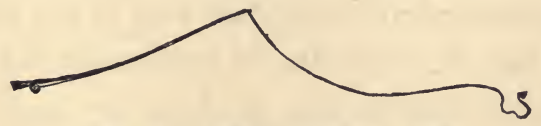

Fig. 18. -THE "swITCH" CAST.

stream method of fishing, except that it is easiest. I heard, only the other day, a prominent angler argue that he missed fish more frequently, because of the bellying of the line, in up stream fishing. Now, the bellying is 
kept taut by the stream, and the strike is thus never lost, and the fact that one strikes dead against the mouth of the rising fish instead of with a tendency to pull the fly out, as is the case when fishing down stream, renders the up stream position even more tenable than before. When it is borne in mind that the big trout of the Itchen and Test, and some other rivers of England-running up to three and four pounds-are caught by this method on flies dressed on the smallest procurable hooks (up to No. 16 Limerick), and that these wily fish, living in the most limpid of chalk streams can be caught no other way, the feasibility of my advice may be thought respectable. It is the fashion to deride what is termed the "old fogyism" of Europe, but I can assure the reader there is none of this commodity in its fly-fishing. The up stream, dry flyfishing-as practised on the best rivers of the British Isles -is the evoluted result of the best inventive genius of intelligent, observant anglers, and designed for the capture of the most artful of educated trout. The characteristics of this system of fly-fishing may be fitly detailed at this place.

As before predicated, the angler moves up, if possible, and prefers to cast to a rising fish. If he spies one rising regularly, he gently walks within casting distance, the line probably trailing behind him in the water. To make the cast he urges the fly backwards and forwards twice or thrice through the air, until his quick eye sees by the flying bait that he has enough line out to allow of its falling about a yard above the rising fish. By this time the fly is dry ; its swift passage through the air enables it to become so, and the next time it is cast right in front to the spot designated, and, when it falls, the angler 
watches its course without making a movement of the rod. It floats, of course, and if the fish does not take it just as soon as the radius of its circle of vision is passed, it is lifted again from the water, dried, and cast as before. If you are fishing "likely spots" instead of a rising fish, the same procedure is gone through with, and the result has ever been to me satisfactory, often beyond all expectations. Of course, on very rapid mountain streams, this method should be modified to suit circumstances, but under no existing or possible conditions is it necessary to fish down stream on an open fairly slow stream.

Some object-that motion should be given to the fly (if so, give it by all means ; fishing up stream does not pre-vent this!), but I would again urge that this is not necessary to be natural. Land flies, blown on the water, certainly do kick and endeavor to get ashore, but those born of water larvæ do not. Their home is on the water, where they lay their eggs and perish, and it is natural for them to flutter into air once in awhile, and then to settle down and be blown as a disruddered sailing vessel, whithersoever the wind listeth.

Supposing the fish rises to your fly-strike, not roughly but sharply, rather with a swift pulling motion than a jerk. That everlasting "turn of the wrist," which we piscatorial scribblers are so wont to recommend, is a delusion to the learner. Anything like a jerk sends the point of a fly-rod forward, unless it is immoderately stiff, and, of course, retards the hooking stroke. To make this plain, let the reader take his fly-rod and try his most artful of sharp strikes. One of the morals is, "Don't 
use too whippy a rod." Always strike from the winch$i$. e., without placing the hand round the line, and for this purpose the check should be set "stiffish."

After hooking a fish keep the point of the rod well up, your line free to run off the winch, and yourself cool. That is all the direction you need; the fish will teach you the rest. Several of your largest fish, of course, will inevitably be lost through unskilful "playing," but if I were to write a hundred pages of directions I could not really help the tyro. Letting the rod do its work is the prime secret, and, of course, keeping the tip well up allows of this. Did you ever try pulling against a strong elastic band-I have, in training for rowing-to see how long you could keep making efforts, and how much your efforts amounted to in pounds, each time? If not, take my word for it that the continued tension is the greatest of inventions for taking the strength out of one's muscles, and it is the same with a fish. A good cane or greenheart rod will kill much stronger fish, on a tight line even, than is usually believed. Check every rush of the fish, and don't be too impatient to get him into the boat. Half the pleasures of life lie in pursuit; conquest is "flat, stale and unprofitable" as compared with it. Hence, I believe in getting all the sporting power there is in a fish out of him. I have played fish purposely till they neerled no landing net. Of course, however, the man who has the pot to fill cannot stop to "fool around" like this.

I do not propose to give directions in reference to salmon fishing at this time. There is an army of authorities who are better qualified to do this than I. It is 
sufficient to say here that the general principles of stream "trout" fishing are applicable to lake tront fishing and the "lordly salmon." If a man is a good truut fisherman he will have no difficulty in catching salmon; but, on the other hand, there is many a good salmon fisher who makes a poor trout angler. I must not forget to say, also, that in salmon fishing the up stream, dry flyfishing has no place, because the fly is not an imitation of any known insect. This reservation is the only one of any real importance to be made. 


\section{H A P T E R III.}

\section{TROUT FLY-MAKING.}

The art of fly-dressing is a most beautiful one arid more than repays him who studies it as he goes along creating things of beauty; moreover, it grows on his inclinations, and I personally know several gentlemen, and even ladies, whose spare time is filled up most agreeably, and to their own profit, be it said, by fly-making. Ay ! and their flies outshine, in some particulars, even the

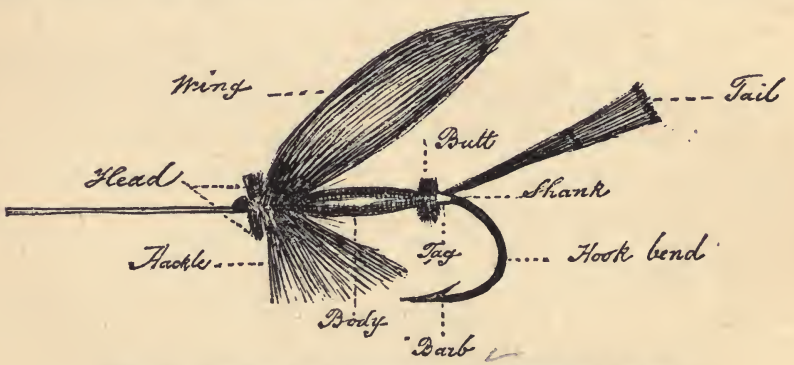

Fig. 19.-TROUT FLY-SHOWING DIFFERENT PARTS.

finished productions of professional tiers, especially in faithfulness to nature ; for, of course, one of the primal objects in fly-tying is to imitate nature closely - a fact of which the often hard-worked and badly paid professional cannot, always reduce to practice, if he would. The salmon fly is, of course, not an imitation; rather let us call it a "poem of color," the beauty and efficiency of which depends on the variety and harmony of its component parts.

It is not remarkable that fly-making has been practiced 
so long ago as two thousand years-for nothing is new but that which is forgotten-but it is strange that we find no references made to it by the ancients except Martial and Alian. The former simply says:

"Who hath not seen the scarus rise

Decoyed and caught by fraudful flies."

But AElian gives an account of the hippurus and its dressing in the following complete manner in his "De Natura Animalium": "The Macedonians who toil on the banks of the. Astreus, which flows midway between Berea and Thessalonica, are in the habit of catching a fish in that river by means of a particular fly called the hippurus. A very singular insect it is, bold and troublesome, like all its kind; in size a hornet, marked like a wasp, buzzing like a bee. The predilection of the fish for this prey, though familiarly known to all who inhabit the district, does not induce the angler to attempt their capture by impaling the living insect. Adepts in the art had contrived a taking device (captiosa qucedam machina) to circumvent them, for which purpose they invest the body of a hook with purple wool and having two wings of a waxy color, so as to form an exact imitation of the hippurus. They drop these abstruse cheats gently down stream. The scaly pursuers, who hastily rise and expect nothing but a dainty bait, are immediately fixed by the hook." According to the "Bibliotheca Piscatoria" this passage was first pointed out by Stephen Oliver, author of "Scenes and Recollections of FlyFishing," and I have transcribed it because it so clearly identifies the existence of the subject before us in the 
earliest times. Moreover, it tells of the method of using the lure-viz. : "They drop these abstruse cheats gently down the stream," and as this is the generally accepted mode in this country to-day, the fact is interesting.

From this period, as far as my reading serves me, a hiatus occurs in the history of fly-making. Not until the first book on fishing in the English language was printed, is the subject again traceable. This fish book, the reader needs scarcely to be told, is that of Dame Julyana Berner's, of Sopwell Priory, St. Albans, written " to the entent that your aege maye the more floure and the more lenger to endure." This fair anglei author advises fishing for "trowte" in "leppynge tyme" with a "dubbe," and at the conclusion of her treatise she gives directions for making of twelve sorts of "dubbes for troughte and graylynge." The details of one or two of these will suffice for comparison with those I shall speak about in future pages. The doone fly: "The bodye of the doone woll and wyngs of the pertryche." Another doone: "The bodye of blacke woll, the wyngs of the blackest drake and jay of the wing and under the tayle." This work bears on the title page of the original edition, "Emprynted at Westminstre by Wynkyn de Worde, the . yeare of Thyncarnacon of our Lord 1496." *

So much for the history of the artificial fly. To trace it from this point to the present time would be a labor of love of almost herculean dimensions, but quite barren

* An American edition of this charming]y quaint old treatise is published by the O. Judd Company, 751 Broadway, New York, under the editorship of Mr. Geo. Van Siclen, an angling writer who seems to have been imbued with a large share of the spirit of Walton in all his utterances. 
of practical results. The reader must imagine the interest it has aroused in order to fill the interregnum, and permit me to now plunge in medias res of the subject of its manufacture as it now is.

The first consideration in reference to fly-making is the selection of a hook, and it is necessary to remind the

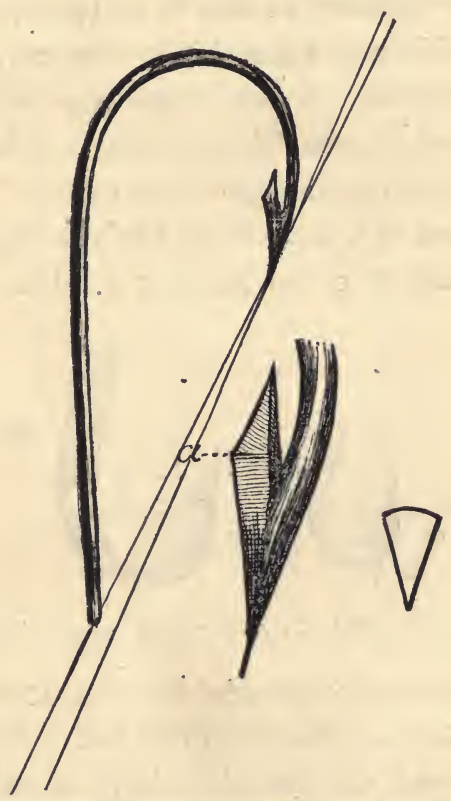

Fig. 20.-AUTHOR's IDEAL OF HOOK.

reader of the unavoidable principles which should guide the angler in this selection. First, and chief, is strength ; second, penetration; third, fouling or hooking power; fourth, holding power. Strength is a matter pertaining to the maker, and a good maker is not likely to sell a weak article. Hence, deal with a respectable firm and pay 
the best price-it is cheapest in the end, say I. Penetrating power depends on the point being sharp, the barb not unduly rank, and the line of impact being, as nearly as possible, coincident with the direction of force applied. The fouling or hooking power is nearly equal in all hooks with a straight vertical section-that is, not made with a "kirbed" or side twist (which injures penetration), providing all other things are equal, and the holding power depends on the nearness of the point to the opposite part of the shank, the distance between it and the first bend, and on the shape of the barb.

My own ideal of a hook is set forth in Figure 20, and I make it a present to the angling public. It has never

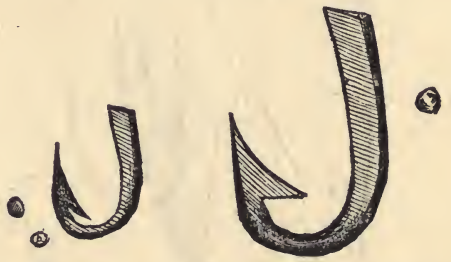

Fig. 21. - HOOKS OF A. D. 1496-FROM BOKE OF ST. ALBANS.

been manufactured wholesale, but the few I have made for my own use have demonstrated the unfailing accuracy of the hook in all the qualities I have named as desirable. As will be observed, the chief peculiarity of the hook lies in the form of the barb. A section of it at $A$ shows it is brought to an edge razor-wise, and this is carried on down to the point. Then the slanting off of the upper part of the barb is claimed as an important improvement, allowing, as it does, of instant penetration without loss of holding power. Added to this-the line of impact is 
nearly coincident with the direction of force applied. (See dotted lines.) It will, I think, anyhow, be conceded that this hook is a great advance on that in use in 1496four hundred years ago. (See Figure 21.) Another hook of high reputation on the "other side" is that brought out by Mr. Cholmondeley Pennell recently, both with tapered shank, and with an eye formed by a continuation of the shank. Figure 22 shows these hooks, though, I am sorry to say, very imperfectly. The advantages of an
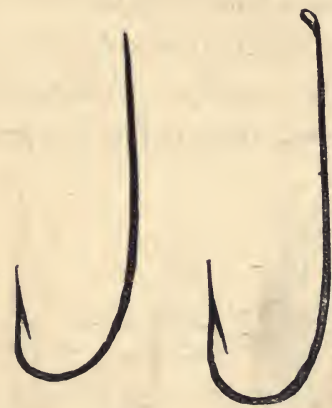

Fig. 22.-PENNELL'S EYED AND TAPERED HOOK.

eyed hook are very great-whether of the bashful or bold order.

A writer of some repute, in the "Fishing Gazette," June 6, 1885, thus sums up the advantages of the turn down hooks, and, though I believe my own pattern (with turn UP eye added) far superior (yet, until some firm undertakes to make it, it is practically useless), I give the opinion for what it is worth. "Having," the writer states, " made a thorough trial of flies dressed on these hooks against flies dressed on ordinary hooks with gut lappings," he thus sums up: "The 
result of the week's fishing, during which my worst day was four brace, and my best day nine brace [this is very good sport on English clear streams] is on every point favorable to the flies tied on to turn-down eyed hooks.

(1.) The flies never flick off.

(2.) They can be changed-attached and detached-in less than half the time.

(3.) They are stronger, because, whenever the gut gets at all frayed at the head, it can be at once shifted (reknotted on), whereas with flies lapped on gut the weakening at the head commences very soon, and any change involves sacrificing the fly. Consequently, the fly is in many cases used long after it has become weak. But be-

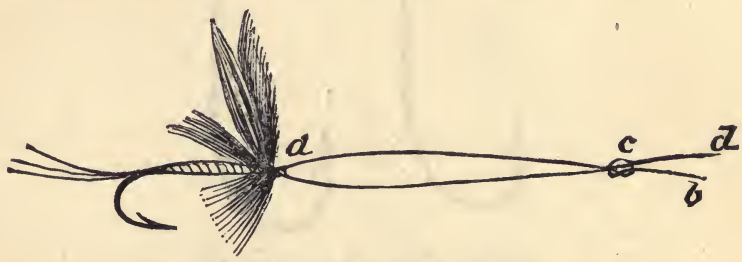

Fig. 23.—THE "ЈАМ" кNот.

yond this there is, I think, an actual extra strength imparted by the form of knotting to the eyed hook (Mr. Pennell's 'jam' knot) as compared with the ordinary lapping.

(4.) The turn down eyed hooks appear to me to hook more fish in proportion to rises, and to lose fewer fish after being hooked. I have never met with an instance of the knot slipping."

Though it is debatable if Mr. Pennell invented the "jam" knot, or has any property in it at all, it certainly is the simplest and probably the strongest fastening for 
trout and grayling flies, dressed on eyed hooks, ever applied to that purpose; while, at the same time, owing to the hook's eye having only to be large enough to pass the gut once through it, it is also the smallest and neatest.

Figure 23 shows the knot and its method of tying, in accordance with the following explanation : First-take the fly by the head with the eye turned upwards. Pass two or three inches of the end of the gut leader, previously softened by moistening, through the eye towards the point of the hook and then, letting go the fly, double back the gut and make a single slip knot (c, fig. 23) round the center link, $d$.

Second-draw the slip knot tight enough only to admit of its just passing freely over the hook's eye ( $a$, fig.

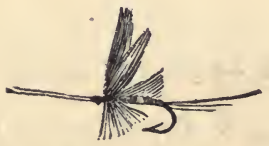

Fig. 24._" JAM" кNOT PULLED TIGHT.

23), and then run it down to and over the said eye-when, on gradually pulling the central link tight the "jam" knot is automatically formed, as shown in figure 24 , which shows the fly, actual size. Finally, cut off the superfluous gut end to within from rather more than one-sixteenth to one-eighth of an inch, according to size of the hook.

For salmon flies an additionally secure knot-if such be possible-has been tested. It is shown in Figure 25, and is termed the "double-jam" knot. The method of tying it is as follows: Take the hook by the bend between the finger and thumb of the left hand, and with the eye turned downward, in the position shown in the dia- 
gram ; then-the gut being first thoroughly soaked-push the end, within a couple of inches or so, down through the eye, $b$, towards the point of the hook ; then pass it round over the shank of the hook, and again from the opposite side downwards through the eye in a direction away from the hook's point (the gut end and central link, $c$, will now be lying parallel) ; make the double slip knot, $a$, round the central link and pull the said knot itself perfectly tight; then draw the loop of gut together with the knot, $A$, backwards (towards the tail of the fly) un-

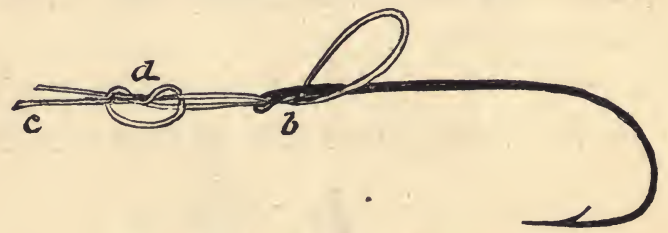

Fig. 25.-KNOT FOR SALMON FIIES.

til the knot presses tightly into and against the metal eye of the hook, $b$, where hold it firmly with the forefinger and thumb of the left hand, while with the right hand-and "humoring" the gut in the process-the central link is drawn tight, thus taking in the slack of the knot. When finished, cut the superfluous gut end off close.

All other kind of hooks, the 0'Shanghnessy and Sproat, made by Allcock, of Redditch, England, seem to me far and away the best. Allcock's Sproats in particular, are free from that vice which the other makers seem unable to get rid of-viz., breaking short off behind the barb. 
TROUT FLY-MAKING.

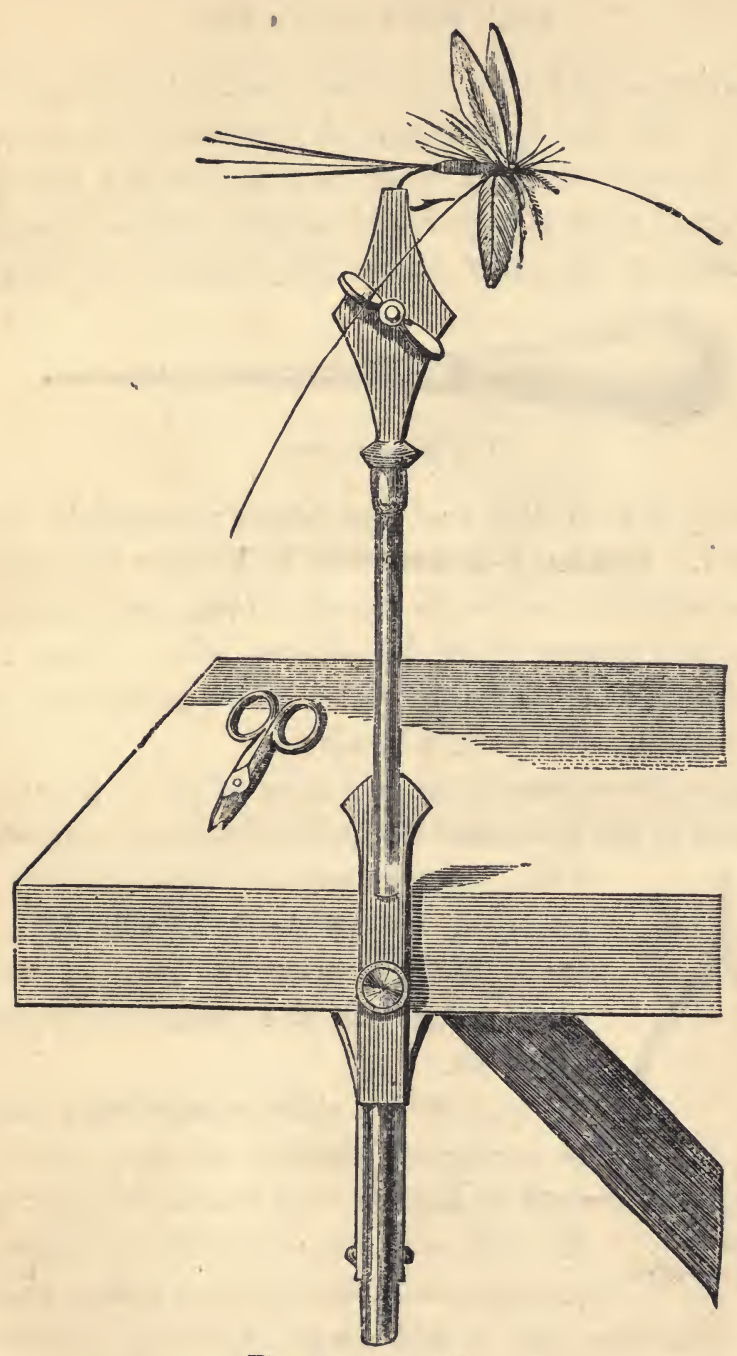

Fig. 26.-FLY VISE. 


\section{TOOLS FOR FLY-MAKING.}

Having settled upon the hooks, the next consideration is the tools for fly-making. A great many of the oldtime fly tiers use only their fingers, but the extreme delicacy of some of the smaller midges, and the intricacy of many of the chief larger flies, render the supple-

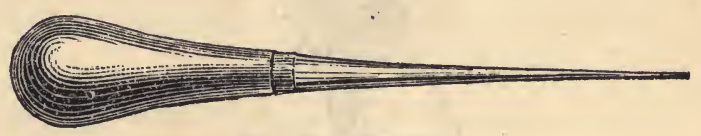

Fig. 27.-stiletto.

mentary aid of the vise and pincers extremely conrenient. Besides, $I$ believe that it is quite impossible for an adult to learn to tie a good, strong, neat, intricate trout and salmon fly by his fingers alone. The less handling a fly receives, the better for its appearance and workmanlike strength and integrity.

Figure 26 represents the best form of vise. I do not know if it can be bought in this country in any numbers.

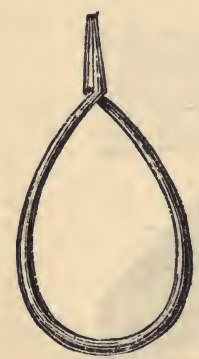

Fig. 28. SPRING PLIERS. I can, however, put any one in the way of procuring the article if he will write to me. The engraving on page 65 fully explains its use, and needs no further comment.

Figure $2 \%$ is a stiletto exceedingly useful in arranging feathers, pricking out the wool or mohair bodies, undoing knots in the silk, etc., etc., and will, as the tyro proceeds, be looked on as a valuable assistant. The same may be said also of Figure 28, representing spring pliers for holding whipping silk or tinsel, 

etc., at tension in the progress of making a fly, and so leaving the hands free to attend to other parts of its manufacture. They are of steel, which should be nickelplated, or of brass-preferably the latter. The learner should have at least two pairs in his possession.

The last tool, but not least, is a pair of good, sharppointed embroidery or surgical scissors. They should be kept in a sheath when not being used, and never used on anything but feathers, fur or silk. Another ordinary pair will do for cutting gut.

\section{MATERIALS FOR FLY-MAKING.}

Let me, at the outset, premise that there is no hard and fast rule as to these materials, and it is in the selection of them-the perception of fitness-that the best flymakers excel. I have seen a prominent fly-maker of this country pick a morsel out of an old sock, a couple of hairs from his own beard, and a feather from a dilapidated and decaying pigeon's wing lying by the roadside and make a fly that killed a brace of magnificent trout. But that is, of course, an extreme instance, and I only mentian it to illustrate the possible variety of sources from which material may be derived. Ordinarily, the flymaker's cabinet contains the fur and feathers of all kinds of beasts and birds. From the docile camel-the "ship of the desert"- - to the mighty condor of the Andes, the fur and feather are gathered, and mean indeed is the creature that does not possess possibilities in the eyes of the enthusiastic fly-tier; again, be it said, as an ultimation, that the taste and sense of suitability for usefulness in the maker is the only guide as regards the materials of 
the art. Of course, generally, I may enumerate those materials that are most in use, for the benefit of the learner. After he has gone carefully a little into the processes of the beautiful art he will begin to select material for himself, and, though probably he will still continue to follow the formulas I shall give in a future chapter for the chief flies, yet he will by no means consider himself bound to them if a softer, better, or fitter material presents itself.

Briefly, then, the requisites of all fly-tiers' collections are : Silks-floss and sewing of every shade (the sewing silks are useful for whipping); the floss of the plates is simple embroidery silk; worsteds of every shade ; cotton-batting, for making foundations of very large bodied flies ; mohair of all possible tints ; tinsel, flat, in various sizes, and oval, or of the pattern termed "flat-worm;" chenille of various patterns and sizes; ostrich feathers; peacock eye feathers; hackles-i.e., feathers from the necks of "roosters" of all possible colors, especially black and white (which is a "bull," neither being colors at all). These hackles will, in many cases, require to be dyed. Next-the feathers of jungle cock, scarlet ibis, large heron, swan, wild goose, wild turkey, pin-tail duck, widgeon, teal, duck, crow, Indian crow, yellow-hammer, kingfisher, American and English jay, English, American, golden, and argus pheasant, robin, pigeonin short, all and every bird one comes across, with perhaps the trifling exception of the carrion-eating vulture; furs of squirrel, cat, rabbit, mole, weasel, skunk, bear, pig's wool-i.e., the short hair under the bristles of a certain kind of pig ; hare's flax-the short wool under 
the outer coat, etc., etc.; all ought to find a place. Of course, the best of gut (not omitting the ordinary waste ends of the hank) must be included.

At the time when Blacker wrote his much overrated book on fly-making, there were no Judson's or Diamond dyes, and naturally he resorted to such as were available. Now, I cannot overestimate the value of the Diamond preparations for most of the uses required of them by the fly-maker. Be careful, however, to buy

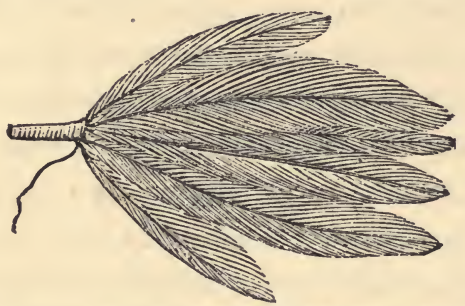

Fig. 29.-BUNCH OF FEATHERS FOR DYEING.

those sold for silk, and following the directions exactly, or the result will not be good. Figure 29 shows a bunch of hackles prepared for dyeing.

If one does not desire to go to the trouble of "bunching" the feathers, they may be dyed all together, and after being washed and pressed between a dry cloth, to remove superfluous moisture, they can be dried so as to re-establish their fibers in this way. Get a stiff paper bag and put the feathers in it loosely ; then, leaving the mouth open, stand the bag on a moderately hot stove. Of course, they will very soon get warm-and you must watch that they do not scorch-but the bag will be filled with warm air, and should now be taken and shaken with energy. This must be repeated at intervals till the 
feathers are dry, when they will be found of very satisfactory plumago. Some of these dyes, however, are not very satisfactory - such as the browns and their shades, and I therefore give some formulas from the last edition of "Foster's Scientific Angler," one of the most reliable and practical of modern angling books :

"In preparing a batch of feathers for staining, the uniform size required should be selected ; these should be first soaked in warm water, in which has been placed a scrap of common soap or soda; this removes the oil natural to the feathers, and enables the dye to strike evenly throughout; when drained they are ready for the dye. In case of large feathers it may be as well, in order to strike a delicate hue, to first steep in a solution of sulphuric acid, but, generally speaking, this is uncalled for. We now append a few useful recipes for natural dyes :

Fiery Brown.-Camwood, logwood or partridgewood chips in equal parts, boiled in pure water.

OLIve. - Fustic and cam wood or logwood in equal parts, with a very small portion of copperas added when at the point of boiling; the last named determines the shade. The outside of large onions boiled, also, are good.

GreEs.-An infusion of fustic chips, to which must be added oil of vitriol, in a quantity sufficient to gain the shade required.

Light Yellow. - Barberry bark in solution.

Dun.-Logwood and copperas.

Browr.-Fustic chips, two-thirds; logwood, one-third; boil in rain water.

BLACK.-One-half pound logwood chips, boil in half a pint of water; this done, put in one ounce copperas 
and stir up." Gut may be stained by weak solutions of the Diamond dyes, and by any of the above.

Among the list of materials, wax and varnish must not be omitted. Cobblers' wax was for a long time used as the best ; but a colorless wax made as follows is, in my opinion, the best, and takes the varnish better than any others I have used :

WHITE WAX.-Four ounces best white resin, one-half ounce fresh lard, one-quarter ounce white wax. Melt the resin first; then add the wax and then the lard; let it simmer for a quarter of an hour; then pour into a basin of cold water and pull it like taffy. The longer you pull it the whiter it becomes.

VARNISH.-Brown scale shellac dissolved in alcohol is a good varnish for flies with dark heads. Bleached shellac is better, however, producing, as it does, an almost colorless varnish. The best of all is a varnish $I$ call the crystal varnish, made as follows: Take a quantity of the best gum copal and pick out the lightest colored and clearest nodules. Now, test them for their fitness by touching each with a drop of the oil of rosemary. If the gum becomes at once sticky where the oil touched it, it will serve your purpose. Put these pieces on one side. When you have enough, say three or four 'ounces, pulverize them in an iron or glass mortar, and spread the dust over a shallow dish in a thickish layer. Next, pour oil of rosemary over the layer of gum till it is just covered. Let it stand a little time, till the gum is permeated, and then stir the whole mass together. It should form a plastic, sticky paste. Now, add alcohol gradually; and it is well if you place the dish over a water bath, to 
aid the mixing and solution, and as soon as possible pour the whole into a bottle, adding alcohol as you think it is required to form a sufficiently thin varnish. This is a very superior varnish and will resist water much longer than shellac, though it does not dry quite so quickly.

\section{H A P T E R I V.}

LESSONS IN FLY-MAKING.

Having familiarized yourself with your tools and materials, it now becomes fit that your first fly be attempted. We will, if you please, manufacture together the "Alex-

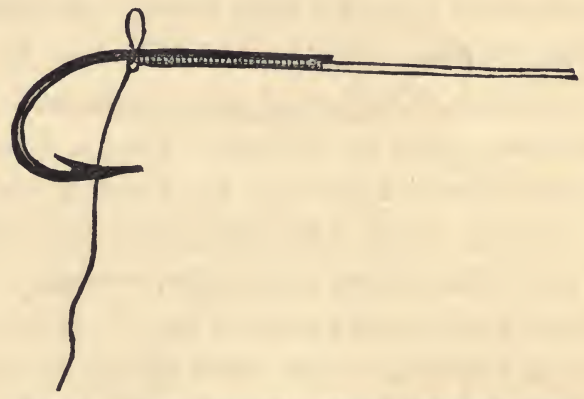

Fig. 30.-HOOK WHIPPED READY FOR DRESSTNG.

andra," a noted fly both here and on the "other side." It is peculiarly easy to make, considering its efficiency, and its attractive appearance when complete will commend it to the eye of the laboring tyro, hence, I select it in preference. The hooks in the illustrations are purposely shown large to aid in rendering the explanations cléar. 
Materials Requiked.-Hooks, any size you prefer, but usually about number seven or eight Sproat, Pennell or O'Shaughnessy; green whipping silk, peacock herl, two whisks of any dark feather for tail, black hackle, gut.

Directions. - Take the hook between the left forefinger and thumb, place the gut underneath the hook shank, having first crushed the end of it between your teeth; begin whipping the hook and gut together, leaving about one-eighth of an inch of the shank untouched (fig. 30). Continue whipping till that part of the shank exactly opposite the point is reached, and then tie with the half

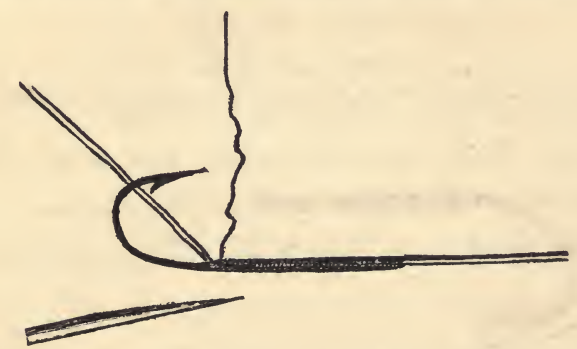

Fig.31. - SHOWING TAIL READT FOR ATTACHMENT, AND TINSEL ATTACHED. hitch shown, drawing it tight. Of course, your silk has been previously well waxed.

Now, take two whisks or fibers of any dark feather to form the tail, and placing as shown at Figure 31, take one turn of the silk and fasten as before. Then take a piece of tinsel and attach it also by means of one turn and the half hitch knot. Then run your silk in one or two turns round the hook to end of shank, drawing it tight between the uncovered part of the shank and the gut. Now wind the tinsel evenly up the shank, holding it between the fingers or the pincers, take one turn round 
it and fasten as before (fig. 32). Cut off the remaining end of tinsel closely (but not too close), and then take breath.

So far, so good. Your next operation is the fixing of

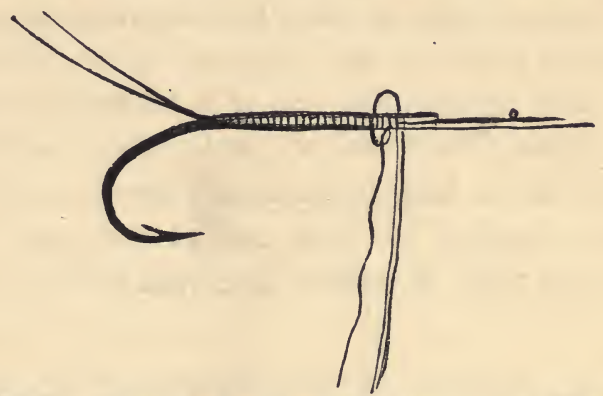

Fig. 32.-TINSEL WOUND, SHOWING METHOD OF TYING.

the hackle. Take a good hackle and draw the fibers back between the finger and thumb until it has the appearance shown in Figure 33. Then place the point

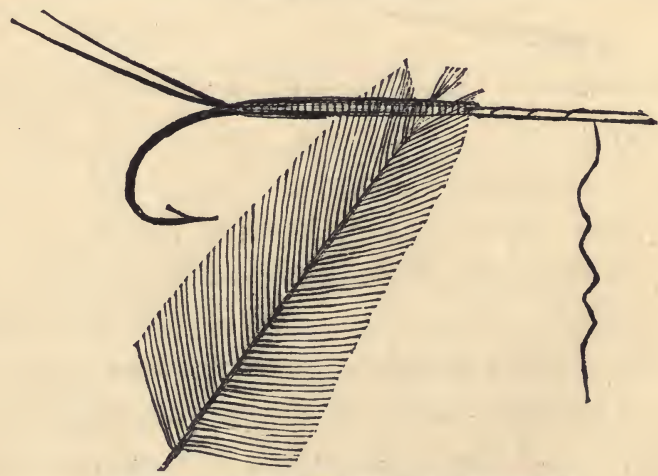

Fig. 33. - MODE OF ATTACHING HACKLE.

on the shank, as shown, and secure with a turn and a knot; next (I am supposing you have the hook 
fixed in your vise), wind the hackle round the shank of the hook, stroking the fibres of each coil towards the bend of the hook as it is made, to make room for each succeeding one. Do this till the appearance shown in Figure 34 is reached. Then, taking the hackle

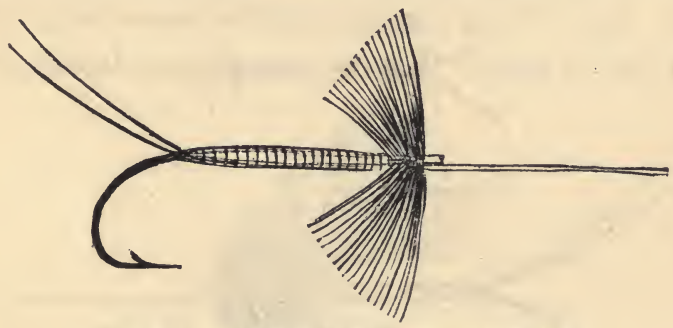

Fig. 34. - hackLe ATtaCHed AND TIED.

butt in your left hand, pass the silk once or twice round over the hackle midrib and secure with two half hitches. This done, cut off the loose end, and pressing the fibers all back towards the bend, take one more turn and half hitch to secure any of the loose fibers, that may possibly be out of place, in their proper position. It ought to look like Figure 34, but if it doesn't, try again.

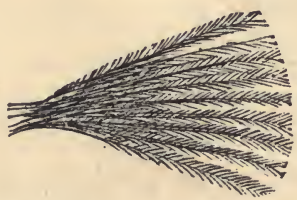

Fig. 35.-BENCH OF PEACOCK HERL.

It is purely your own fault that it doesn't, and there is no difficulty in the matter that practice will not overcome. Indeed, this is a cardinal axiom, and I must insist on it as of ever present force in fly-making.

Now, take the curled fibers of a peacock's eye-feather 
and nip off a sufficient number to form a bunch like Figure 35. Now, place them on the shank end of the hook, holding them in position between the forefinger, thumb and shank, and take a quick turn of silk over them, then a half hitch to enable you to let go of your work. See if it is straight and symmetrical; if not, gently set it right; if it is, reapply the forefinger and

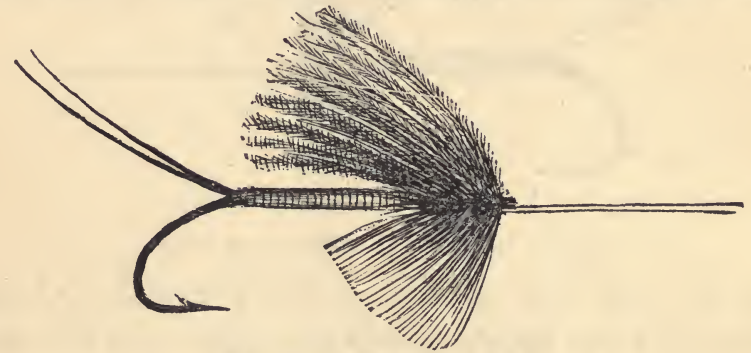

Fig. 36. - ALEXANDRA FLY.

thumb and take three or four more turns and tie with two half hitches. Touch it with varnish and your fly is finished (see fig. 36), and may thus be described:

Name.-Alexandra.

Body.-Silver tinsel.

Wings.-Peacock herl.

Hackle or Legs._Black rooster.

Tail.-Two dark fibers.

The learner, now that he has his material and tools before him, might as well make a dozen or so of these flies, to better prepare him for the next lesson. They will not be wasted, as they are invaluably good killers in this country, especially when the fish are at ground or midwater feeding.

Our next task is to make a "Palmer." This time weare 
imitating, somewhat closely, the caterpillar of the arctia caja moth, and I select it for manufacture because of its educational fitness for the present purpose, irrespective of its "killing" recommendations-though these are undeniably great.

Materials for Golden Palmer.-Bright brown hackle, peacock herl, gold tinsel, orange tying silk; hook, long shanked Carlisle.

Directions. - Whip on the hook as before. Then, at the end nearest the bend, attach a strip of gold tinsel, a strip of peacock herl, and a hackle by the point; then run the silk back to the end of shank without twisting it round the shank as before, and retain it between the gut and hook, as in the case of the Alexandra. Now, twist the tinsel tightly up the shank of the hook, as in the case of the Alexandra, and fasten off. Next, take the herl and run it in a loose helix or coil up to the end f fasten off. This allows of the tinsel showing 'through. Now, take the hackle and wind it on the tinsel above each coil of herl but close to it, and when you get to the end of the shank take two or three turns with it close together, so as to make the hackle look "fuzzy" at the head. Tie, cut off end of silk, and varnish, and your fly is donebeing thus formally described :

Name.-Golden Palmer.

Body.-Peacock herl, ribbed gold twist, bright brown hackle over all ; tying silk, orange, well waxed.

Materials for Plain-Bodied Hackle.-Whisks for tail ; floss silk for body ; fiber of ostrich tail for head ; hackle; tying silk; all these to be of colors correspond- 
ing to the standard dressing of the particular kind selected for imitation.

Directions. - Whip on the hook, leaving quite a large section unwhipped at the end of the shank; then, by two

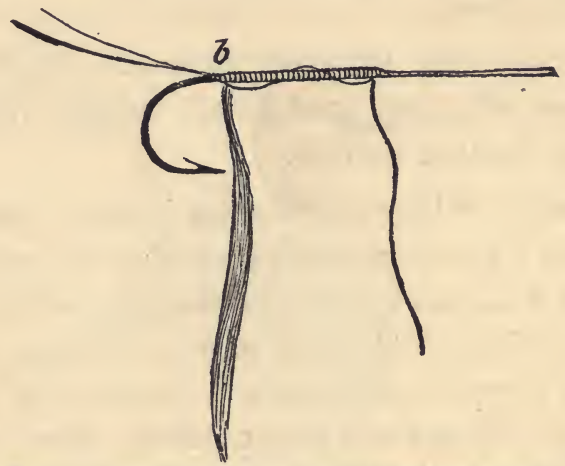

Fig. 37.-First stage of PLANN-BODied HaCkLE.

turns and a half hitch, secure the floss silk (fig. 37) and the two whisks at $b$. Having led your tying silk up to the end of the shank and looped it between the gut

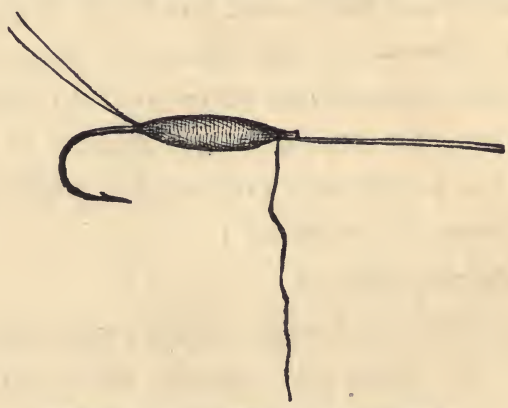

Fig. 38.-PLAN BODY OF HACKLE.

and hook as before, take the floss silk between the finger and thumb and wind it up evenly, as shown at Figure 38, 
and secure it with a turn and a half hitch. Next, take your hackle and insert it, point before; wind it closely and tie. Cut off the loose end and varnish (see fig. 39).

Figures 40, 41 and 42 represent a Hackled Golden Palmer, made substantially on the principle of the Golden.

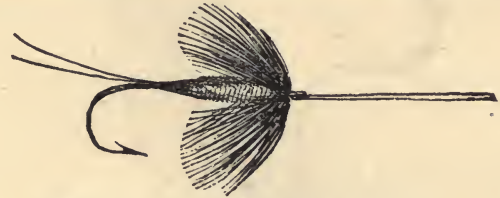

Fig. 39.-PLAIN HACKLE FIIISHED.

Palmer before described. The difference, however, is instead of the hackle running up the body it is at the head.

From the great unwinged lures of the trout I now pass to the domain of the more difficult " winged" flies. The putting on of a wing is the pons asinorum of the tyro, and I will let him down easily, to begin with, by explain-

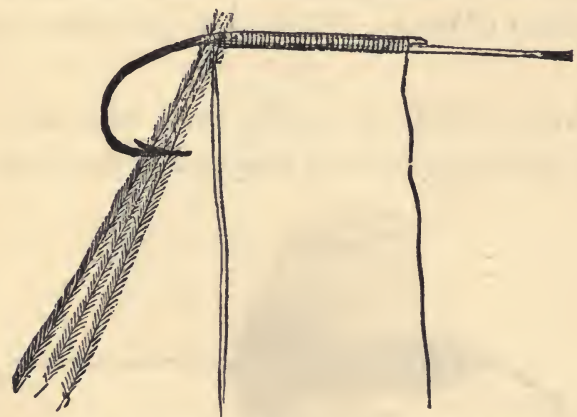

Fig. 40.-First stage of golden Pat.mer.

ing the make of the easiest winged fly I know of. This is the so-called May fly or drake (Ephemera vulgata), and the following is a good, useful imitation for all trout waters : 
Materials for May Fly.-Clean wheat straw, three strands of pheasant tippet, brown hackle for legs, and two feathers of mallard's breast for wings. Red-brown

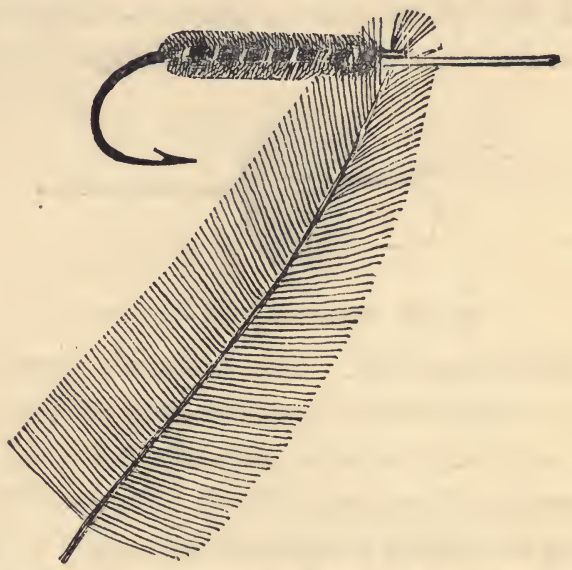

Fig. 41.-SECOND STAGE OF GOLden PaLMer.

twist silk for ribbing. Hook, long in shank and light in build.

Directions.-First, tie on the hook to a loop of gut; fasten off, having previously whipped in the three whisks.

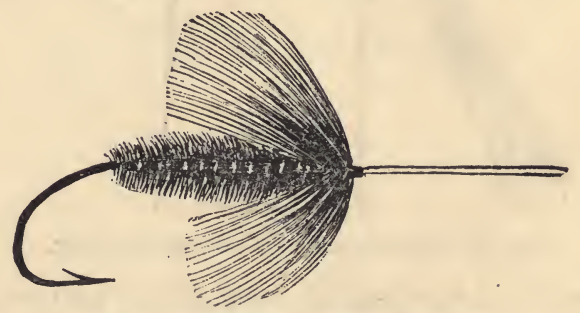

Fig. 42.-Golden PALMER FINISHed.

Now, take a piece of nice, clean yellow straw and soak it a few minutes in warm water to soften it; then carefully 
pare it with a sharp knife at each end till it tapers nicely, and slip it over the loop of gut; if possible, do all this without splitting the straw. Then, with some red-brown silk, waxed with the colorless wax, attach it firmly by several turns opposite the point of the hook and wind spirally up to the loop. (See fig. 43.) Se-

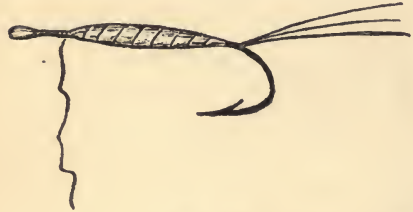

Fig. 43.

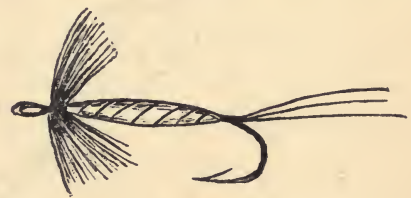

Fig. 44.

cure this end of the straw and the body is finished. Now take the hackle and twist it as shown in Figure 44, and you are ready for the wings.

The sort of feather suitable is shown in Figure 45 . Carefully proportion the sizes of the two feathers you select to the size of the body and hook, and as this fly is in-

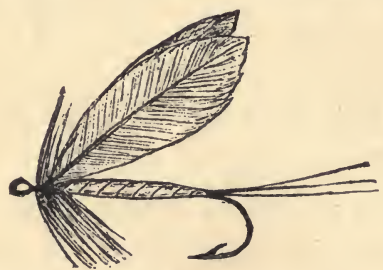

Fig. 45.

tended to float, it is advisable to fix the feathers the concave side outwards, but care must be taken that this concavity is not too great, or a very ugly appearance is produced. The appearance of this fly when finished is shown at Figure 45. The particular dressing is thus described : 
Green Drake or May Fly. - Body. - Wheaten strand ribbed with red-brown silk.

Legs. - Brown hackle.

Tail.-Three strands from pheasant's tippet feather. Wings.-Breast feather of mallard.

Another difficult but very close imitation is made by

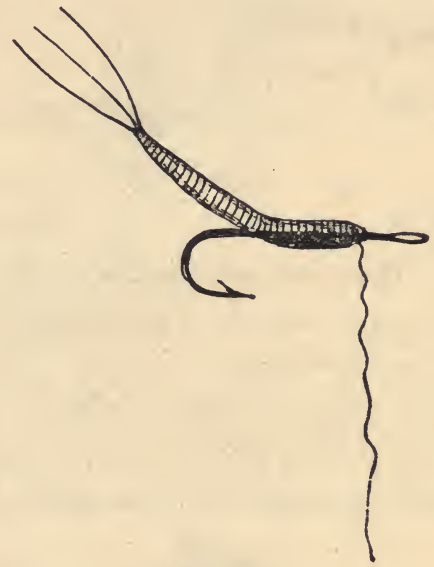

Fig. 46.

substituting a gut body for the straw, an idea of which may be gathered from Figure 46 .

It is thus made : Take a length of gut, dyed yellow, and soak it till quite soft. Now, cut several pieces of stoutish gut into lengths of an inch or less, burn one end of them in a flame to imitate the real insect; these ends are placed at the end of body - the whisk or tail consists of three rabbit's whiskers. Lay all the pieces of gut together and the whisks in therr place and bind round from the extremity with the strand of yellow gut. When you arrire at the center or thereabouts of the insect take your 
hook, previously bound on gut, and include it, carrying the coils on till the shoulder of the body is reached. Now, cut off the interior pieces of gut to a taper, and, with the waxed silk, secure the whole tightly. A hackle and wings complete the tout ensemble.

The making of a winged, compound-bodied, hackled and tailed fly is a sample of the higher flights of the fly

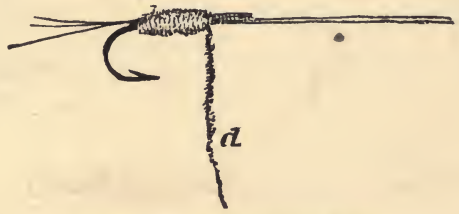

Fig. 47.-COMPOLND FLY.

tyer, and the method of accomplishing this I propose to show next. The fly I will select is an English one, containing in its make-up the separate advantages of the blue and hare's ear dun flies. It is undoubtedly a killer in this country.

Materials. - Blue dun hackle, silver tinsel, hare's ear fur or mohair of a yellow and dun color mixed, yellow

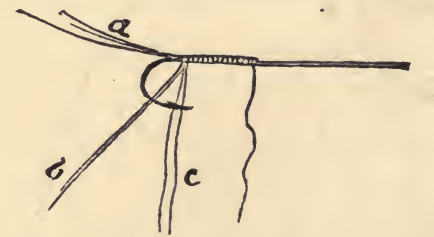

Fig. 48.-FIRST STAGE OF COMPOUND FLT

floss, red-brown hackle and dun colored feather for wings (preferably from the blue heron).

Directions. - First, take the hook and fix it in the vise ; then whip on the gut as before. Next, attach the three 
( $a$, fig. 48) whisks from a blue dun hackle ; then silver tinsel, with two turns, $b$; next, your yellow silk, $c$. Then unravel your tying silk and take a little of the hare's ear fur, spin it amongst the strands, as at $a$ in Figure 4\%. The next process is to run it around the

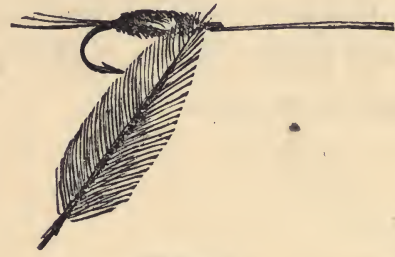

Fig. 49.

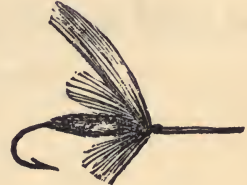

Fig. 50.-FLY FINISHED.

shank and fasten off ; next, rib with the yellow silk; then attach your hackle and, next, the wings. Figures 49 and 50 show the processes.

Such are the processes of making an ordinary trout fly. A somewhat different proceeding is necessary in respect to the manufacture of large lake trout flies, where the bodies

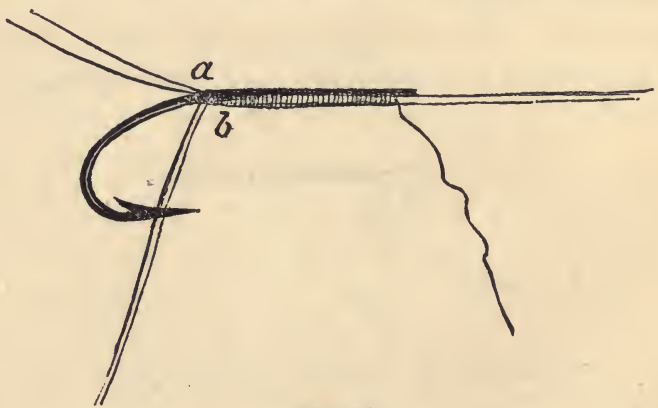

Fig. 51.

are preferred to be full and rotund. The ordinary "Scarlet Ibis" fly is a familiar illustration of this (fig. 58). 
The Scarlet Ibis. - Description: Hook, No. 1 Sproat ; tag, gold cord or tinsel ; tail, fibers of ibis quill feather ; body, scarlet mohair ribbed with gold cord or tinsel; legs or hackles, stained cardinal; wings, two small ibis wing feathers.

Directions for Making.-Take the hook between thumb and forefinger of the left hand-or fix in the vise -and evenly bind on the gut, leaving a quarter of an inch bare at the shank end. Next, take a length of tinsel

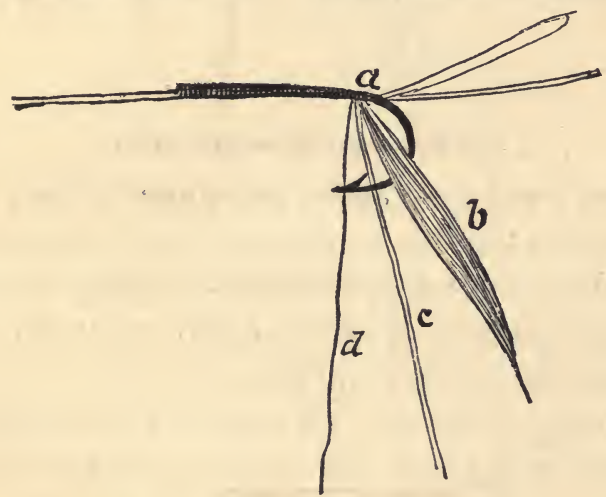

Fig. 52.-TBIS FLY, FIRST STAGE.

and placing its free end toward the shank, wrap it round, securing it with a half hitch of the whipping thread. Next take a couple or three fibers of ibis and attach them as you did the tinsel. (See fig. 51.) Now, take the tinsel and roll it several times at the end of the binding, which attaches the hook to the gut, to form the tag. Tie it (see $a$, fig. 51). Having secured it, let it hang down full, as shown; it will be wanted presently. Now take a portion of mohair, pulling it from the bulk and shaping it with a slight twist till it assumes the shape indicated in Figure 
$52, b$. Twist each end between the finger and thumb to a thread-like taper and attach one of them ; tie the end pointing toward end of shank by two turns and a half hitch. It will then present the appearance of Figure $52, b$.

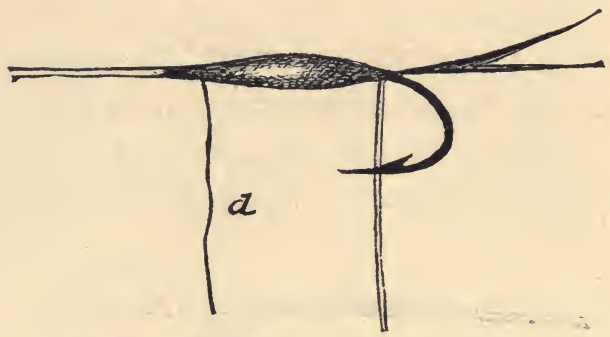

Fig. 53.- mBIS FLY, SECOND STAGE.

And here, just a word before going any further. I want the novice to carefully go through the foregoing and to thoughtfully study Figure 52, and his work, and see that they agree perfectly up to this point. $C$ is the tinsel, $b$ the mohair and $d$ the tying silk.

The tying silk ( $d$, fig. 52) must now be brought along the shank of the hook and looped in between the shank

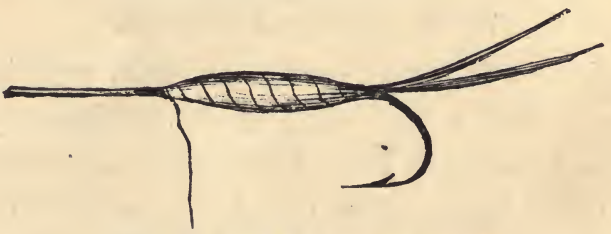

Fig. 54.-IBIS FLY, THIRD STAGE.

and gut. It is then out of the way of the next. process, which consists in winding the mohair. Take the end and wind the strip evenly round the hook without twisting it. It must be done so that it tapers towards the end of the shank, and for this purpose it is 
obvious that just sufficient mohair should have been picked out, and no more, for the purpose. If it is then properly done the appearance of the body (fig. 53) should have

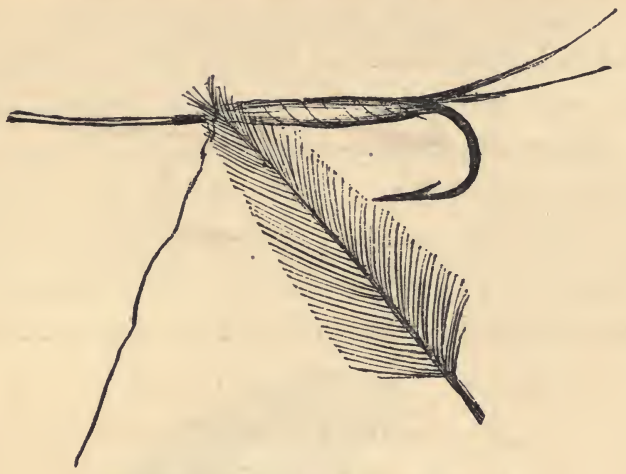

Fig. 55.-IBIS FLY, FOURTH STAGE.

been attained, and it is made fast by a couple of turns of silk (at $a$ ) and a half hitch, the silk being again placed out of harm's reach between gut and steel, as before.

The next operation is winding the ribs. For this pur-

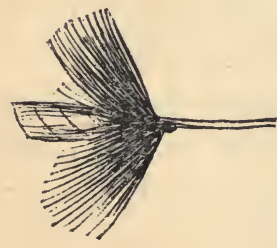

Fig. 56.

HACKLE WOUND.

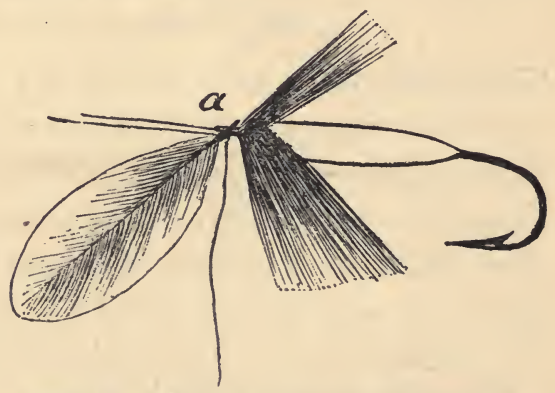

Fig. 57.-IBIS FLY, SHOWING Method of TYING WINGS.

pose take the tinsel between the thumb and finger and wind it spirally up to the end of the mohair (fig. 54). Then 
take your pincers and secure them to it, so as to retain it in its place ; release the whipping silk and take a turn and tie again, returning the silk to its place between the shank and gut.

Now select your hackle. I often use two-one superimposed on the other; they appear bushier than one only. Secure the hackle, as shown at Figure 56, with the point to end of shank, and taking your scissors snip off the point, not too close, however, or in winding you may chance to pull the hackle off, when a loss of time results, which is important if you are economical of time.

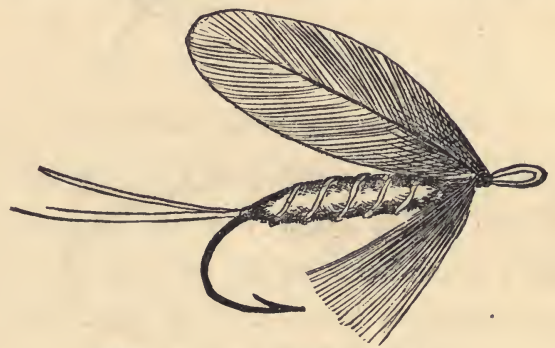

Fig. 58.-IBIS FLY FINISHED.

The hackle being secured and the tying thread placed out of the way, wind the former round the hook, stroking back the fibers of each layer with the forefinger and thumb of the left hand. This is best done by aid of the vise, and it is important, as I have before stated, that the fibers of each layer may lie straight and not be involved one with the other. (See fig. 56.)

Having wound the hackle round a sufficient number of times, the next thing is to secure it, which is done as follows (I repeat these directions to save reference back) : Secure the butt end of the hackle between the fingers of 
the left hand or the spring pincers. Then release the tying silk and wind it rapidly and tightly round the hackle, finishing with a cloven hitch-i. e., two half hitches. Next, snip off the end of your hackle and preen the fibers with the stiletto and you have the legs of the fly made as shown in Figure 56. Do not use the scissors to trim the hackle when on ; this is the sign of amateurish work. Adjust the size of each part of a fly before putting it together. That is the proper way. In order

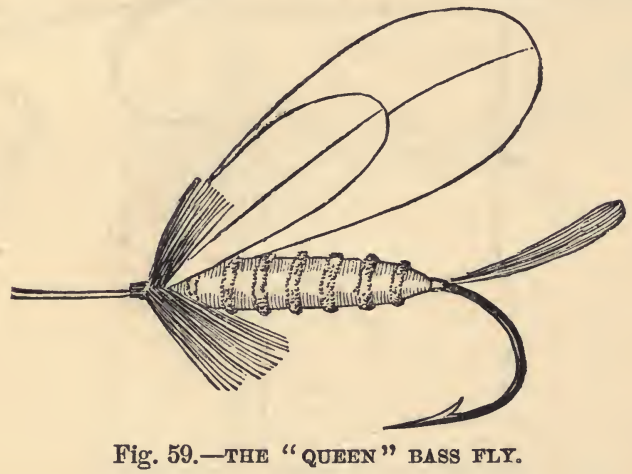

to arrive at the right proportion, it is a good plan to buy a pattern from a first-class maker.

The next consideration is the wings. These are composed of two small feathers of equal size from the red ibis, and are first prepared by stripping off all the fluffy part nearest the end of the quill. They are then taken and neatly placed in the position shown at $a$, Figure $5 \%$, and secured by two or three turns and a half hitch of the silk. Then turn them into their proper position, holding them firmly between finger and thumb while lapping the sllk round. Figure 5\% roughly represents the method 
of thus arranging the quill end of the feather, and it is evident that if the feather be turned in this way it cannot slip or be pulled out.

The next operation is to varnish with the crystal varnish, and the Scarlet Ibis is consummated. (See fig. 58.)

Another style of fly in advance of the foregoing is shown in Figure 59. It is a "fancy" bass fly of larger

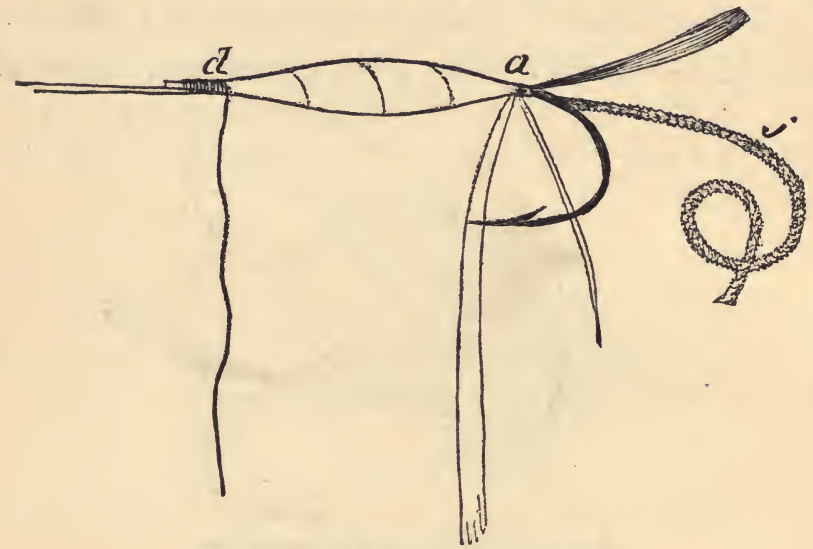

Fig. 60.-FIRST STAGE OF BASS FLT.

size than anything that has gone before. It is known to me as "The Queen," and may be thus described :

Name.-The Queen.

Hook. $\%$. Sproat.

Body.-Yellowish green chenille over cardınal floss silk.

Tail.-Ibis, fibers of quill feather.

Tag.-Gold tinsel.

Wings.-Center feather, white goose ; two outer, scarlet ibis.

Hackle.-Guinea fowl. 
Materials. - Chenille, of medium gauge, cardinal floss silk, ibis feathers, cardinal tying silk, guinea fowl feather, goose feather, cotton batting for filling of body, 2\% Sproat hook, wax, varnish and gut.

Directions.-After binding the hook on, a piece of cotton batting, to form the body, is taken and moulded with the fingers round the shank of the hook. Next, attach the cardinal floss silk at $a$ (fig. 60), then the ibis feathers for tail, and next, the chenille. Now, take the chenille silk and ibis right back, and attach a piece

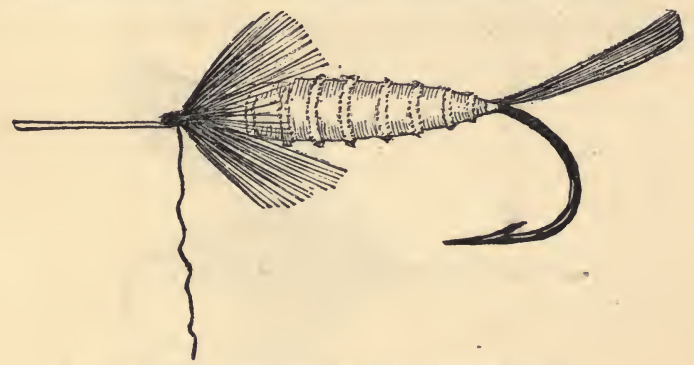

Fig. 61.-SECOND STAGE OF BaSS FLY.

of tinsel behind the others and roll it round evenly. Fasten and cut off end. Now, roll the floss silk, $a$, very evenly and tightly over the cotton and secure it at $d$. The chenille, $j$, is then wound in coils round the silk. See Figure 61. . The gallina or guinea fowl hackle is then wound on, and this requires care. A failure or two should not daunt the learner, for in the end he will be successful.

The next operation is the placing of the wings. The large white feather is put on first and secured-be careful to crush the quill end soft before passing the whipping round it. Then the two smaller ones are 
put in place precisely as you did with the Scarlet Ibis fly, and Figure 59 represents the achievement.

In Figure 62 the reader has an effective kind of fly which may be thus described :

Name.-Black June.

Tag.-Gold or silver tinsel.

Body.-Peacock herl.

Hackle.-Black.

Wing.-Crow feather.

Directions.-Attach gut and tinsel as before and snip off the tinsel close. Now, take the eye or sword feather

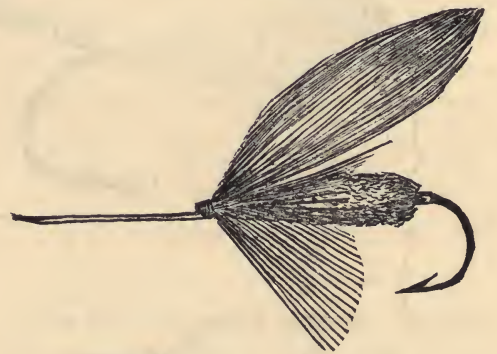

Fig. 62.-BLACK JUNE FLY.

of a peacock and detach three or more of the fibers; lay them close together, place the points towards the end of shank of hook, take two turns of silk and fasten; then bring the silk up the gut out of the way as before. Now, take the herl fibers and wind them together as if they were one thread on the shank of the hook, taking care not to handle the body with the warm fingers, or the little fibers will be pressed down and the appearance of the fly spoiled. Finish off as before, leaving a good space for the hackle and wings.

Now, take two hackles-you want the hackles of this 
fly to be bushy-and wind them in the ordinary way, and after finishing off you are ready for the wings. These require a little preparation. Take a feather of sufficient

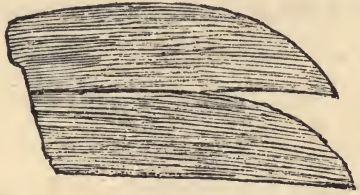

Fig. 63.-PIECES OF FEATHER FOR WINGS.

size, and with the left forefinger and thumb, hold about three-quarters of an inch tightly by the roots next the quill or midrib. Then, with the right forefinger and thumb, even out the ends, taking care not to break the "felting" which holds the fibers together. Now, gently but with decision, cut off a piece from a " right" feather and a piece from a "left," and fold them together, one on the other. Take these between the finger and thumb of the left hand

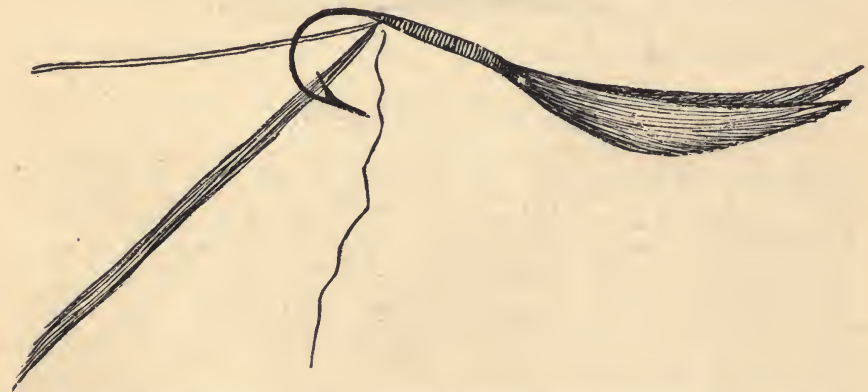

Fig. 64.-METHOD OF PLACING FEATHERS FOR TURNED HEADS.

-between the pulp of the tips, with the roots pointing to your right. Then, with the right forefinger and thumb, pinch the ends together, opening the tips of the finger and thumb to admit and retain the contracted ends. 
Now, place the latter on the hook, and tightly and rapidly, taking care not to break your silk, take two or three turns round the whole and make a half hitch. Now, release your hand and look at the work done. If the wings are set right, and neatly gathered in a symmetrical taper at the base, take your scissors and cut them to a neat ending. Then dip your varnish brush and give the feather ends a slight soaking with the varnish, and then wind the silk till an even and solid head is formed. Tie, cut off the silk, varnish again, and the fly is finished.

The strongest flies are made with turned heads, and these are generally very much used in this country.

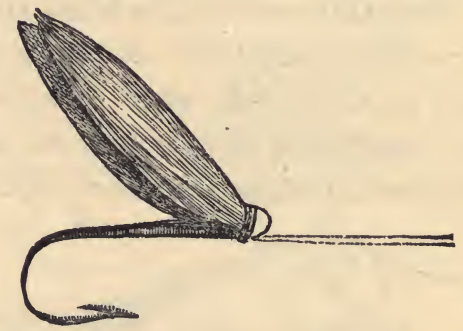

Fig. 65.-WINGS TURNED.

(See figs. 64 and 65.) In forming these flies the wing is put on first, as in Figure 64. The tinsel and body, etc., are then attached afterwards. After the hackle is tied in situ, the wings are then taken and firmly turned back and secured in their place (see fig. 65), and, if desired to be separated, the thread is passed once or twice between them. These flies do not, as a rule, look so neat and graceful, but their lasting power is unquestionable. 


\section{H A P'T E R V}

\section{STANDARD TROUT FLIES AND THEIR DRESSINGS.}

In the preceding chapter I have given directions by which the dullest reader can make a fly of the kinds in ordinary use in this country - that is, if he will but take the trouble. In the present chapter I propose giving a list of standard flies easy to make and at the same time effective. In getting the list and details of material ready I have had the invaluable assistance of Mr. C. F. Orvis, of Manchester, Vermont, joint author of "Fishing with the Fly," and his daughter, both most accomplished fly tyers, and have arranged that the flies named should be dressed by him for those who have not the inclination or time to make them for themselves. To those, however, who are determined to profit by the instructions given, a few words in reference to materials generally, and the plates of material in particular, may not be deemed superfluous here. First, always endeavor to get feathers from birds of some age. Hackles -and, indeed, all feathers-are more elastic and tougher from such birds than when derived from young ones, and are, therefore, more lasting. All feathers, also, should be stored in dry, dark boxes-cigar boxes are moth repellent and of very convenient size. To absolutely prevent moth, it is only necessary to employ camphor roughly crumbled and mixed with equal quantities of napthalin crystal. The wings of birds are best, denuded of feathers, and the latter, from the right and left wings, kept sepa- 
rate and clearly labeled, somewhat thus: "Mallard wing-under feather-right," so that when the wings of a fly are to be selected, the right and left sicles may be ready to your hand. Sometimes the right and left fiber can be picked from one feather, but that is the exception. Tinsels must not be handled, but kept in air-tight boxes - a clean, dry, wide-mouthed bottle is a very good receptacle.

\section{REMARKS ON PLATES OF ACTUAL MATERIAL.}

No. 1.-Flat silver tinsel. This tinsel is sold in sevenyard lengths, of about five-eighth inch tinsel braid, by the gold lace makers ; it is comparatively inexpensive, but if not kept from the air and damp soon tarnishes. Before using it on a fly it is not a bad plan to varnish it over with a thin coat of collodion. This preserves it somewhat from climatic influences. If tinsel tarnishes in keeping, it can be cleansed by rubbing a little alcohol over it.

No. 2.-Flatworm tinsel. This is far to be preferred to the wholly metallic tinsel where it can be used, but the flat is far more brilliant and scintillating in the water, and hence for immediate use far preferable. These remarks, of course, apply to the same pattern of tinsel in gold.

No. 3. - See remarks on No. 1.

Nos. 4 to 15, inclusive, are ordinary embroidery silks, and can be procured at any dry goods store. Pearsalls are the best and fastest colors. Of course, in using, it should be split or untwisted, one or both strands being used, according to the size of fly, etc. These silks should be kept from the light, for even the natural 
colored feathers of birds will fade if exposed to bright sunshine, and one cannot expect silk to stand the test better than Nature's own designed creation.

Nos. 16 to 19, inclusive, are worsteds, also procurable at any of the dry goods stores. In place of these, mohair is frequently used, and pig's wool-or the short hair between the bristles of a hog-and for salmon and highpriced flies, seal's fur, dyed various colors. These worsteds are split in the using and used according to size of intended flies.

Nos. 20 and 21.-Cilenilles. These are of very useful character and ought to be used more than they are. They can be procured of any shade and thickness at the repositorias of fancy silk goods.

No. 22.-Crows' feathers. From the wing feather choose the blackest and most evenly-tipped fibers.

No. 23. - frey domestic turkey. This varies from a mottled black and white to dark brown and brownywhite. It should be chosen as nearly as possible with small mottlings of black and white. Very pleasant feathers to work with.

No. 24.-White swan, white goose, duck, hen, or pigeon feathers from wings. Choose the thinnest at the base of fibers nearest the quill.

No. 25.-Brown turkey tail jeather. This should be chosen whenever possible of rich dark brown and light brown, mottled regularly.

No. 26.-Silver Black Hackle, or white cock-a'-bonddhu. Choose for preference very clear black tapering center, pure silver white tips. 
No. 27. - Mottled Hackle, from Plymouth Rock chickens.

No. 28.-Cock-a'-bonddhu Hackle. Black center, brown tips. Acquire them whenerer you get a chance. 'They are most useful for a variety of flies.

No. 29.-Brown Hackle. Ditto repeated. A good hackle is short in fiber, with thin, strong mid-rib. Get your hackles as near the colors I have described as possible, but do not discard those that are near the shade but not it exactly. On the hook they look different from what they do off it.

No. 30.-1bis. The feather shown is the small breast feather, and but inadequately expresses how beautiful and useful the whole feathers of the bird are. The entire skin is one blaze of scarlet, and hardly a feather is wasted in fly making. A whole skin is quite necessary to the amateur fly maker.

No. 31.-Mallard. This feather is from the breast of the mallard, and is given as typical of the sort of fibers required for a large variety of flies from its near relations - the wood-duck, pintail and canvasback. In all cases where this beautifully mottled feather is indicated, it is taken from the breast. The feathers from each are so similar that I do not think it necessary to repeat the others.

No. 32.-Brown Hen. Taken from the quill feather of a brown hen or rooster. Nearly every feather on a brown chicken is useful.

Nos. 33 and 34.-Feather from underside of mallard wing. These feathers provide the metallic looking dun wings of a great variety of flies and vary in shade from a 
white silver pearly to a dull, almost black, dun. Turn up the wing of the mallard and there they are before you.

No. 36. - Blue Heron. This is a very useful substitute for the dove in the Henshall, though, perhaps, Dr. Henshall would not think it an improvement. It is sometimes impossible to get the grey dove wings, and a noted Florida fisherman tells me he has substituted this feather with great adrantage among the many fly rising fish abounding in the waters of that region.

No. 3\%.-Ostrich herl from the plumes of the bird. This

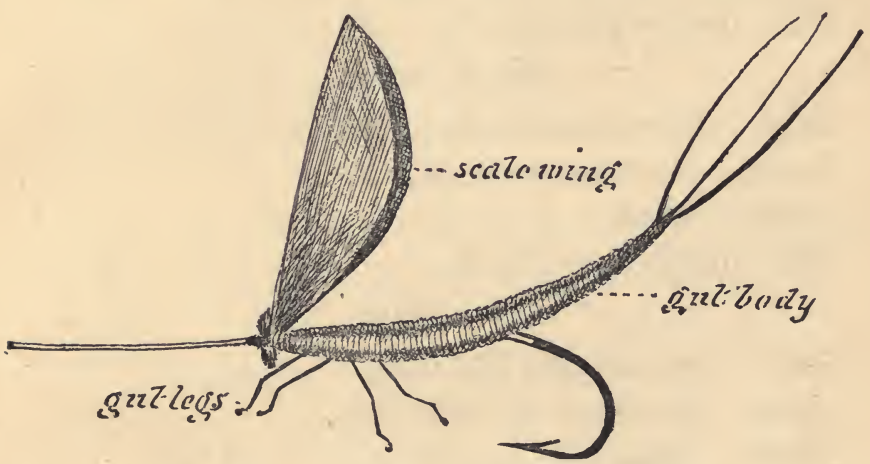

Fig. 66.-KEENE'S NEW " SCALE" WING FLY.

is exceedingly useful for the heads of flies, and makes a very attractive furnish-leader, being strong and light.

With these plates at hand, the directions themselves arranged with the most transparent simplicity, and Figure 19 , page 56 , showing the meaning of the terms used in reference to a fly, I leave it to the candid reader if the "force of nature can further go" in the direction of complete explanation of the subject of fly making? 
ABBEY.

Body. Crimson silk ribbed, gold tinsel (Nos. 12 and 3). Wings. Pintail duck (No. 31).

Hackle. Brown (No. 29).

Tail. Three strands tippet of golden pheasant.

Tag. Gold tinsel (No. 3).

\section{ALDER.}

Body. Peacock herl (No. 35).

Wings. Wood-duck (No. 31).

Hackle. Brown (No. 29).

Tag. Gold tinsel (No. 3).

\section{BLACK JUNE.}

Body. Black chenille. (No. 21).

Wings. American crow (No. 22).

Hackle. Black.

Tag. Gold tinsel (No. 3).

\section{BLACK GNAT.}

Body. Peacock herl (No. 35).

Wings. American crow (No. 22).

Hackle. Black.

RED ANT.

Body. Scarlet silk (No. 6).

Wings. Ibis (No. 30).

Hackle. Red or scarlet, stained.

Tag. Peacock herl (No. 35).

\section{RED SPINNER.}

Body. Crimson silk ribbed, gold tinsel (No. 12). Wings. Mallard's under feather (No, 33) Hackle. Brown (No. 29). 
Tail. Three fibers brown hackle (No. 29).

Tag. Gold tinsel (No. 3).

$$
\text { RED FOX. }
$$

Body. Reddish brown worsted (No. 17).

Wings. Under feather of mallard's wing (No. 33).

Hackle. Brown (No. 29).

Tail. Three strands black hackle.

Tag. Gold tinsel (No. 3).

\section{IBIS.}

Body. Scarlet silk ribbed, gold tinsel (Nos. 12 and 3). Wings. Ibis (No. 22).

Hackle. Scarlet, stained. Tag. Gold tinsel (No. 3).

\section{STONE FLY.}

Body. Grey silk ribbed, silver tinsel (Nos. 10 and 1). Wings. Mallard's under wing feather (No. 34).

Haikle. Grey (No. 27).

Tail. Three fibers black hackle.

Tag. Silver tinsel (No. 1).

\section{SILVER BLACK.}

Body. Black silk ribbed, silver tinsel (Nos. 15 and 1). Wings. Crow (No. 36).

Hackle. White with black center (No. 26).

Tag. Silver tinsel (No. 1).

\section{SHOEMAKER.}

Body. Grey and faded pink silk in alternate bands (Nos. 10 and $\%$ ).

Wings. Two pairs-inner, mallard breast wing (No. $31)$; outer pair, pintail. 
Hackle. Brown (No. 29).

Tail. Three strands mallard (No. 31).

Tay. Gold tinsel (No. 3).

\section{MONTREAL.}

Body. Dark crimson silk ribbed, with gold tinsel (Nos. 8 and 31).

Wings. Turkey's wing feather (No. 25).

Hackle. Scarlet.

Tail. Three fibers ibis (No. 29).

Tag. Gold tinsel (No. 29).

PROFESSOR.

Body. Yellow silk ribbed, silver tinsel (Nos. 5 and 1). Wings. Pintail duck, breast feather (No. 15).

Hackle. Brown (No. 29.)

Tail. Three fibers ibis (No. 30).

Tag. Silver tinsel (No. 3).

BROWN COFLIN.

Body. Light brown worsted (No. 17).

Wings. Under feather mallard's wing (No. 34).

Hackle. Brown (No. 29).

Tail. Three fibers black hackle.

Tag. Gold tinsel (No. 3).

\section{BLEE BOTTLE.}

Body. Blue silk ribbed, gold tinsel (Nos. 9 and 3). Wings. American crow (No. 22).

Hackle. Black.

Tag. Gold tinsel (No. 3).

\section{COWDUNG.}

Body. Greenish brown worsted (No. 16). 
Wing. Brown hen's wing feather (No. 32).

Hackle. Brown (No. 29).

Tag. Gold tinsel (No. 3).

CLARET.

Body. Claret silk ribbed, gold tinsel (Nos. 8 and 3).

Wings. From brown hen's feather (No. 32).

Hackle. Black.

Tag. Gold tinsel (No. 3).

SETH GRENE.

Body. Green silk ribbed, yellow silk twist (Nos. 11 and 5).

Wings. Lead colored feather from under mallard's wing (No. 34).

Hackle. Brown (No. 29).

Tail. Three strands mallard (No. 31).

Tag. Gold tinsel (No. 3).

SOLDIER PALMER.

Body. Scarlet silk ribbed, gold tinsel (Nos. 6 and 3).

Hackles. Brown; one short up the body above tinsel, one full at head and shoulders (No. 29).

Tag. Gold tinsel (No. 3).

WHITE MILLER.

Body. White chenille (No. 20).

Wings. White pigeon or goose (No. 24).

Hackle. White.

Tag. Orange silk (No. 4).

PALE EVENING DUN.

Body. Yellow silk ribbed, gold tinsel (Nos. 5 and 3). Wings. Mallard's under wing feather (No. 33). Hackle. Yellow. 
Tail. Three fibers from mallard's feather (No. 31). Tag. Gold tinsel (No. 3).

YELLOW DRAKE.

Body. Yellow silk ribbed, gold tinsel (Nos. 5 and 3). I Wings. Mallard's feather, stained yellow (No. 31). Hackle. Yellow. Tag. Gold tinsel (No. 3).

\section{YELLOW MAY.}

Body. Same as yellow drake (Nos. 5 and 3). Wings. White goose or pigeon, stained yellow. Hackle. Yellow. .

Tag. Gold tinsel (No 3).

CAMLET DUN.

Body. Dark slate mohair ribbed, with a few coils of orange silk (Nos. 18 and 4).

Wing. Curlew (from wing).

Hackle. White.

Tail. Three fibers black hackle.

Tag. Silver tinsel (No. 1).

\section{CALDWELL.}

Body. Claret silk ribbed, gold tinsel (Nos. 8 and 3). Wing. Pintail duck (No. 31).

Hackle. Brown (No. 29).

Tail. Three fibers wood-duck (No. 31).

Tag. Gold tinsel (No. 3).

\section{FERN FLY.}

Body. Straw colored silk ribbed, silver tinsel (Nos. 14 and 1).

Wings. Pearly feather from under mallard's wing (No. 34). 
Hackle. White (No. 7).

$$
\text { FIRE FLY. }
$$

Body. Red silk, plain (No. 24).

Wings. White goose (No. 24).

Hackle. Cock-a-bonddhu (No. 28).

Tag. Gold tinsel (No. 3).

$$
\text { COACHMAN. }
$$

Body. Peacock herl (No. 35).

Wings. White goose (No. 24).

Hackle. Brown (No. 29).

Tag. Gold tinsel (No. 3).

\section{BROWN HACKLE.}

Body. Peacock herl (No. 35).

Hackle. Brown (No. 29).

Tag. Gold tinsel (No. 3).

\section{BLACK HACKLE.}

Body. Black silk (No. 15).

Hackle. Black.

Tag. Gold tinsel (No. 33).

GREY HACKLE.

Body. Green silk ribbed, gold tinsel (Nos. 11 and 3). Hackle. Mottled hackle (No. 27).

Tag. Gold tinsel (No. 3).

$$
\text { CONK-A-BONDDHU HACKLE. }
$$

Body. Peacock herl (No. 35).

Hackle. Cock-a-Bonddhu (No. 28).

Tag. Gold tinsel (No. 3).

\section{FIERY BROWN.}

Body. Brown worsted (No. 19). 
Wings. Brown hen's feather (No. 32).

Hackle. Brown (No. 29).

Tail. Three fibers scarlet ibis (No. 30).

GREEN DRAKE.

Body. Straw silk ribbed, loose coils with black silik twist (Nos. 14 and 15).

Wings. Wood-duck (No. 31).

Hackle. Brown (No. 29).

Tail. A few fibers of wood-duck (No. 31).

GENERAL HOOKER.

Body. Yellow silk ribbed, six coils green silk twist (Nos. 5 and 11).

Wings. Lead colored feather under mallard's wing (No. 32).

Hackle. Brown (No. 29).

Tay. Gold tinsel (No. 3).

\section{CINNAMON.}

Body. Brown worsted (No. 19).

Wings. Speckled brown hen (No. 32, same species of feather but speckled).

Hackle. Brown (No. 29).

Tail. Three strands black hackle.

Tag. Gold tinsel (No. 3).

\section{LAKE FLIES.}

KNIGHT TEMPLAR.

Body. Claret silk ribbed, silver tinsel-about six coils (Nos. 9 and 2).

Wings. Equal parts white goose and black crow (Nos. 24 and 22). 
Hackle. White.

Tail. Black crow and white goose, three fibers each (Nos. 24 and 22).

Tag. Silver tinsel (No. 1).

GRASSHOPPER.

Body. Brown worsted (No. 4).

Wings. Jungle cock's feather; above it one strip yellow straw color, goose, dyed, and one red ibis (No. 30 ), about three fibers each.

Hackle. Scarlet.

Tait. Yellow, swan and pintail duck (No. 31); three fibers of each.

Tag. Gold tinsel and one-sixteenth inch green silk (Nos. 3 and 11).

Head. Peacock herl (No. 35).

TOMAH-IO.

Body. Silver cord, flat worm pattern (No. 2).

Wings. Wood-duck (No. 31).

Hackle. Yellow and scarlet.

Tail. End of yellow hackle.

Tag. Silver tinsel (No. 1) and one-eighth inch peacock herl (No. 35).

\section{HENSHALL.}

Body. Peacock herl (No. 35).

Wings. Grey dove, small feathers or blue heron (No. $36)$.

Hackle. Hair from deer's tail (white).

Tail. Three strands peacock blue curled feather from sword.

Tag. Gold tinsel (No. 3). 


\section{LORD BALTIMORE.}

$B c d y$. Orange silk (No. 4), ribbed black silk twist, six coils (No. 15).

Wings. Black crow (No. 22) and two jungle cock's feathers, outside.

Hackie. Black.

Tail. Crow (No. 22).

Tag. Gold tinsel (No. 3).

GREY DRAKE.

Body. White silk (No. 13) ribbed, six coils, with black (No. 15) and white silk twist (No. 47) spun together.

Wings. Mallard's feather (No. 19).

Hackle. Mottled (No. 12).

Tag. Silver (No. 13).

ORIOLE.

Body. Black silk (No. 15) ribbed, six coils ; flatworm tinsel cord (No. 2).

Wings. Swan, dyed yellow (No. 24).

Hackle. Black.

Tail. Black and white (Nos. 22 and 24).

Tag. Gold tinsel (No. 3).

NO-NAME.

Body. Yellow silk (No. 5) ribbed, silver flatworm tinsel, five coils (No. 2).

Wings. Pair small ibis feathers (No. 30), outside, white swan (No. 24).

Hackle. Brown (No. 29).

Tait. Ibis (No. 30).

Tag. Silver tinsel and red silk (Nos. 1 and 6). 
CANADA.

Body. Black silk (No. 15), ribbed silver flatworm tinsel, five coils (No. 2).

Wings. Turkey wings or tail (No. 23).

Hackle. Yellow.

Tail. Small ibis feather turned flatwise (No. 30).

Tag. Silver tinsel (No. 1).

\section{JUNGLE COCK.}

Body. Scarlet silk (No. 6) ribbed, gold tinsel (No. 3).

Wings. Jungle cock's feather, single.

Hackle. White, with black center (No. 26).

Tail. Three wood-duck fibers (No. 31).

Tag. Gold tinsel (No. 3).

No. 68 .

Body. Yellow silk (No. 5).

Wings. Turkey's wing feather (No. 23).

Hackle. White, with black center (No. 26).

Tail. Three fibers ibis (No. 30).

Tag. Gold tinsel (No. 3).

\section{GRIZZLY KING.}

Body. Green silk ribbed, silver tinsel (Nos. 11 and 2). Wings. Pin tail duck (No. 31).

Hackle. Grizzled (No. 2\%).

Tail. Red ibis (No. 30).

Tag. Gold tinsel (No. 3). 


\section{FLIES WITH GUT OR QUILL BODIES AND SCALE WINGS.}

Some little time since, a long letter appeared in the English "Fishing Gazette," headed: "Materials for Artificial Fies," from a prominent English sportsman, in the course of which, he said: "What is really required is a substance which combines the lightness and buoyancy of the feather in the air as well as in the water, with the toughness and power of the quill to retain its shape, together with the pliability, transparency and texture of the gold-beater's skin, and the property of being easily stained or dyed ; and this material, as far as I know, has yet to be discovered." 'This set me thinking, and nearly a year ago I discovered a material which I denominate "Scale," inasmuch as it is in laminænot because it is a fish scale; much less is it similar to the Macnee pike scale, which latter becomes dry and brittle after a little using. I claim that this material absolutely fulfils the requirements laid down, and I have entrusted C. F. Orvis, of Manchester, Vt.-by far the best practical fly tyer I know of-with the preparation of these scalewinged flies. When the scale wings are applied to gut or the famous quill bodies, a fly is formed of superlative imitation, and from the durability of the materials employed, it is practically indestructible by the teeth of fish.

By careful experimenting, it has been found that the following flies are the most suitable in pattern for the material. Figure 66 gives a rough idea of the style of fly which, if not so beautiful to the user's eye as the feathered lure, is at least quite as faithful to the original insect. 
FOLLOWING IS THE LIST REEERRED TO.

Brown Coflin, Fiery Brown, Pale Evening Dun, Black Ant, Fiery Drake, Red Fox, Blue Dun, Green Drake, Red Spinner, Claret,

Cowdung, Deer Fly, Gauze Wing, Stone Fly,

Emerald Gnat, Hoskins, Hawthorn, Scarlet Ibis, Emerald Dun, Morrison, Soldier, Orange Black, Yellow May.

\section{FLIES FOR BASS.}

The following is a list of nine original lake trout and bass flies especially suitable for trolling, and designed for this purpose by the author. Of course, they can be used for casting if so desired. The methods of their manufacture are described in a former part of the work.

\section{BENLY.}

Hook. $\%$ Sproat.

Body. Greenish yellow chenille.

Wings. Mallard's small feather from wing, with black tip, stained vellow.

Hackle. Guinea fuwl feather, stained yellow.

Tail. Guinea fowl feather tip.

Tag. Gold tinsel.

BLLE RANGER.

Hook. $\%$ Sproat.

Body. Blue chenille.

Wings. Mallard's white feather under wing in center, blue jay barred feather each side.

Hackle. Blue, stained. 
Tail. Blue jay barred feather tip.

Tag. Gold tinsel.

GIPSY.

Hook. $\%$ Sproat.

Body. Black chenille.

Wings. Same as "Benly."

Hackle. Yellow, stained.

Tail. Yellow feather tip, stained.

Tag. Gold tinsel.

QUEEN.

This fly is described on page 91 .

cOUNTESS.

Hook. $\%$ Sproat.

Body. Yellow chenille.

Wings. Inner feather, ibis; outer pair, mallard's breast feather.

Hackle. Cardinal.

Tail. Fibers from mallard's breast feather.

Tag. Gold tinsel.

SYLPH.

Hook. $\%$ Sproat.

Body. Yellow floss silk, and about six coils yellow chenille.

Wings. Inner, white feather from under mallard's wing; outer, ibis, pair.

Hackle. Yellow.

Tag. Gold tinsel.

TIGER.

Hook. $\%$ Sproat.

Body. White and black chenille. 
Wings. Mallard's small feather, tipped with black, sţained yellow.

Hackle. Guinea fowl, stained yellow.

Tail. Guinea fowl, stained yellow.

Tag. Gold tinsel.

DUKE.

Hook. $\%$ Sproat.

Body. Green chenille over crimson silk.

Wings. Ibis inside, mallard's black tip feathers outside.

Hackle. Black center, white tips.

Tail. Ibis.

Tag. Gold tinsel.

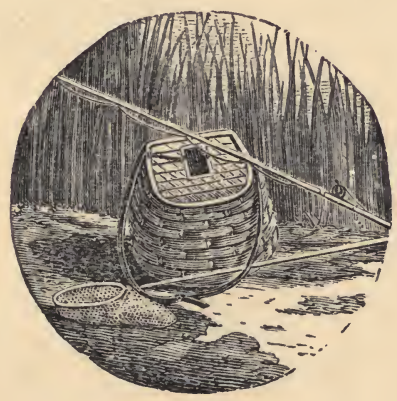





\section{Alphabetical Catalogue}

\section{$\because-0 \mathrm{~B} \cdots \cdots$ \\ 0. Judd Co., David W. Judd, Pres't,}

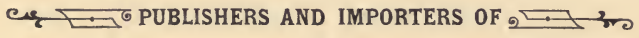

All Works pertaining to Rural Life.

751 Broadway, New Iork.
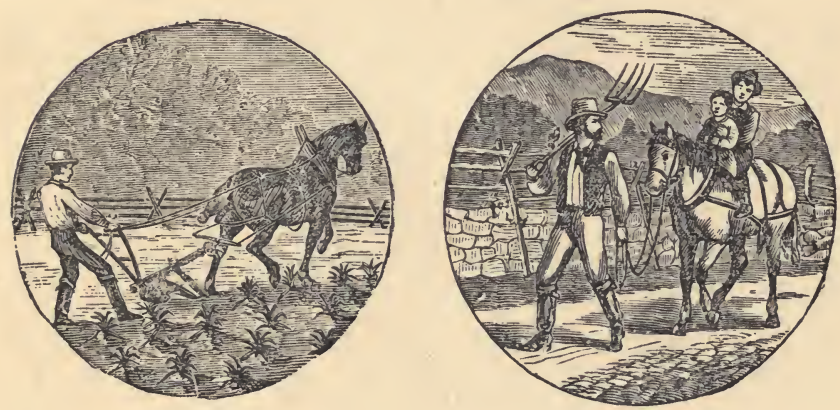

Agriculture, Horticulture, Etc.

\section{FAIR.V ANT GAIREN.}

Allen, R. L. and L. F. New Americau Firm Book..........\$2.50

American Farmer's Hand Book .................... 2.5?

Asparagus Culture. Flex. Cloth... $\ldots \ldots \ldots \ldots \ldots \ldots \ldots \ldots \ldots$

Bamford, C. E. Silk Culture. Paper....................... 30

Barry, P.' 'The Frnit G.urden. New and Revised Edition......... 2.00

Bommer. Method of Making Manures .........................

Brackett. Farm Tilk. Paper 50c. Cloth ................. . .5

B rill. Farm-Gardening and Seed-Growing... ... ........... 1.00

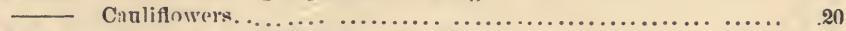

Broom-Corn and Brooms. Paper .................... .50 
Curtis on Wheat Culture. Paper....................... $\quad .50$

Emerson and Flint. Manual of Agriculture............. 1.50

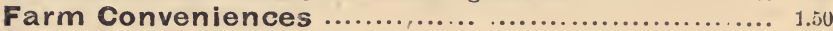

Farming for Boys... ............................... 1.25

Farming for Proilt... .............................. 3.75

Fitz. Swwet Potalo Culture. Now, Revised and Enlarged Edition...... $\quad .69$

Flax Culture. Paper ................................... . .30

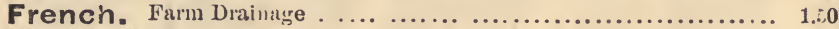

Fuller, A. S. Practical Forestry .......................... 1.50

Gregory. On Calbarges ......................................

$\underline{0}$ On Carrots, Mangold ivurtzels, etc......................

—-On Fertilizers................................... 40

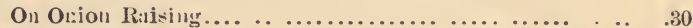

On Squaslies ................................... .30

Harlan. Farming with Green Mautres .................. 1.00

Harris. Insects Injurious to Vegetation. Plain \$4. Col'd Engravings. 650

Harris, Joseph. Gardeniug for Young and Old... ............ 1.25

Talks on Manures. New and Revised Edition... 1.

Henderson, Peter. Gurdening for P!easure................ 1.50

Gardening for Protit. New and Enlarged Evition. 2.00

Gurlen and Farm Topics.... ... ................. 1.50

Henderson \& Crozier. How the Farm Pays................. 2.50

Hop Culture. New and Revised Edition. Paper................ $\quad .30$

Johnston. Agrienltural Chemistry $\ldots \ldots \ldots \ldots \ldots \ldots \ldots \ldots \ldots \ldots, 1.75$

Johnson, M. W. How to Plant. Paper............... . .50

Johnson, Prof. S. W. How Crops Feed ................. 2.00

Jones, B. W. The Peanut Plant. Paper........................

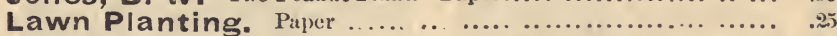

Leland. Farm Homes, In-Doors. and Ont-Doors. New Edition...... 1.50

Long, Elias A. Oruameutal Gardening for Americaus ........... 2.00

Morton. Furmer's Calendar ............................. 5.00

Nichols. Chemistry of Farm and Sea..................... 1.25

Norton. Elements of S.ientific Agrienlture................. .75

Oemler. Trnck-Farming at the Sonth ....................... 1.50

Onions. How to Ritise them Profitally....................... $\quad .20$

Our Farm of Four Acres. Paper ..................... 30

Pabor, E. Colorado as an Agricultural State ... . . . . . ..... 1.50

Pedder. Land Measurer for Farmers. Cloth................. . 60

Plant Life on the Farm ............................. 1.c0

Quinn. Money in the Garden ........................... 150

Register of Rural Affairs. 9 vols. Each................ 150

Riley. Potato Pests. Paper ...................................... 50

Robinson. Facts for Frrmers.............................. 5.00

Roe. Play and Profit in my Garden .......................... 150

Roosevelt. Five Acres Too Mnch ....................... 150

Silos and Ensilage. New and Enlarged Edition.............. 50

Starr, Farı Echoes.................................. 1.00

Stewart. Irrigation for the Farm, Garden and Orchard ........... 1.50

Ten Acres Enough.... ... ... ................. 1.00

The lllustrated Dictionary of Cardening. Vol. 1.,. 500

The Soil of the Farm............................... 100

Thomas. Farm Implements and Machinery................... 1.50 
Tim Bunker Papers; or, Yankee Farming.......... 1.50

Tobacco Culture. Papcr................................. .25

Treat. Injarious Insects of the Farm end Garden.............. 2.00

Villes. School of Chemical Manures ......................... 1.25

High Farming without Manures....................... .25

Artificial Manures.... .......................... 6.00

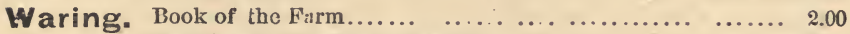

Draining for Profit and Health..................... 1.50

— Elements of Agriculture............................ 1.00

— Farmers' Vacation.............................. 3.00

- Sanitary Drainage of Houses and Towns. ............ 2.00

Sanitary Condition in City and Country Dwellings......... $\quad .50$

Warington. Chemistry of the Farm..................... 1.00

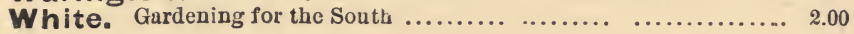

\section{FEUTE, FLOWEIS, FTC.}

American Rose Culturist ... . ..................... $\quad .30$

American Weeds and Useful Plants................... 1.75

Boussingault. Rural Economy .............................. 1.60

Choriton. Grape-Grower's Guide................................

Collier, Peter. Sorwhum, its Culture and Manufacture............. 3.00

Common Sea Weeds. Boards ............................

Downing. Fruits aud Fruit Trees of America. New Edition.......... 5.00

Rural Essays................................. 3.00

Elliott. Hand Book for Fruit-Growers. Patper 60c. Cloth.... ... . . 1.00

Every Woman her own Flower Gardener.............. 1.00

Fern Book for Everybody .............................. $\quad .50$

Fuller, A. S. Grape Culurist.......................... 1.50

Illustratud Strawberry Culturist $\ldots \ldots \ldots \ldots \ldots \ldots \ldots \ldots, \quad .20$

Small Fruit Culturist. New Edition................ 1.50

Fulton. Peach Culture. New aud Revised Edition .................. 1.50

Hein rich. Window Flower Garden...........................

Henderson, Peter. Hand Book of Plants... .............. 3.00

Practical Floriculture................. 1.50

Hibberd, Shirley. The Amateur" Flower Garden ... ... ...... 2.50 The Amateur's Greenhouse anc: Conservasory 250 The Amateur's Rose Book................. 2.50

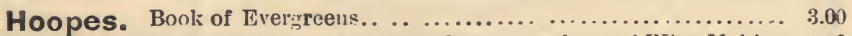

Husmann,Prof.Geo. American Grape growing and Wine Making 150

Johnson. Winter Greeneries at Home...................... 1 co

Moore, Rev. J. W. Orange Culture.................... 101

My Vineyard at Lakeview ......................... 1.25

Origin of Cultivated Plants ........................ 1 i5

Parsons. On the Rose............................. 150

Quinn. Pear Culture for Profit New and Revised Edition ......., 100

Rivers. Miniature Fruit Garden .......................... 10 n

Rixford. Wine Press and Cellar.......................... 150 
Robinson. Ferus in their Homes and Ours................. $\quad 1.50$

Roe. Success with Small Fruils........................... 5.00

Saunders. Insects Injurious to Frnits... ................ 3.00

Sheehan, Jas. Your Plants. Paper...................... .40

Stewart. Sorgh"m and Its Products........................ 1.50

Thomas. American Fruit Culturist...................... 2.00

Vick. Flower and Vegetable Garden. Cloth................... 1.00

Warder. Helges and Evergreens ...................... 1.50

Webb, Jas. Cape Cod Cranberriıs. Paper. .................. 40

White. Cranberry Calure .. ............................... 1.25

Williams, B. S. Orchid Grower's Manual... ... . ... . . ... 6.50

Wood, Samuel. Modern Wincluw Gardening ................ 1.25
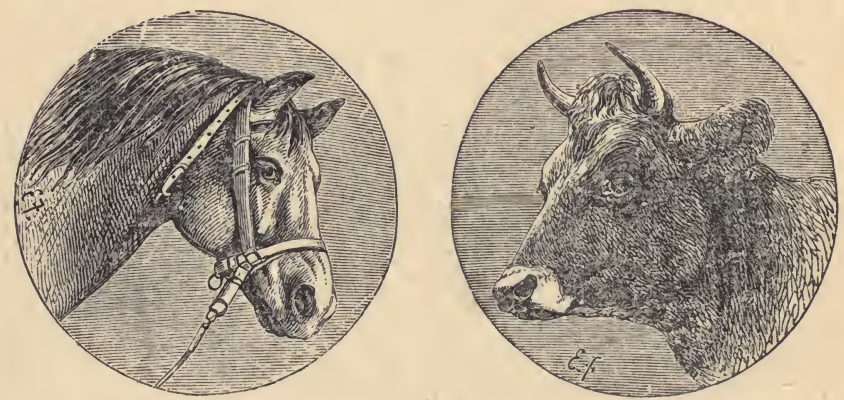

\section{Cattle, Dogs, Horses, Sheep, Swine, Poultry, Etc.}

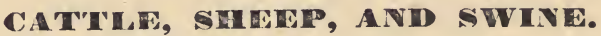

Allen, L. F. American Cattle. New and Revised Edition......... 2.50 Armatage, Prof. Geo. Every Man His Own Cattle Doctor. 8vo.. 7.50 Armsby. Mannal of Cattle Feeding........................ 2.50

Cattle. The Varieties, Breeling, and Mmagement.............. .75;

Coburn, F. D. Swine Husbandry. New andi Revised Edition..... 1.75

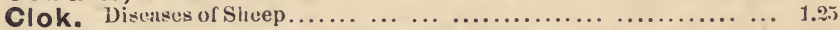

Dadd, Prof. Ceo. H. American Canle Doctor. 12mo......... 1.50

American Cattle Doctor. 8vo. Cloth..... 25)

Fleming. Veterinary Obstetrics........................ 6.0.

Guenon. On Milch Cows $\ldots \ldots \ldots \ldots \ldots \ldots \ldots \ldots \ldots \ldots \ldots \ldots \ldots$. (n)

Harris, Joseph. On the Pig.......................... 150

Jennings. On Cattle and their Diseases.................... 125

Oי Shern. Swine, and Poultry,.................. 1.25 
Jersey, Alderney, and Guernsey Cow .............. 1.50

Keeping One Cow.................................. 1.00

Macdonald. Food from the Far West...................... 1.50

McClure. Diseases of the American Horse, Cittle, and Sheep....... 2.00

McCombie, W m. Cartle and Cattle Briedirs............... 1.50

Martin, R. B. Hog-Raising and Pork-Making.............. .40

Miles. Stock Breeding.... ... ......................... 1.50

Powers, Stephen. The American Murino for Wool and Mutton.

A practic il and valuable work. . ......................... 1.75

Quincy, Hon. Josiah. On Soiling Cattle... ............... 1.25

Randall. Fine Wool sheep Husbandry. .................... 1.00

_- Practical Slsepherd..... .. ....................... 2.00

Reasor. On the Hog...................................... 1.50

Sidney. On the Pig................................... $\quad .50$

Shepherd, Major W. Prairie Experience in Handling Cattle... 1.00

Stewart, Hen ry. Shepherd's Manual. New and Enlarged Edition.. 1.5C

Stewart, E. W. Feeding Animals ...................... 2.00

The Sheep. Its Varieties and Management. Boards............. .75

Youatt and Martin. On the Hog.... .................. 1.00

Youatt. On Sheep.... .............................. 1.00

\section{DOGS, E'TC.}

Burgess. American Kennel and Sporting Field. 8vo ........... 3.00

Dog - Tne Varieties and Management............. $\quad .50$

Dogs of Great Britain, America, and Other Countries, Compiled from Stunehenge and other Stantard Writers. T'the most Cumplete Work ever Publisne i on the Dorg. $12 m o \ldots . . . . .2 .2 .00$

Forester, F. 'The Dog, by Dinks, Mayhew, and Hutchinson. Svo ... 3.00

Floyd, Wm. Hints on Dor Breaking. $12 m o \ldots \ldots \ldots \ldots \ldots \ldots \ldots \ldots . . .50$

Hallock, C. Dog Fanciers' Directory and Medical Guide. 18mo.... .25

Hammond, S. Dog Trainng. 12mo .................... 1.00

Hill, J. W. Manarement and Diseases of the Dog. $12 \mathrm{mo} . . . \ldots \ldots \ldots . .2 .2 .00$

Hooper, J. J. Dog and Gun. Paper....................... $\quad .30$

Hutchinson, G. N. Durr Breaking. $8 v 0 \ldots \ldots \ldots \ldots \ldots \ldots . . . \ldots . . .60$

Idstone. The Dog. Illustrated. 12 mo ...................... 1.25

Laverack, E. The Sctter. 4to ... .................... 3.00

Mayhew, E. Dogs ; Their Mana..ement. $16 \mathrm{mo..............} \mathrm{.75}$

Points for Judging Different Varieties of Dogs. Paper ............................................

Richardson. Dogs; Their Origin and Varieties. Pap $r$ 30c. Cloth .60

Shaw, T. Vero. Illustrated Book of the Dos. 4 to.............. 8.00

Stables, Gordon. Our Friend the Dng. Svo................ 3.00

Practical Kennel Guide... ... ............. 1.50

Ladies' Dorg as Companions.............. $\quad 2.00$ 
Stonehenge. The Dog in Ifeaith and Disease. $8 v 0 \ldots \ldots \ldots \ldots \ldots . \quad 3.00$

Dogrs of the British Islands. 8ro............... 6.00

T'he Greyhomind.......................... 5.50

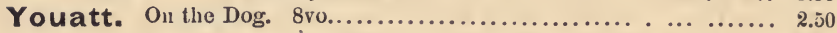

\section{HOREES, RIDING, FTC.}

Anderson, E. L. Moderu Horsemanship. 8vo …........ 7.00

The Gallop. 4to. Paper ................. 1.00

Armatage, Geo. Every Man His Own Horse Doctor, togrether with

Blaine's Velerinary Art. 8vo. $\frac{1}{3}$ morocco ................... 7.50

Armatage. Geo. Horse Owner and Stableman's Companion. $12 m o \quad 1.50$

Battersby, Col. J. C. The Bridle Bits. A valuable little work

on horsentuship. Fully illustrated. $12 \mathrm{mo} \ldots \ldots \ldots \ldots \ldots \ldots \ldots \ldots .1 .00$

Baucher, F. New Method of Horsemanship. 12mo............. 1.00

Bruce. Stud-Book. 4 vols.............................. 35.60

Chawner, R. Diseases of the Horse and How to Treal Them. 12mo 1.:5

Chester. Complete Trutting and Pacing Record ............... 10.00

Dadd, G. H. American Reformed Horse Book. 8vo............. 2.50

Modern Horse Doctor. $12 m o \ldots \ldots \ldots \ldots \ldots \ldots \ldots . .1 .50$

Day, W. The Race Hurse in 'Truining. 8vo.................. 6.25

Du Hays, C. Purcheron Horse. New and Revised Edition. 12mo.. 1.00

Durant. Horseback Ridling.... .......................... 1.:5

Famous Horses of America. Cloth. 4to.............. 1.50

Gleason, O. R. How to Handle aud Educate Vicious Horses...... 1.00

Going, J. A. Veterimary Dictionary. 12mo.................. 2.00

Herbert, H. W. Hints to Horse Keepers. $12 \mathrm{mo} \ldots \ldots \ldots \ldots \ldots \ldots$....... 1.75

Helm, H. T. American Roadsters and Trotting Horses. 8vo....... 5.00

Horse, The; Its Varieties and Management. Boards. .. ........ .75

Howden, P. How to Buy and Sell the Horse. 12mo ............ 1.00

Jennings, $\mathbf{R}$. Horse Training Made Easy. $16 m \ldots \ldots \ldots \ldots \ldots \ldots . . .25$

Thu Horse and His Diseases. 12mo............. 1.25

Law, J. Veterinary Adviser. 8 vo........................ 3.00

Liautard. Chart of Age of Domestic Animals.................. $\quad .50$

Animal Castration. $12 m 0 \ldots \ldots \ldots \ldots \ldots \ldots \ldots \ldots . \ldots \ldots$

Manning. The Illustrated Stock Doctor........................ 5.00

Mayhew, E. Illnstrated Horse Management. 8vo... ........... 3.00

McClure, R. Disenses of American Horses, 12mo ................

American Gentleman's Stable Guide. 12mo.......... 1.00

Miles, W. On the Horse's Font. 12:no..................... .75

Rarey. Horse Taner and Farrier. $16 m o \ldots \ldots \ldots \ldots \ldots \ldots \ldots \ldots \ldots, \quad .50$

Riding and Driving.. ............................... .20

Riley, H. On the Mule. $12 m$............................... 1.50

Russell. Scientifit Horse-Shoeing........................ 1.00

Saddle Horse, The. Complete Guide to Riding and Training.... 1.00

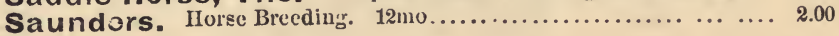


Stewart, R. American Farmer's Horse Book. 8 ro ............. 3.00

Stonehenge. Every Horse Owier's Cyclopiedia. 8vo.......... 3.75

On the Horse in the Stable and the Field. English

Edition. $8 \mathrm{vo} \ldots \ldots \ldots \ldots \ldots \ldots \ldots \ldots \ldots \ldots, 3.50$

On the Horse in the Stable and the Field. American

Edlition. $12 m 0 \ldots \ldots \ldots \ldots \ldots \ldots \ldots \ldots, 2.00$

Tellor. Diseases of Live Stock. Cloth, 2.50; Sheep.............. 3.00

Wallace. American Stutl-Buok. Per vol..................... 10.00

Williams. Veterinary Medicine.......................... 5.00

_ Vererinary Surgery $\ldots \ldots \ldots \ldots \ldots \ldots \ldots \ldots \ldots \ldots \ldots \ldots, \quad 7.50$

Woodruff. The Trotting Horse in Am.rica. 12mo.. ............ 2.50

Woods, Rev. J. G. Horse and Man........................ 2.50

Youatt \& Skinner. The Horse. 8 vo................... 1.75

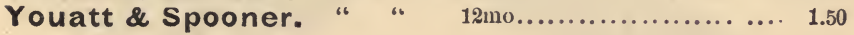

\section{POULTEY AND BEES.}

Burnham. New Poultry Book.......................... 1.50

Cook, Prof. A. J. Bee-Kreper's Guide or Matnual of the Apiary.... 1.2.

Cooper, Dr. J. W. Game Fowls....................... 5.00

Corbett. Ponltry Yard and Market. Paper................... $\quad .50$

Felch, I. K. Ponltry Culture. ......................... 1.50

Halsted. Artificial Incubation and Inculators, Paper ............ , 75

Johnson, G. M. S. Practical Poultry Kueper. Paper............ ..50

King. Bee-Keeper's Text Book............................ 1.00

Langstroth. On the Honey aul Hive Bee................... 2.00

Poultry. Breeding, Rearing, Feeding etc. Boards .. ............ $\quad .50$

Profits in Poultry and their Profitable Management. Most complete Work extaut..... .. .............. 1.00

Quin by. Mysteries of Bee-Keeping Explained (Edited by L. C. Root). 1.50

Renwick. Thermostatic Incubator. Paper 36c. Clorli............ .56

Root, A. I. A, B, C, of Bee Culture......................... 1.25

Standard Excellence in Poultry................... 1.00

Stoddard. An Errr-Farm. Rovised and Enlarged................ $\quad .50$

Wright. Iilustratecl Book of Poultry ........................ 8.00

- Practical Ponltry-Keeper... .................... 2.00

Practical Pigeon Kecper............................ 1.50

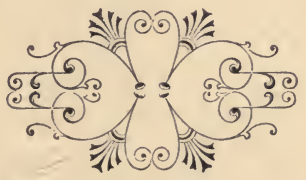



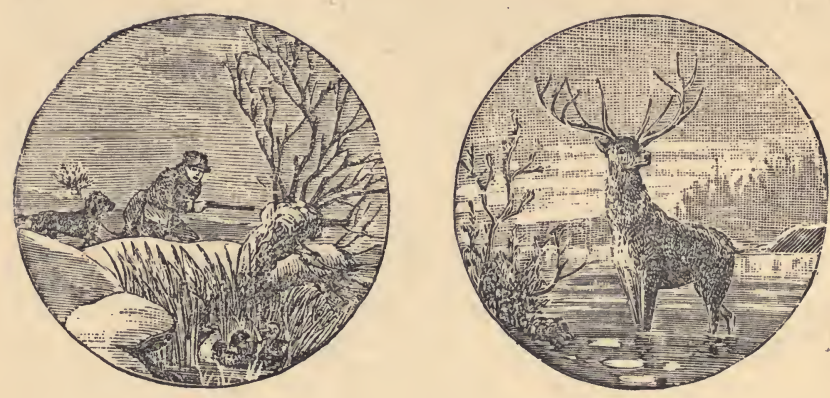

\section{OurSportsman's Books}

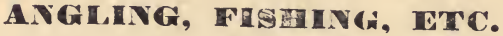

Burgess, J. T. Practical Guide to Bottom Fishin r, Trolling,

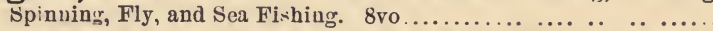

Fish Hatching and Fish Catching. By Roosevelt and

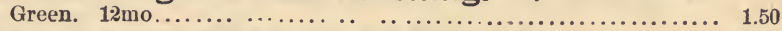

Forester, F. Fish and Fishing. New Edition. 8vo............. 2.50

Fishing with Hook and Line. Paper... ........... .25

Fysshe and Fysshynge, from the Boke of St. Albans.......... 1.00

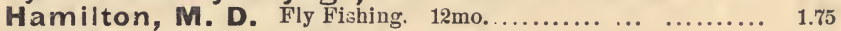

Harris. The Scientific Angler-Foster.................... 1.50

Henshall, J. A. A Book of the Black Bass. $8 v 0 \ldots \ldots \ldots \ldots \ldots . . .60$

Keene, J.H. Fly-Fishing and Fly-Making. 1:mo. Just Published.. 1.50

Practical Fisherman. 12mo.... ................ 4.00

King, J. L. Troutin $q$ on the Brul: River. 12mo............... 1.50

Norris, 'T. American Fish Culture. 12mo.. .. ............... 1.75

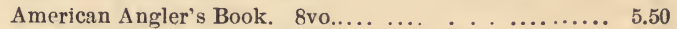

Orvis, Charles F. Fishing with the Fly. Crown 8vo......... 2.50

Pennell, H. C. Bottom; or. Float Fishing. Boards............... .50

Fly-Fishing and Wornt-Fi-hing. Boards......... .50

Trolling for Pike, Silmon, and Trout. Boards.... $\quad .50$

Prime. I go a Fis!ing ............................... 2.50

Random Casts from in Angler's Note Book... ............. $\quad .50$

Roosevelt, R. B. Game Fish of the Northern States and British

Provinces. $12 \mathrm{~m} \%$................... 2.00

Superior Fishing: or. the Striped Bass, Tront, Black Bass, and Blue Fish of the Northern

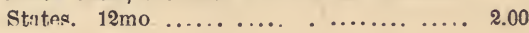


Roosevelt \& Green. Fish H:tching and Fislı Cutching.... . . ... 1.50 Slack, J. H. Practicil Trout Culture. 12ruo.... .................. 1.00 Scott, G. C. Fishing in American Wat rs. 8vo ............... 2.50 Walton \& Cotton. Complete Augler. 8vo.................... 5.00

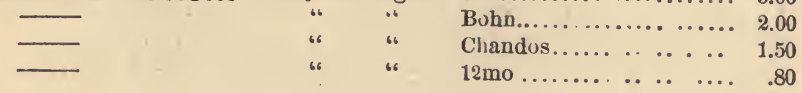

\section{$\longrightarrow \infty$ \\ BOATING, CANOEING' SARLING, WTC.}

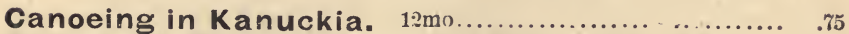
Fellows, H. P. Bıatin $r$ Trips on New England Rivers. 12mo..... 1.25

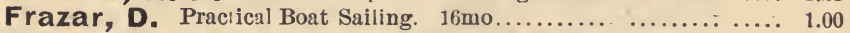

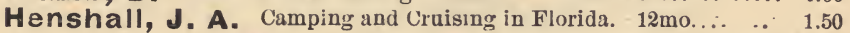
Kemp, Dixon. Manual of Yacht and Boat Saiiing (the Standard Authority). Royal 8vo. Illustrated. .................... 10.00

Kemp, Dixon. Yacht Designing. Folio..................... 25.00

Kunnardt, D. T. Small Yaclits. $4 t 0,14 \frac{1}{2} \times 12 \frac{1}{2} \ldots \ldots \ldots \ldots \ldots . . \ldots . \ldots 0$

Prescott, C. E. The Sililing Buat. 16mo.................. $\quad .50$

Steele, T. S. Canoe and Camera. $12 \mathrm{mo} \ldots \ldots \ldots \ldots \ldots \ldots \ldots \ldots \ldots . \ldots . \ldots . . .50$

Swimming. Routledge.................................. $\quad .20$

\section{WIALI SPOITS AND NATURAL HISTORY.}

American Bird Fancier, Enlarged edition................ .50

Adams, H. G. Favorite Song Birds........................ 1.50

Archer, Modern. Paper............................... $\quad .15$

Bailey. Our Own Birls.................................. 1.50

Bird-Keeping. Fully Illustrated........................ 1.50

Brown. Tixidermy ................................... 1.00

Canary Birds. New and Revised Edition. Paper, 50c. Cluth..... $\quad .75$

Coues. Key to North American Birds......................... 10.00

Cocker. Manual...................................... 1.50

Edwards. Ruhbits ................................. 1.25

Goode and Atwater. M.nhraden ....................... 2.00

Holden. Book of Birds ..................................... .25

Lawn Tennis Hand Book.......................... .75

Packard. Guicle to Sundy of Insacts......................... 5.00

- Hall Hout Insects............................... 250

Common Insects................................ 1.50

Practical Rabbit Keeper............................ 1.50

Swimming, Skating and Rinking................... .25

Van Doren. Fishes of ihe Eist Atlantic Coast.................. 1.50

Warne. Angling. Boards.............................. $\quad .50$

Wilson. American Ornithology. 3 vols ... .................... 18.00

Wilson and Bonaparto. American Ornitlolngy. $1 \mathrm{vol} \ldots \ldots . .7 .00$ 


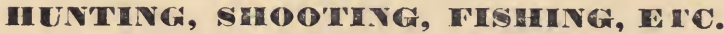

Adirondacks Guide. Wallace........................ 2.00

Amateur Trapper. Boards.. ......................

Batty, J. H. How to Hunt and Trap. $12 m$ c................. 1.50

Practical 'Taxidermy. $12 m 0 \ldots \ldots \ldots \ldots \ldots \ldots \ldots \ldots, 1.50$

Barber. Crack Shot-the Rifleman's Gnide. 12mo................ 1.25

Bogardus, Capt. Field, Cover, and Trap Shooting. 12mo...... 2.00

Bumstead. On the Wing................................ 1.50

Dead Shot. A Truatise on the Gun...................... 1.25

Farrow. How to Become a Crack Shot. $121110 \ldots \ldots$............ 1.00

Forester, F. Life and Writings-D. W. Judd. 2 volumes. 8vo ... 3.00

Field Sports. 2 volumes. 8 vo................. 4.00

Complete Mannal for Yomug Siortsmen. 8vo ...... 2.00

American Game in its Season. 8vo............. 1.50

Gildersleeve, H. A. Rifles and Markmamship. $12 \mathrm{mo} \ldots \ldots \ldots . . .50$

Gloan. 'The Breech-loader................................. 1.25

Gould, J. M. How to Camp Out. 16mo.................. $\quad .75$

Greener, W. W. Choke Bore Guns. 8vo .................. 3.00

The Gun and its Development................. 2.50

Gun, Rod, and Saddle. "Ubique"................ 1.00

Hallock. Sportsman's Gatzeleer and General Guicle--A Treatise on all Game and Fish of North America. Instruction in Shooting, Fishing, Taxidermy, and Wooderalt, with Directory of Principal Game Rcsorts and Maps. New and Revised Edition. 12mo............. 3.00

Henderson, H. Practical Hiuts on Camping. 12mo .......... 1.25

Lewis, E. J. The American Sportsman. 8 ro $\ldots \ldots \ldots \ldots \ldots \ldots \ldots .2 .50$

Murray. Adventures in the Wildemess. $12 \mathrm{mo}$. . . . . . . . . . . . 1.25

Murphy, J. M. Amerisan Game Bird Shooting. 12mo......... 2.00

Newhouse. Trapper's Guicle. 8 vo....................... 1.50

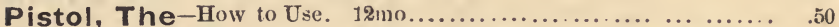

Prescott, C. E. Practical Hints on Rifle Practice with Military Arms.............................................. .50

Roosevelt, R. B. Florida, and the Game Water Birls of the Atlantic Const and Lalkes of the Unite! States. $12 m 0 \ldots \ldots . \ldots . \ldots . .2 .00$

Samuels. Birds of New England ind Arijacent States............ 4.00

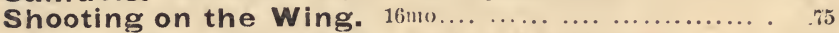

Smith, George Putnam. The Law of Field Sports.. .. ... 1.00

Stonehenge. Rural Sports-The Standard Encyclopxdia of Field

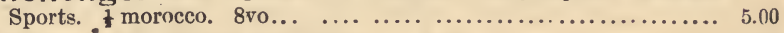

Thrasher, H. Huiter and Trapper. 12mo................... .7.

Wingate, G. W. Manual for Rifle Practice. $16 \mathrm{mo} . \ldots \ldots \ldots \ldots \ldots . . .60$

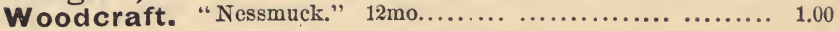




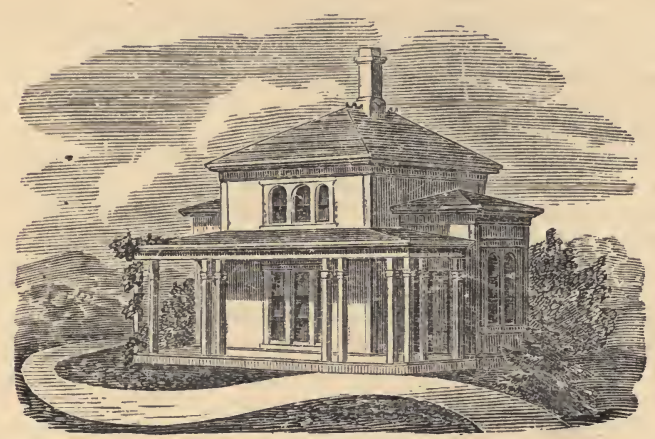

\section{ARCHITECTURE, ETC.}

Allen, L. F. Rural Arcbitecture ......................... 1.50

American Cottages .................................. 5.00

Ames. Alphinbets . ..................................... 1.50

Atwood. Comtry and Suburban Houses..................... 150

Barn Plans and Out-Buildings $\ldots \ldots \ldots \ldots \ldots \ldots \ldots \ldots \ldots$

Bell. Carpentry Made Eas:................................ 5.00

Bicknell. Cottare and Villa Architecture................. 400

_ Detuil Cottage and Constructive Architect ure.............. 6.00

—_Modern Architeetural Designs and Details............. 10.co

— Public Buildings New........................ 2.50

- Street, Store, and Bank Fronts. New.............. 2.50

School-Honse and Cimrch Architectnre.............. 2.50

Stables, Out-builuingrs, Finces, etc................. 2.50

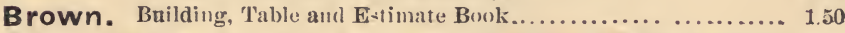

Burn. Drawing Books, Archituctural. Illiustrated and Ornamental.

3 Vols. Each................................ 1.00

Cameron. Plasterer's Mamuai..............................

Camp. How Can I Leam Architecture....................... $\quad .50$

Copley. Piain and Omamental Alphabets .................... 800

Cottages. Hints on Economical Building... .................. 1.00

Cummings. Architectural Details......................... 6.00

Elliott. Lland Book of Practicai Landscape Garlening.............. 1.50

Eveleth. School-Honse Architecture...................... 4.00

Fuller. Artistic: Homes.. ..... . .......................... 3.50

Gilmore, Q. A. Roads and Street Pavements................ 2.50

Gould. American Stair-Builder"s Guile. ..................... 2.50

- Carpenter's and Builder's Assistant.................... 2.50

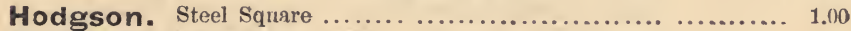

Holly. Art of Saw Filing ...... . ........................ .

Harney. Barns, Ont-Buildin:s, and Fences ................. 4.00

Hulme. Mathematical Drawing Iustruments.................... 1.50 
Hussey. Home Building.. .............................. 2.50

Nitional Cottage Architecture.......................... 4.00

Homes for Home Builders. Just Published. F'ully Illustrated. 1.50

Interiors and Interior Details.................... 7.50

Lakey. Village and Coutry Honses ...................... 5.00

Modern House Painting ........................ 5.00

Monckton. National Carpenter and Joiner ................. 5.00

National Stair-Bıilder...................... 5.00

Painter, Gilder, and Varnisher's Companion..... 150

Palliser. Amer can Cottage Homes.... ...................... 3.00

Model Homes............................... 1.00

Useful Details.............................. 2.00

Plummer. C'arpenters' and Builders' Guide................... .75

Powell. Fonndations and Fonndation Walls... ................ 2.00

Reed. Coltage Housus ................................. 1.25

Hons: Plans for Everybody. .. .................... . 1.50

Dwellings................................... 3.00

Riddell. Carpenter and Joiner Modernized................... 7.50

— New Elements of Hand Railing.... . . ............... 7.00

Lessous on Hand Railin for Learuers................ 5.00

Rural Church Architecture...................... 400

Scott. Beautiful Homes.............................. 2.50

Tuthill. Practical Lessous in Architectural Drawing............. 2.50

Weidenmann. Beastilying Country Homes. A superb quarto Vol. 10.00

Woodward. Cottages and Farm Houses.................... 1.10

Country Homes.... .................... 1.00

National Architect. Volumes 1 and 2. Eacl.............. 15.00

Suburban and Country Houses.................. 1.00

\section{MISCELLANEOUS.}

Collection of Ornaments......................... 2.00

Common Sea Weeds.......................... .50

Common Shells of the Seashore................. $\quad .50$

Corson, Miss Juliet. Cooking School Text Book........... 1.25

- Twenty five Cent Dinners. New Edition. .25

De Voe. Market Assistant ............................. 2.50

Dussauce. On the Manufacture of Vinegar.................. 5.00

Eassie. Wood and its Uses.............................. 1.50

Eggleston. Roxy ................................... 1.50

Circuit Rider... ... ........................... 1.50

School Boy.................................. 1.00

Qneer Stories................................. 1.00

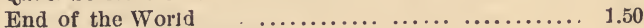

Mystery of Metropolisville...................... 1.50

Hoo-ier Schoolmaster.. ........ .............. 1.25

Elliott, Mrs. Housewife. New and Revised Edilion.... ........ 1.25

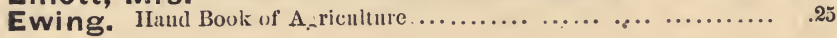


Ferns and Ferneries. Paper... ........................$^{25}$

Fisher. Grain Tubles.................................... $\quad .40$

Fowler. Twenty Years of Inside Life in Wall Street............. 1.50

Gardner. Carriage Painters' Manual .... . . . . . . . . . ....... 1.00

How to Paint... ......................... 1.00

Hazard. Butter Making.................................. .25

Household Conveniences.......................... 1.50

How to Detect the Adulterations of Food. Paper... .25

How to Make Candy............................... $\quad .50$

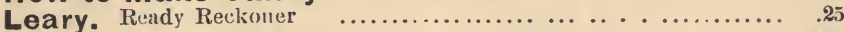

Myers. Havana Cigars............................... .25

Our Farmers' Account Book... .................... 1.00

Parloa, Miss. Cook Book.............................. 1.50

Ropp. Commercial Calculator............................ .50

Scribner. Lumber and Log-Buok.............................

Ware. The Sugar Beet................................. 4.00

Weston, J. Fr'shl Water Aquarimm. Paper.................. . 25

Weir, Harrison. Every Day in the Comitry.................... .75

Wingate, Gen. G. W. Tlirongh the Yellowstone Park......... 1.50

Williams. Lutlies' Fancy Work........................... 1.50

Evenin Amnsements....................... 1.50

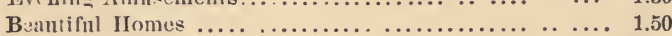

L Ladies' Needle Work ........................ 1.00

Artistic Embroidery ........................ 1.00

Willa rd. Practical Butter Book......................... 1.00

— Practical Dairy Hu-bandry ...................... 3.00

Warne's Useful Books. Boards. Witl practical Illustrations: The Orcharrl and Fruit G.rden. By Elizabeth Watts......... .50

Vequablis and How to Grow Them. By Elizabeth Watts .... $\quad .50$

Cattle and their Varieliex.... ........................ .50

The Dog and its Varieties............................. .50

Flowers and Flower Giırle.ı. B. ELIzabeth W atrs........... .50

Hardy Plants for Little Fronl Girdens..... .. . . ............. . $\quad .50$

Poultry-A॥ Original and Practical Guide to their Mamagement... $\quad .50$

The Moderı Fencer. By C.pt. 'T. GвIFғтін............... $\quad .50$

Tlie Modern Gymnast. By Chiarles Spencer... ............ $\quad .50$

Cattle and their Varieties and Manigement................. .75

The Horse and its Varieties and Management................. $\quad .75$

Sheep and its Varieties and Management.................... $\quad .75$

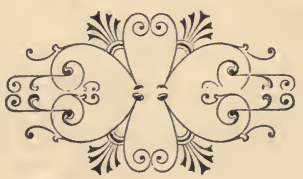




\section{Our Very Latest Publications.}

Through the Yellowstone Park on Horseback. By

Gien. G. W. Wingate ... ........................... 1.50

Fly-Fishing and Fly-Making. By Keene... ............ 1.50 How to Handle and Educate Vicious Horses. By

O. R. Gleason...................................... 1.00

The Law of Field Sports. By Geo. P. Smith............ 1.00

Bridle Bits. A Treatise on Practical IIorsemanship. By CoL. J. C.

BАTTERSBY. .................................. 1.00

The Percheron Horse in America and France ... 1.00

Profits in Poultry. Useful and Ornamental Breds .. ......... 1.00

Cape Cod Cranberries. By James Webs. Paper......... .50

How to Plant. By M. W. Johnson....................... . .50

The American Merino for Wool and Mutton. By

Stephen Powers..................................... 1.75

\section{$\longrightarrow \infty$ \\ New and Revised Editions.}

Hallock. Sportsman's Gazetteer......................... 3.100

Stewart. Irrigation for the Farm, Garden and Orchard............ 1.50

Farm Implements and Machinery. Bу Tномаs...... . 1.50

Egg Farm. By Stopdard. Cloth.. ....................... .50

Play and Profit in My Garden....................... 1.50

Silos and Ensilage ................................ .50

Send Postal for Complete Catalogne of onr Pablications regarding Horses and Horsemanship, Hunting, Fishing, and all other Out-Door Sports and Pastimes.

0. JUDD CO., DAVID W. JUDD, Pres't. Y51 BROADWAY, NEW YORK. 



14 DAY USE

RETURN TO DESK FROM WHICH BORROWED LOAN DEPT.

This book is due on the last date stamped below, or on the date to which renewed.

Renewed books are subject to immediate recall.

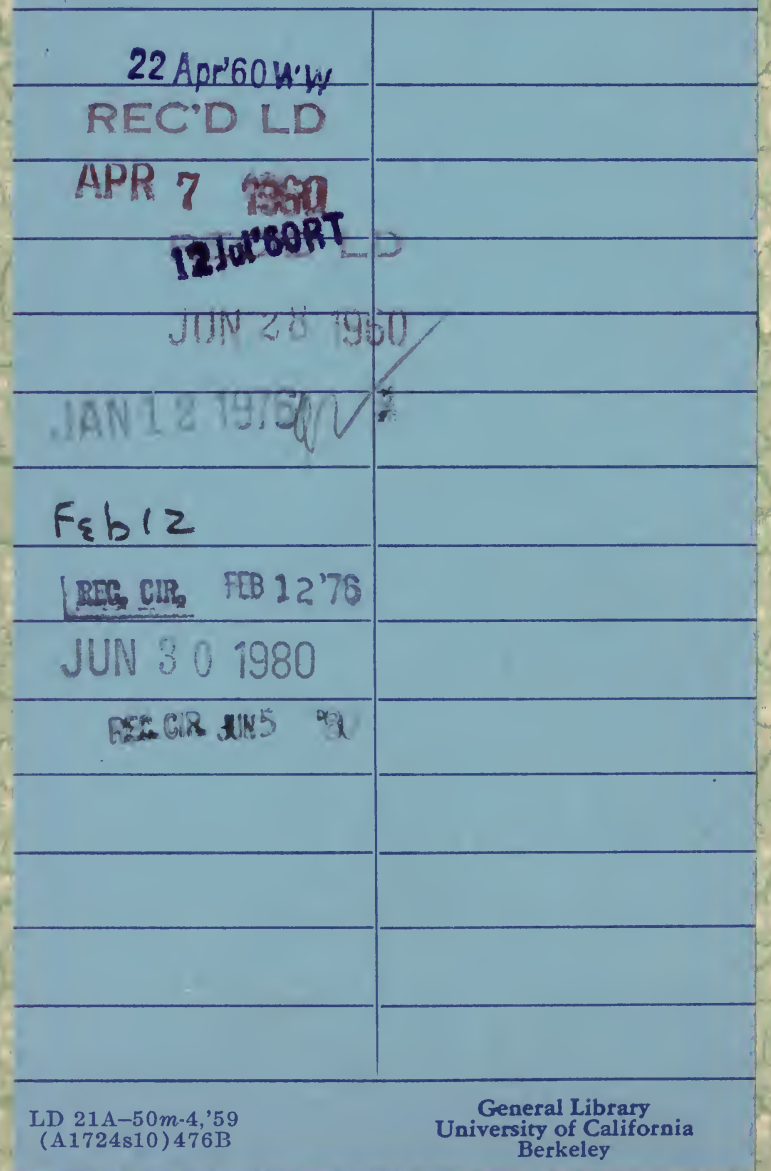




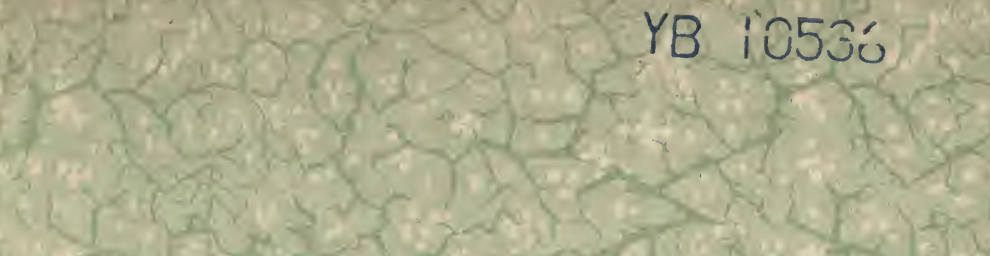
ans

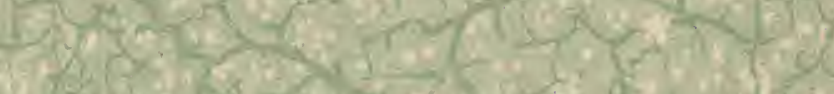

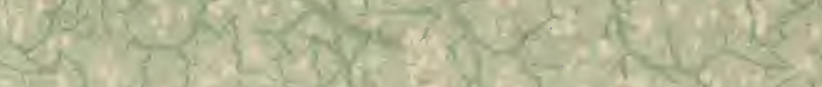

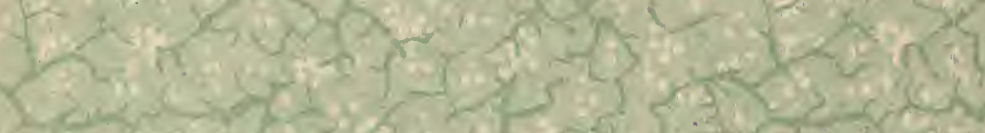

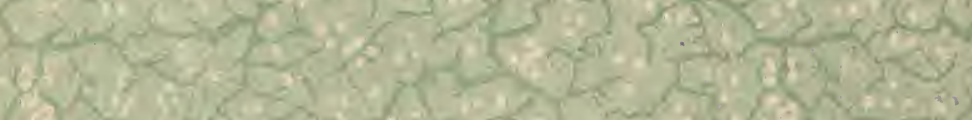
$\lim _{0,2}+2+2$.

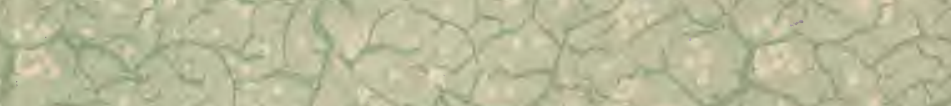

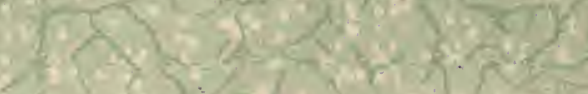

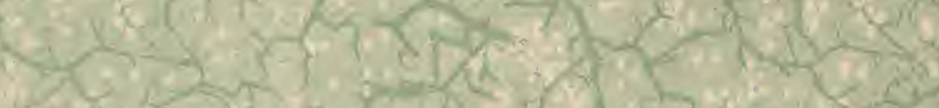

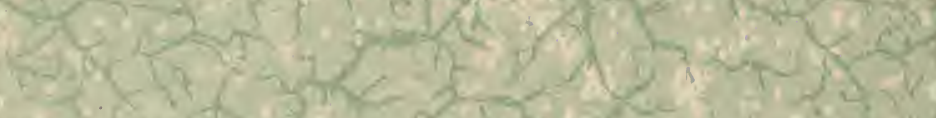

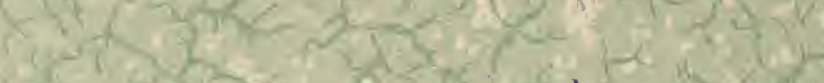

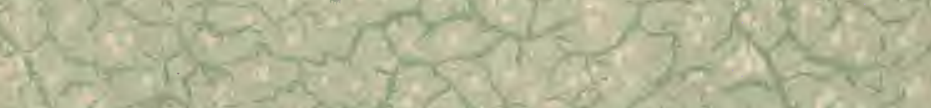
$77-2 x+2 n$ 
